Key Words:

XAFS

Permanganate

Peroxide

Retention:

Permanent

Characterization of Plutonium, Neptunium, Strontium on Manganese Solids from Permanganate Reduction

Martine C. Duff, Douglas B. Hunter, David T. Hobbs, Arthur Jurgensen, and Samuel D. Fink

SEPTEMBER 19, 2002

Westinghouse Savannah River Company

Savannah River Site

Aiken, SC 29808

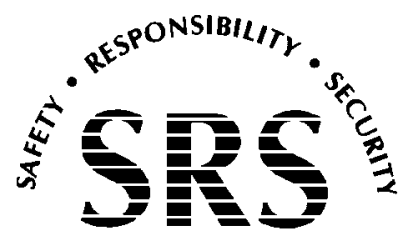

SAVANNAH RIVER SITE

Prepared for the U.S. Department of Energy Under

Contract Number DE-AC09-96SR18500 
This document was prepared in conjunction with work accomplished under Contract No. DE-AC09-96SR18500 with the U. S. Department of Energy.

\section{DISCLAIMER}

This report was prepared as an account of work sponsored by an agency of the United States Government. Neither the United States Government nor any agency thereof, nor any of their employees, makes any warranty, express or implied, or assumes any legal liability or responsibility for the accuracy, completeness, or usefulness of any information, apparatus, product or process disclosed, or represents that its use would not infringe privately owned rights. Reference herein to any specific commercial product, process or service by trade name, trademark, manufacturer, or otherwise does not necessarily constitute or imply its endorsement, recommendation, or favoring by the United States Government or any agency thereof. The views and opinions of authors expressed herein do not necessarily state or reflect those of the United States Government or any agency thereof.

This report has been reproduced directly from the best available copy.

Available for sale to the public, in paper, from: U.S. Department of Commerce, National Technical Information Service, 5285 Port Royal Road, Springfield, VA 22161, phone: (800) 553-6847, fax: (703) 605-6900

email: orders@ntis.fedworld.gov

online ordering: http://www.ntis.gov/help/index.asp

Available electronically at http://www.osti.gov/bridge

Available for a processing fee to U.S. Department of Energy and its contractors, in paper, from: U.S. Department of Energy, Office of Scientific and Technical Information, P.O. Box 62, Oak Ridge, TN 37831-0062,

phone: (865)576-8401,

fax: (865)576-5728

email: $\underline{\text { reports@ adonis.osti.gov }}$ 
Key Words:

XAFS

Permanganate

Peroxide

Retention:

Permanent

\title{
Characterization of Plutonium, Neptunium, Strontium on Manganese Solids from Permanganate Reduction
}

\author{
Martine C. Duff, Douglas B. Hunter, David T. Hobbs, Arthur Jurgensen \\ and Samuel D. Fink
}

SEPTEMBER 19, 2002

Westinghouse Savannah River Company

Savannah River Site

Aiken, SC 29808

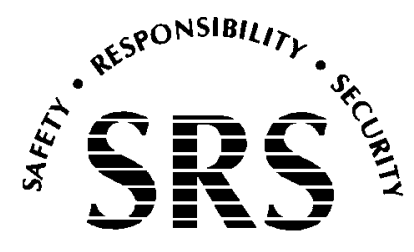

SAVANNAH RIVER SITE

Prepared for the U.S. Department of Energy Under

Contract Number DE-AC09-96SR18500 


\section{REVIEWS AND APPROVALS}

M. C. Duff, Author, Waste Processing Technology

Date

D. B. Hunter, Author, Nonproliferation Technology

Date

D. T. Hobbs, Author, Waste Processing Technology

Date

A. Jurgensen, Author, Analytical Development Technology

Date

S. D. Fink, Level 4 Manager and TFA Lead, Waste Processing Technology

Date

W. D. Clark, DOE-SPP Technology Integration Manager

Date

H. D. Harmon, Manager, Process Engineering

Date

J. T. Carter, Director of Engineering, SWPF

Date

W. L. Tamosaitis, Manager, Waste Processing Technology

Date

\section{Page ii}


WSRC-TR-2002-00366, REVISION 0

M. H. Tosten, Design Check, Materials Technology

Date

Page iii 


\section{TABLE OF CONTENTS}

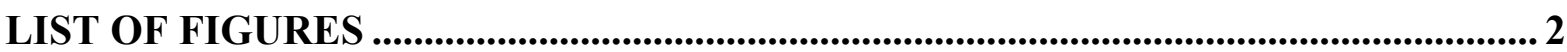

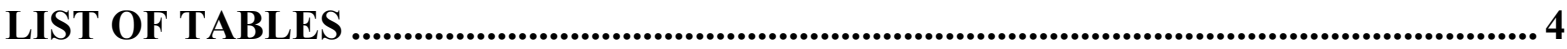

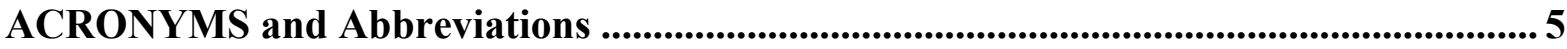

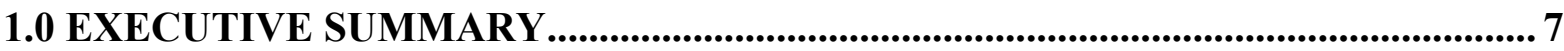

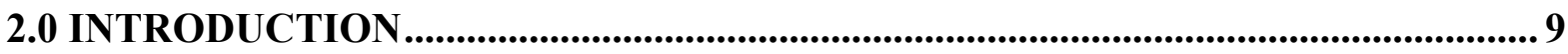

2.1 Use of Mn Oxide Solids for Removal of Radionuclides from Solutions and the

Influence of Mn Oxide Structure .................................................................................................... 9

2.2 Uptake Mechanisms of Metals by Surfaces...................................................................... 12

2.3 Use of XAFS Techniques to Characterize Metal Uptake by Surfaces....................... 14

2.4 Experimental Objectives.......................................................................................................... 15

3.0 MATERIALS AND EXPERIMENTAL METHODS.................................................... 16

3.1 Sample Preparation ..................................................................................................................... 16

3.1.1 Actinide-containing Mn Samples .................................................................................. 16

1.1.2 Actinide-free Mn Oxides............................................................................................... 17

1.1.3 XANES and EXAFS Data Collection .................................................................... 17

1.1.3.1 Studies Conducted at the National Synchrotron Light Source ..................... 17

1.1.1.2 Studies Conducted at the Advanced Photon Source....................................... 20

1.1.4 XANES and EXAFS Data Analyses..................................................................... 21

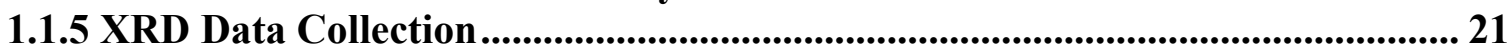

4.0 RESULTS........................................................................................................................ 23

4.1 Background .................................................................................................................. 23

4.1.1 Characterization of Pu on Surfaces with XAFS ....................................................... 23

4.1.2 Characterization of Np on Surfaces with XAFS......................................................... 23

4.2 XANES Studies ............................................................................................................................... 24

4.2.1 Manganese XANES Studies with the Non-radioactive Mn Solids ....................... 24

4.2.2 Actinide XANES Studies with the Actinide-loaded Mn Solids ............................ 25

4.2.2.1 Plutonium XANES Studies...................................................................................... 28

4.2.2.2 Neptunium XANES Studies ................................................................................... 28

4.3 EXAFS Analyses ............................................................................................................. 30

4.3.1 Manganese Chi Data for the Actinide-free Manganese Oxide Samples............. 30

4.3.2 Strontium Chi Data for the Actinide-free Mn Oxide Samples.............................. 30

4.3.3 Plutonium Chi Data for the Mn Sample ................................................................... 33

4.3.4 Neptunium Chi Data for the Mn Sample ................................................................... 33

4.3.5 Manganese Fourier Transform Data for the Actinide-free Mn Samples........... 37

4.3.6 Plutonium Fourier Transform and Model Fit Data................................................. 47

4.3.7 Neptunium Fourier Transform and Model Fit Data ............................................... 51

4.4 X-ray Diffraction Analyses of Mn Samples....................................................................... 53

4.4.1 Mn Oxide Formation in Highly Basic Solutions......................................................... 56

4.5 Influence of Strontianite on Sr and Actinide Removal .................................................... 57

5.0 CONCLUSIONS ......................................................................................................................5 57

6.0 ACKNOWLEDGEMENTS.........................................................................................5 58

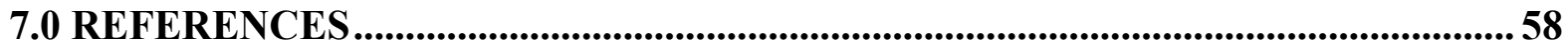




\section{LIST OF FIGURES}

Figure 2.1 Basic building blocks of Mn(IV) oxides. Edge- and corner-sharing Mn octahedra are the most common linkages observed in naturally occurring Mn oxides. Red arrows point to the distance between the $\mathrm{Mn}$ atoms in the linked Mn octahedra.

Figure 2.2 Simplified diagram of the types of associations a metal could have with a surface:

A) Structural incorporation, B) Outer-sphere (electrostatic) sorption, C) Specific or innersphere sorption and D) Surface precipitation. Blue rings denote first, second and third shell environments that can be probed with XAFS techniques.

Figure 3.1 Diagram of the downstream portion of the hutch table at NIST beamline X23a2 (not drawn to scale).

Figure 4.1 Normalized Mn XANES spectra for the non-radioactive permanganate sample 0 and several $\mathrm{Mn}$ oxide reference materials. Spectra for $\mathrm{MnCO}_{3}$, bixbyite, birnessite and pyrolusite from Fredrickson et al. (2002) and spectra for cryptomelane and todorokite from Duff et al. (2002).

Figure 4.2 Plot of the plutonium-XANES spectra for the Pu-loaded $\mathrm{Mn}$ sample and the $\mathrm{Pu}$ standards: $\mathrm{Pu}(\mathrm{IV}) \mathrm{O}_{2}, \mathrm{KPu}(\mathrm{V}) \mathrm{O}_{2} \mathrm{CO}_{3}$ and $\mathrm{Ba}_{3} \mathrm{Pu}(\mathrm{VI}) \mathrm{O}_{6}$. The $\mathrm{Pu}$-loaded $\mathrm{Mn}$ oxide solid had a calculated loading of $2310 \mathrm{mg} \mathrm{Pu} \mathrm{kg}{ }^{-1}$ of $\mathrm{MnO}_{2}$ [added as $\mathrm{Pu}(\mathrm{IV})$ ]

Figure 4.3 Plot of the neptunium-XANES spectra for the Np-loaded Mn sample. Energy calibration performed with a $\mathrm{Zr}$ metal foil at the $\mathrm{Zr}$ K-edge. The $\mathrm{Np}$ loading for the $\mathrm{Mn}$ sample was $1550 \mathrm{mg} \mathrm{Np} \mathrm{kg}^{-1}$ of $\mathrm{MnO}_{2}$.

Figure 4.4 The $k^{2}$-weighted chi data for $\mathrm{Mn}$ in the solids formed in the actinide-free permanganate tests (listed in Table 3-2) and a FEFF simulation of the Mn oxide called birnessite. Samples 0, 1, 5 and 6 had $0.045 \mathrm{M} \mathrm{H}_{2} \mathrm{O}_{2}$ as the reductant. Samples 2, 3, 4 and 7 had $0.045 \mathrm{M}$ sodium formate added as the reductant.

Figure 4.5 The $k^{3}$-weighted chi data (the plot of the wavevector in reciprocal space) for $\mathrm{Sr}$ in the four Sr-treated Mn samples and a FEFF simulation of the chi data for the mineral strontianite $\left[\mathrm{SrCO}_{3(\mathrm{~s})}\right]$. Samples 1 and 5 had $0.045 \mathrm{M} \mathrm{H}_{2} \mathrm{O}_{2}$ added as the reductant. Samples 2 and 7 had formate added as the reductant.

Figure 4.6 The $k^{1}$-weighted chi data (the plot of the wavevector in reciprocal space) for $\mathrm{Pu}$ in

the Pu-loaded Mn oxide sample.

Figure 4.7 The portion of $k^{1}$-weighted chi data (the plot of the wavevector in reciprocal space) for $\mathrm{Pu}$ in the $\mathrm{Pu}$-loaded $\mathrm{Mn}$ oxide sample that was selected for model fits. ................... 35

Figure 4.8 The $k^{2}$-weighted chi data (the plot of the wavevector in reciprocal space) for $\mathrm{Np}$ in

the Np-loaded sample

Figure 4.9 FT and model fit data for Mn in Sample 0 (4-hour equilibration without seed Sr) -

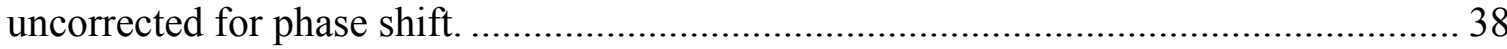

Figure 4.10 FT and model fit data for $\mathrm{Mn}$ in Sample 1 (4-hour equilibration using $\mathrm{H}_{2} \mathrm{O}_{2}$ with seed Sr) - uncorrected for phase shift. .................................................................. 39

Figure 4.11 FT and model fit data for Mn in Sample 2 (4-hour equilibration using formate with seed $\mathrm{Sr}$ ) - uncorrected for phase shift.

Figure 4.12 FT and model fit data for Mn in Sample 3 (4-hour equilibration using formate without seed $\mathrm{Sr}$ ) - uncorrected for phase shift.

Figure 4.13 FT and model fit data for Mn in Sample 4 (168-hour equilibration using formate

without seed $\mathrm{Sr}$ ) — uncorrected for phase shift.

Page 2 of 65 
Figure 4.14 FT and model fit data for Mn in Sample 5 (168-hour equilibration using $\mathrm{H}_{2} \mathrm{O}_{2}$ with seed $\mathrm{Sr}$ )-uncorrected for phase shift.

Figure 4.15 FT and model fit data for Mn in Sample 6 (168-hour equilibration using $\mathrm{H}_{2} \mathrm{O}_{2}$ without seed $\mathrm{Sr}$ ) - uncorrected for phase shift.

Figure 4.16 FT and model fit data for Mn in Sample 7 (168-hour equilibration using formate with seed $\mathrm{Sr}$ )- uncorrected for phase shift.

Figure 4.17 Large sheets of edge-sharing Mn octahedra (i.e., those solids that can be identified by XRD because they have sufficient long range crystalline order) would have a Mn-Mn CN of 6 . The reduced $\mathrm{CN}$ of 4 that the sheets are limited in size. For example, the assembly of atoms above consists of $6 \mathrm{Mn}$ (green) around a central $\mathrm{Mn}$ (red). The average $\mathrm{Mn}-\mathrm{Mn} \mathrm{CN}$ would be 3.43

Figure 4.18 FT and first shell model fit data for the Pu-loaded Mn oxide sample-uncorrected for phase shift. ....................................................................................................... 48

Figure 4.19 FT and second coordination shell model fit data for the Pu-loaded Mn oxide sample - uncorrected for phase shift.

Figure 4.20 Model of the fits from EXAFS data analyses showing the association of more than one $\mathrm{Pu}$ atom (blue spheres) and a Mn atom (gold spheres) in the outer shell of the $\mathrm{Pu}(\mathrm{IV})$ (red spheres), that has eight first-shell $\mathrm{O}$ atoms (green spheres).

Figure 4.21 FT XAFS data and first shell model fits for the Np-loaded Mn oxide sampleuncorrected for phase shift. 52

Figure 4.22 X-ray powder diffractogram for Sample 0 (containing $\mathrm{H}_{2} \mathrm{O}_{2}$ and no seed $\mathrm{Sr}$ ). Figure 4.23 X-ray powder diffractogram for Sample 1 (containing $\mathrm{H}_{2} \mathrm{O}_{2}$ and seed $\mathrm{Sr}$ )... 54 Figure 4.24 X-ray powder diffractogram for Sample 2 (containing formate and no seed Sr). 55 Figure 4.25 X-ray powder diffractogram for Sample 3 (containing formate and seed Sr)..... 55 


\section{LIST OF TABLES}

Table 3-1 Salt solution composition used in permanganate testing with the actinides............ 16 Table 3-2 Sample preparation and chemical data for the U-, Np-, and Pu-loaded Mn oxide samples that were prepared for XAFS analyses............................................................ 19

Table 3-3 Description of the preparation of actinide-free Mn oxide samples that were analyzed using Sr- and Mn-XAFS spectroscopic and XRD techniques. ........................... 20 


\section{ACRONYMS AND ABBREVIATIONS}

\section{Al}

Am

APS

ANL

BNL

$\mathrm{CN}$

$\delta(\mathrm{K})$

DW

EXAFS

$\mathrm{E}$

$\mathrm{E}_{0}$ or Eo

$\mathrm{E}_{0}$ Shift

$\mathrm{F}$

$\mathrm{Fe}$

FEFF

FFIT

FT

$\hbar$

HLW

$\mathrm{H}_{2} \mathrm{O}_{2}$

$k$

$\mathrm{m}$

$\mathrm{M}$

$\mathrm{Mn}$

MSR

MST

$\mathrm{N}$

$\mathrm{Na}$

$\mathrm{Na}_{4} \mathrm{Mn}_{14} \mathrm{O}_{27} \bullet 9 \mathrm{H}_{2} \mathrm{O}_{(\mathrm{s})}$

$\mathrm{Np}$

NSLS

$\mathrm{O}$

Oax

Oeq

$\mathrm{OH}^{-}$

$\mathrm{Pu}$

$\mathrm{R}$

R-space
Aluminum

Americium

Advanced Photon Source

Argonne National Laboratory

Brookhaven National Laboratory

Coordination number

Electronic phase shifts due to atomic potentials

Debye-Waller factor

Extended X-ray Absorption Fine-Structure

$\mathrm{E}$ is the kinetic energy of the photoelectron

EXAFS defined edge energy in electron volts or eV (not equal to edge energy as defined by XANES but is equal to the energy of the photoelectron at $k=0$

A relative value of $\mathrm{E}_{0}$ (a variable in the EXAFS Equation)

Back scattering amplitude of the atom

Iron

An automated computer program for making ab initio multiple scattering calculations of XAFS and XANES spectra for atoms.

A Levenberg-Marquardt fitting program created by researchers at the University of Washington

Fourier-transform

Plank's constant

High Level Waste

Hydrogen Peroxide

Chi where $k$ is the square root of $\left[\left(2 \mathrm{~m} / \hbar^{2}\right) *\left(\mathrm{E}-\mathrm{E}_{0}\right)\right]$

Mass of the photoelectron

Moles per Liter

Manganese

Multiple Scattering Resonances

Monosodium Titanate

Nitrogen

Sodium

A sodium birnessite solid phase material

Neptunium

National Synchrotron Light Source

Oxygen

Axial actinide-oxygen bond

Equatorial actinide-oxygen bond

Hydroxide

Plutonium

Radial distance (in $\AA$ )

R-space pertains to mean atom position or bond distance (radial distance in $\AA$ )

Page 5 of 65 


$\begin{array}{ll}\text { RDF } & \text { Radial Distribution Function } \\ \mathrm{RPP} & \text { River Protection Program } \\ \mathrm{RT} & \text { Room temperature } \\ \mathrm{S} & \text { Sulfur } \\ \mathrm{Si} & \text { Silicon } \\ \mathrm{S} / \mathrm{N} & \text { Signal to Noise } \\ \mathrm{S}^{\wedge} 2 \text { or } \mathrm{So}^{2} & \text { Amplitude reduction factor (an EXAFS equation variable associated } \\ & \text { with central atom shake-up and shake-off effects) } \\ \sigma^{2} & \text { Debye-Waller Factor or Relative Mean Square Disorder in bond length } \\ & \text { (a variable in the EXAFS Equation) } \\ \mathrm{Sr} & \text { Strontium } \\ \mathrm{SrCO} & \text { Strontium carbonate also known as the mineral strontianite } \\ \mathrm{SRTC} & \text { Savannah River Technology Center } \\ \mathrm{Ti} & \text { Titanium } \\ \mathrm{TEM} & \text { Transmission Electron Microscopy } \\ \mathrm{U} & \text { Uranium } \\ \mathrm{WSRC} & \text { Westinghouse Savannah River Company } \\ \text { XAFS } & \text { X-ray Absorption Fine-Structure (XANES plus EXAFS) } \\ \text { XANES } & \text { X-ray Absorption Near-Edge Structure } \\ \text { XRD } & \text { X-ray Diffraction } \\ \text { Zr } & \text { Zirconium }\end{array}$




\subsection{EXECUTIVE SUMMARY}

Nearly 34 million gallons of high-level waste (HLW, the radioactive waste product associated with the dissolution of spent nuclear fuel rods for the recovery of weapons grade materials) await disposition at the Savannah River Site (SRS). The current design for the Salt Waste Processing Facility at the SRS includes use of monosodium titanate (MST) to remove and concentrate the strontium ( $\mathrm{Sr}$ ) and actinides (uranium, plutonium and neptunium) from HLW salt solutions. However, the River Protection Program (RPP) at the Hanford Site in Washington State proposes use of potassium permanganate addition for $\mathrm{Sr}$ and actinide removal from Hanford HLW. Recent studies at the SRS indicate sodium permanganate treatment holds promise for use in the decontamination of $\mathrm{Sr}$ and actinides in SRS HLW.

The mechanism(s) by which the permanganate treatment process removes strontium and the actinides are not known. Studies with actual and simulant wastes show that removal of these species occurs during the precipitation of brownish-black manganese (Mn)-rich solids. ${ }^{1,2}$ Addition of high concentrations $(0.01 \mathrm{M})$ of dissolved stable Sr during permanganate treatment to isotopically "dilute" and precipitate radiostrontium in RPP wastes proved successful. ${ }^{3,4}$ These studies indicate that $\mathrm{Sr}$ carbonate $\left[\mathrm{SrCO}_{3(\mathrm{~s})}\right.$ or strontianite] solids, a crystalline (as opposed to amorphous) phase of $\mathrm{Sr}$, are the primary crystalline Sr-containing solids that form in these systems.

Some wastes at Hanford contain chemical constituents not found in SRS wastes. For example, some Hanford wastes contain high levels of dissolved organic ions whereas the SRS wastes contain few organics. These organics facilitate the reduction of permanganate ion in Hanford wastes. Therefore, the sodium permanganate treatment of SRS wastes may form different solid phase precipitates than those that form during potassium permanganate treatment of Hanford wastes.

Our work investigated the solids by both chemical and structural analysis. These studies provide the following conclusions.

- Addition of Sr nitrate concentration of $0.01 \mathrm{M}$ results in the formation of a $\mathrm{SrCO}_{3(\mathrm{~s})}$ (or strontianite) solid phase as identified by X-ray absorption fine-structure spectroscopy (XAFS) and by X-ray diffraction analyses. These Sr solids form regardless of the reductant used (i.e., hydrogen peroxide or sodium formate). Some of the actinides can sorb and coprecipitate with carbonate minerals. Hence, the Sr probably coprecipitated or sorbed the actinides in HLW solutions upon precipitation.

- Addition of $0.01 \mathrm{M}$ permanganate and reductant (either hydrogen peroxide or sodium formate) to HLW salt simulant solutions results in the formation of a colloidal tetravalent Mn-rich sodium birnessite-type $\left[\mathrm{Na}_{4} \mathrm{Mn}_{14} \mathrm{O}_{27} \cdot 9 \mathrm{H}_{2} \mathrm{O}_{(\mathrm{s})}\right]$ solid phase, which is structurally stable in the salt solutions over a 168 hour period and has a layered structure consisting of polyhedral sheets of $\mathrm{Mn}$ octahedra $\left(\mathrm{MnO}_{6}\right)$. Comparison with literature data from structural characterization studies with bulk birnessite materials indicate the sizes of these Mn oxide particles lie within the nanoparticle range [i.e., on average, the particles (if

Page 7 of 65 
assumed to be spherical) that are less than 20 nanometers in diameter]. The nanoparticles may have a local fractal or amorphous arrangement and they may also have a plate-like hexagonal nature, which is consistent with that of birnessite materials. When formate was used as the reductant, the particle sizes (as inferred from a lower coordination number for $\mathrm{Mn}$ in the second coordination shell) were slightly smaller than when peroxide was used as the reductant. The solids produced when formate is used as the reductant are slightly more amorphous than those that form are when peroxide is used. The particles are nanocrystalline and probably linked together to form larger particles with no crystallographic orientation. These findings explain why the Mn oxide solids in this study could not be characterized by conventional X-ray diffraction analyses.

- The neptunium (Np) in the solids that form upon reduction of permanganate exists as the pentavalent $\mathrm{Np}(\mathrm{V}) \mathrm{O}_{2}{ }^{2+}$ species. No $\mathrm{Np}$ or $\mathrm{Mn}$ atoms exist in the outer coordination shells. The first coordination shell contains several $\mathrm{O}$ atoms. The $\mathrm{Np}$ removal appears to not involve a strong physicochemical association with the Mn oxides. This is evidenced by the absence of Mn in outer coordination shells in the Np EXAFS data. This finding suggests that $\mathrm{Np}$ may undergo outer-sphere sorption, which signifies that the $\mathrm{Np}$ is susceptible to displacement by other ions that also form outer-sphere associations and by displacement from the surface due to changes in ionic strength. Another explanation for $\mathrm{Np}$ removal from solution is that the $\mathrm{Np}$ [added as $\mathrm{Np}(\mathrm{V})$ ] undergoes a change in oxidation state [i.e., from $\mathrm{Np}(\mathrm{V})$ to $\mathrm{Np}(\mathrm{IV})]$. Due to the lower solubility of $\mathrm{Np}(\mathrm{IV})$, this change in oxidation state would result in lower dissolved Np concentration and most likely additional loss of $\mathrm{Np}$ from solution due to sorption. Such processes could be reversible and thus not readily observed in our XAFS experiments.

- The plutonium $(\mathrm{Pu})$ in the permanganate-treated samples is present as $\mathrm{Pu}(\mathrm{IV})$ with eight first shell Pu-oxygen $(\mathrm{O})$ distances. The mechanism of $\mathrm{Pu}$ removal during permanganate treatment involves the incorporation of $\mathrm{Pu}$ into the Mn oxide (birnessite). The sorption may involve specific adsorption of $\mathrm{Pu}$ in the birnessite interlayer regions or isomorphic substitution of $\mathrm{Pu}$ in $\mathrm{Mn}$ site vacancies (where a $\mathrm{Pu}$ atom resides in a site that is normally occupied by a Mn atom). Plutonium is also present in the second coordination shell suggesting that monomeric and polymeric species of $\mathrm{Pu}$ are present in the $\mathrm{Mn}$ oxides.

- Precipitation of a birnessite-type phase and strontianite in the treatments coincides with the precipitation of other salts. The sources of the salts are the dissolved components within the salt simulant solution and the rapidly forming Mn and Sr solids promote the homogeneous nucleation of these salts. The precipitation of these salts effectively lowers the actinide loadings in the precipitants and also increases the solids loadings. Air-drying of the sample may have contributed to the some of the salt precipitation observed.

Our results identify the mechanisms by which $\mathrm{Pu}$ and $\mathrm{Np}$ are removed from solution during permanganate treatment. The governing mechanisms differ for these actinides. Plutonium is strongly associated with the Mn oxide by coprecipitation (mainly, with some adsorption possible). In contrast, the removed neptunium proves easier to release into solution (i.e., reversible removal) after birnessite precipitation.

Page 8 of 65 
WSRC-TR-2002-00366, REVISION 0

\subsection{INTRODU CTION}

The Record of Decision issued on October 17, 2001 identified solvent extraction as the preferred cesium removal process for high-level waste (HLW) treatment at the Savannah River Site. As a pretreatment step for the solvent extraction flowsheet, the incoming salt solution containing small amounts of entrained sludge is contacted with monosodium titanate (MST) to adsorb strontium $(\mathrm{Sr})$, neptunium $(\mathrm{Np})$, plutonium $(\mathrm{Pu})$ and uranium $(\mathrm{U})$.

Permanganate treatment with some Hanford wastes requires an excess of stable "seed" $\mathrm{Sr}^{2+}$ for isotopic dilution of $\mathrm{Sr}^{2+}$ and $\mathrm{Sr}$ precipitation and a reductant (such as formate or oxalate ions, which are endemic to the waste) for acceptable actinide removal. ${ }^{3,4}$ This treatment process involves the formation of two or more solids, which precipitate the $\mathrm{Sr}^{2+}$ [presumably as $\mathrm{SrCO}_{3(\mathrm{~s})}$ ] and actinides [presumably as a manganese (Mn)(III, IV) oxideactinide coprecipitate] in the HLW salt solutions. ${ }^{3}$ For SRS wastes, prior studies show a benefit of adding $\mathrm{Sr}$ for the removal of actinides, including $\mathrm{Pu}$, from SRS waste. ${ }^{1}$

Savannah River Technology Center (SRTC) researchers demonstrated the utility of permanganate reduction with $\mathrm{Mn}$ oxide precipitation in the presence of an alkaline earths (calcium, $\mathrm{Sr}$ ) to rapidly reduce the concentrations of ${ }^{90} \mathrm{Sr}$, americium (Am), $\mathrm{Pu}, \mathrm{Np}$ and $\mathrm{U}$ in high-level tank wastes and waste simulants. ${ }^{1,2}$ Researchers remain uncertain whether the $\mathrm{Mn}$ oxide behaves as freshly precipitated sorbent, or if the radionuclides are included in the precipitating framework. Kinetics studies show rapid removal of $\mathrm{Pu}$ and $\mathrm{Sr}$ from tank waste simulants during the first half-hour, with continual decrease in dissolved $\mathrm{Pu}$ and $\mathrm{Sr}$ concentrations with time. ${ }^{1}$ This result could be consistent with either inclusion into a precipitating framework, or sorption onto a freshly precipitated surface.

To achieve optimal removal of the $\mathrm{Sr}^{2+}$ from SRS waste using permanganate treatment, we must evaluate several aspects before adopting permanganate into the flowsheet. Our report reviews work relevant to Mn oxides and their use in radionuclide decontamination, focuses on the mechanism of radionuclide decontamination during permanganate treatment with simulant SRS HLW salt solutions and characterizes the solids that form. We examine the binding environments of ${ }^{237} \mathrm{~Np}$ and ${ }^{239 / 240} \mathrm{Pu}$ after reaction with permanganate and hydrogen peroxide $\left(\mathrm{H}_{2} \mathrm{O}_{2}\right)$ from $\mathrm{HLW}$ simulants with low carbonate levels (i.e., near $0.03 \mathrm{M}$ $\left.\mathrm{CO}_{3}{ }^{2-}\right)$ and a sodium ion $\left(\mathrm{Na}^{+}\right)$concentration of $5.6 \mathrm{M}$. We also investigate the chemical behavior and speciation of $\mathrm{Sr}^{2+}$ and $\mathrm{Mn}$ in non-radioactive samples after reaction with permanganate in the presence of reductant (either $\mathrm{H}_{2} \mathrm{O}_{2}$ or formate) using X-ray absorption fine-structure (XAFS) spectroscopic and X-ray diffraction (XRD) techniques.

\subsection{Use of Mn Oxide Solids for Removal of Radionuclides from Solutions and the Influence of Mn Oxide Structure}

Manganate solids [the Mn(IV)-dominated oxides] typically have high surface areas and strong affinities for dissolved cations such as $\mathrm{Sr}^{2+}$, for some of the actinides (e.g., $\mathrm{Pu}, \mathrm{Am}$ and $\mathrm{U}$ ) and for other radionuclide fission products in highly alkaline HLW salt solutions and other aqueous radioactive waste streams. ${ }^{4,5}$ Tetravalent and trivalent Mn oxides are

Page 9 of 65 
ubiquitous in the natural environment. They are noted for their high affinity for concentrating actinides [Am, $\mathrm{Pu}]$ and various $d$-transition metals in oceanic and freshwater waters. ${ }^{7,} 8,9,10$

The affinity of these Mn oxides for dissolved ions is related to structure. For the Mn oxides, the basic building blocks are Mn octahedra (Figure 2.1), which can be linked via three orientations to form larger structures. Few sorption studies with Mn oxides discern between the various types of Mn oxide structures and many simply refer to the solids as being Mn oxide material. ${ }^{11,12,13}$ Many of the Mn oxides have similar elemental stoichiometry but they can have different structural arrangements of their Mn octahedra.

For example, the tunnel-structured manganates consist of mainly corner-sharing Mn octahedra (Figure 2.1). These solids have sorption capacities that often exceed that of zeolitic materials. The linkages of the Mn octahedra result in the formation of long tunnels, which can be size excluding to some ions. ${ }^{14}$ The tunnel-structured Mn oxides can have low affinities for $\mathrm{Pu}$ and $\mathrm{Sr}$ relative to cesium (Cs) and other radionuclides such as Am. ${ }^{9}$

Layered Mn oxides have primarily edge-linked Mn octahedra and, until recently, the structures of these layered Mn oxides were unknown (Figure 2.1). ${ }^{15}$ They have a lamellar structure of Mn octahedral layers with interlayer water and hydroxyl groups. In nature, the layered Mn oxides tend to be poorly crystalline and of small particle size but this behavior results in high surface areas per volume. Layered structures often contain interlayer cations, which can be displaced by other sorbing ions such as the actinides. ${ }^{16}$ Layered structures may exhibit some corner-sharing behavior, which gives them more three-dimensional structures than the two-dimensional structures that exist for solids with only edge-linked Mn octahedra.

Some removal of $\mathrm{Np}$ and $\mathrm{U}$ from HLW salt simulant solutions containing multiple radionuclides ( $\mathrm{Sr}, \mathrm{Pu}, \mathrm{Np}$ and $\mathrm{U}$ ) is also observed within the first few hours of equilibration, but the levels of dissolved $\mathrm{Np}$ and $\mathrm{U}$ may increase after four hours. ${ }^{1}$ Little work exists on the testing of $\mathrm{Mn}$ oxides for their ability to sorb $\mathrm{Np}$ from aqueous solutions. ${ }^{1,}{ }^{17}$ However, these sorption studies indicate $\mathrm{Np}$ has a low affinity for Mn oxide solids, relative to several other sorbent solids and the Mn oxide form was not identified. ${ }^{17}$ Similar studies with U reveal that $\mathrm{U}$ also has a fairly low affinity for birnessite, a layered Mn oxide. The transmission electron microscopy (TEM) characterization studies of the solids produced from the permanganate process indicate that they are extremely fine-grained Mn oxide materials with hexagonal and fibrous morphologies. ${ }^{18}$

Synthesis methods for Mn oxides typically include one of the following approaches: permanganate $[\mathrm{Mn}(\mathrm{VII})]$ reduction, reaction of $\mathrm{Mn}(\mathrm{II})$ with $\mathrm{Mn}(\mathrm{VII})$ ion and the oxidation of $\mathrm{Mn}(\mathrm{II}){ }^{6}{ }^{6}, 13,19,20,21,22$ Reduction of permanganate ion in basic media is thought to result in the formation of birnessite $\left[\mathrm{Na}_{4} \mathrm{Mn}_{14} \mathrm{O}_{27} \cdot 9 \mathrm{H}_{2} \mathrm{O}_{(\mathrm{s})}\right]$, a layered Mn oxide - as noted in Krot et al.

(1998) and references therein. ${ }^{19}$ Several analytical methods for Pu isolation use Mn oxide solids (oftentimes produced from the reduction of permanganate ion) to concentrate actinides from solutions and from various waste streams by coprecipitation. 5, 23, 24 


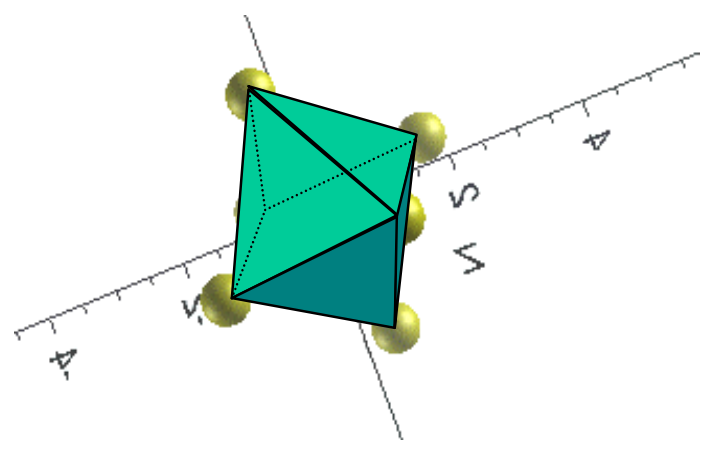

A. One Mn(IV) octahedron with 6 first shell oxygens at $1.9 \AA$ in octahedral symmetry

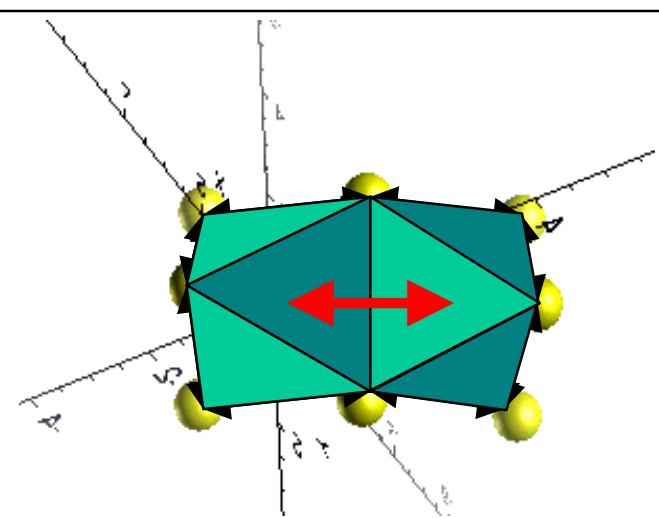

B. Two Mn(IV) octahedra sharing 3 oxygens. Termed "face" sharing, Mn-Mn distance $2.5 \AA$

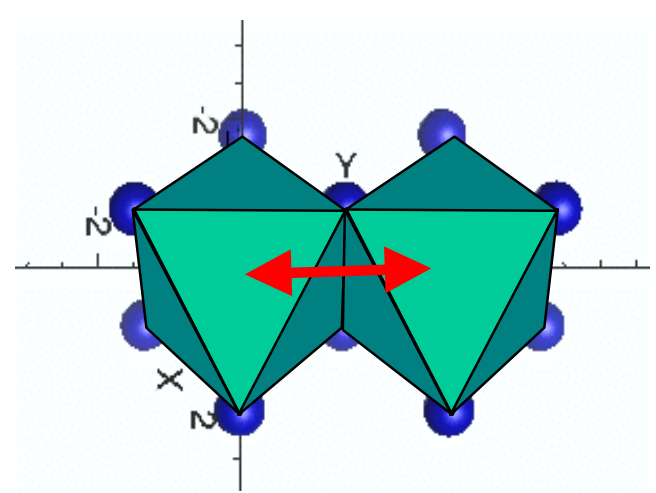

C. Two Mn(IV) octahedra sharing 2 oxygens. Termed "edge" sharing, Mn-Mn distance $2.85 \AA$

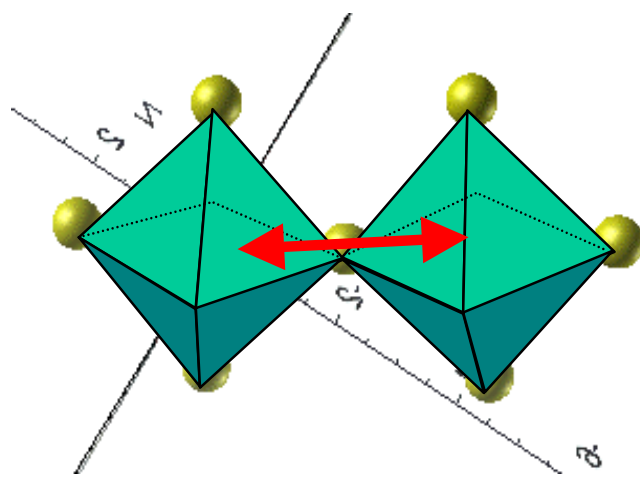

D. Two Mn(IV) octahedra sharing 1 oxygen. Termed "corner" sharing, Mn-Mn distance $3.8 \AA$

Figure 2.1 Basic building blocks of Mn(IV) oxides. Edge- and corner-sharing Mn octahedra are the most common linkages observed in naturally occurring Mn oxides. Red arrows point to the distance between the Mn atoms in the linked Mn octahedra.

NOTE: Due to document format problems, the figure shown above is not a complete reproduction of that presented in the original report document. 
Few studies have investigated the structure of these Mn oxides or why the Mn oxides that form have an affinity for metal ion removal. Additionally, changes in metal redox chemistry may influence metal uptake behavior such as with Pu but few studies have evaluated the chemistry of redox-reactive radionuclides in contact with Mn oxide materials. ${ }^{8}$

\subsection{Uptake Mec hanisms of Metals by Surfaces}

Uptake processes by solids can occur by several mechanisms: structural incorporation, ion exchange (electrostatic or outer-sphere) sorption, specific adsorption and surface precipitation. Figure 2.2 provides a schematic of these processes. Many of these terms have been used loosely in the literature and their use varies with scientific discipline. This presentation focuses on the surface and its interaction with the sorbing or coprecipitating solution species. A more thorough review of these processes is presented elsewhere. ${ }^{25,26}$ The expression of these uptake processes typically depends upon the amount of metal added, solution and solid phase characteristics.

"Ion exchange" can have different meanings, which results in some confusion in the literature. One very general way to express ion exchange is Structural Incorporation, which is the substitution of a solution species for a structural atom:

$$
\mathrm{CaCO}_{3(\mathrm{~s})}+\mathrm{Sr}^{2+} \rightleftarrows \mathrm{SrCO}_{3(\mathrm{~s})}+\mathrm{Ca}^{2+}
$$

This type of sorption typically requires ready access to structural atoms. Although little is known about the structure of the Mn oxide solids formed during permanganate treatment, access [for $\mathrm{Pu}(\mathrm{IV})]$ could occur by substitution of $\mathrm{Pu}^{4+}$ within the vacancies of $\mathrm{MnO}_{6}$ octahedral layers. In this case, the structural incorporation of $\mathrm{Pu}^{4+}$ in the $\mathrm{Mn}$ oxide would result in several $\mathrm{Mn}$ atoms (two or more, on average) at physically realistic distances in the second coordination shell of the $\mathrm{Pu}^{4+}$. Another example of this process would be the exchange of $\mathrm{Na}^{+}$for $\mathrm{Ca}^{2+}$ within the interlayer region of a layered Mn oxide solid (formed upon the reduction of permanganate by $\mathrm{H}_{2} \mathrm{O}_{2}$ or formate ion). Ideally, structural incorporation of anions could also result in a similar number of neighboring atoms in the first coordination shell to that of the replaced ion prior to its release. Therefore, the local environment of the exchanged atom would tend to resemble the environment the newly exchanged atom had before its release (Figure 2.2A). Two exceptions to this would be when the host structure is a nanoparticle and when the structure is amorphous. In these cases, exact determinations of whether the participating metal species resides in a structural vacancy or within an interlayer site are not straightforward. ${ }^{27}$

Ion Exchange in a more restrictive sense is an electrostatic process involving the replacement of one readily exchangeable hydrated ion by another similarly exchangeable ion (Figure 2.2B). This type of sorption is also referred to as Outer Sphere sorption. Ion exchange does not involve the formation of bonds on the participating surface because the sorbed ion is present in the diffuse double layer (DDL). This type of sorption is normally reversible ${ }^{28}$ and is a function of ionic strength (i.e., such as $\mathrm{Na}^{+}$ion concentration). At high ionic strengths, the DDL collapses and less sorption by ion exchange is observed than at low Page 12 of 65 

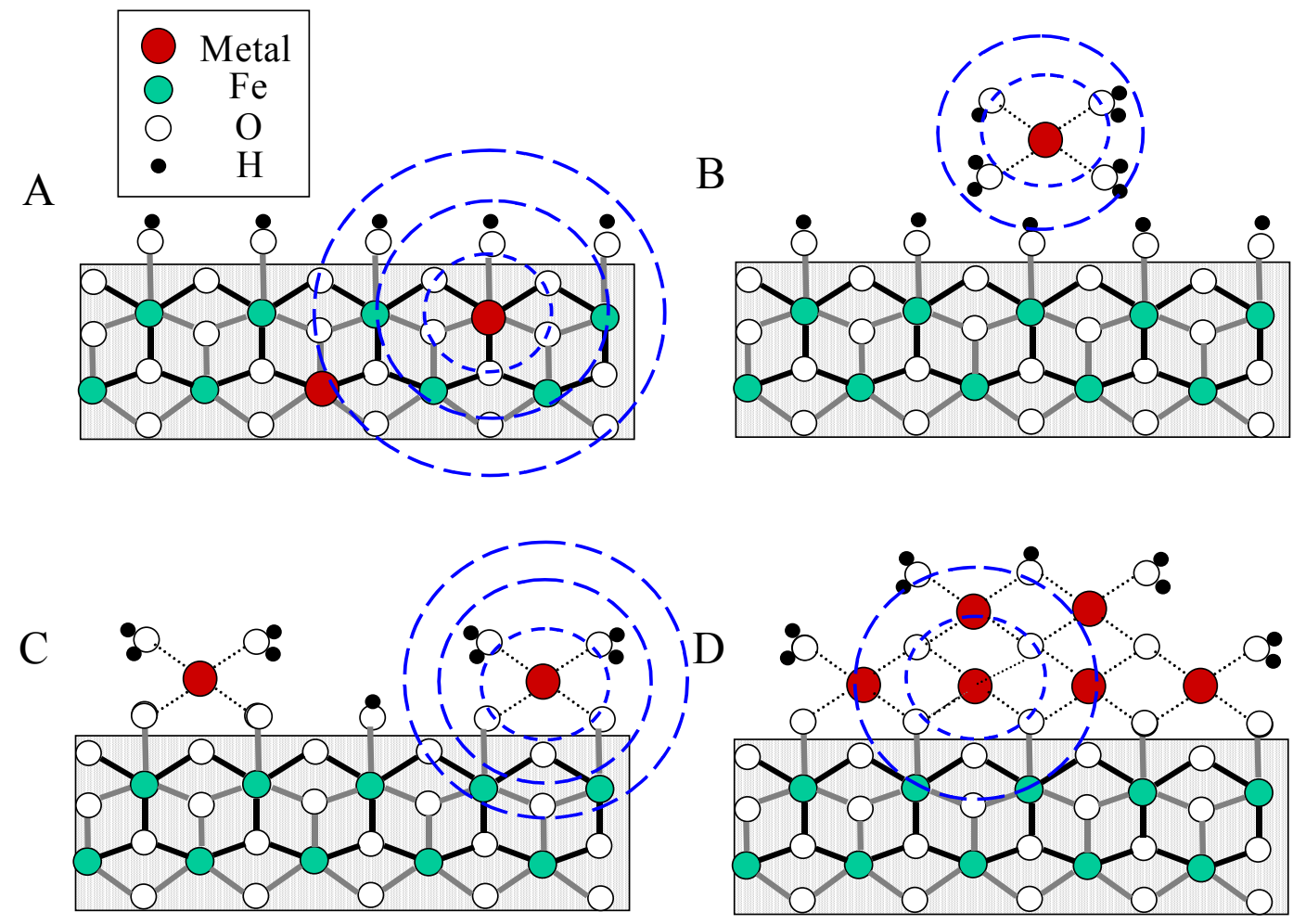

Figure 2.2 Simplified diagram of the types of associations a metal could have with a surface: A) Structural incorporation, B) Outer-sphere (electrostatic) sorption, C) Specific or innersphere sorption and D) Surface precipitation. Blue rings denote first, second and third shell environments that can be probed with XAFS techniques. 
ionic strengths. Ion exchange sorption is often associated with materials that have constant surface charge and exhibit no change in overall surface charge upon ion exchange sorption. An example of this process would be exchange of hydrated $\mathrm{Na}^{+}$ion for hydrated $\mathrm{UO}_{2}{ }^{2+}$ in the DDL. Outer sphere adsorption has been observed with $\mathrm{Sr}^{2+}$ on poorly crystalline Mn oxide hydrates. ${ }^{\text {a }}$

Specific adsorption involves the formation of predominantly covalent bonds with the surface, but the bonds can have some ionic behavior. This type of sorption is often referred to as Chemisorption or Inner Sphere sorption. Specifically adsorbed metals typically have one or more atoms from the participating surface in the second coordination shell (Figure 2.2C). This type of sorption involves the release of $\mathrm{H}^{+}$or structural surface ions (such as $\mathrm{Na}^{+}$in MST) upon sorption. For example, specific sorption of $\mathrm{UO}_{2}{ }^{2+}$ to $\mathrm{MST}$ could result in the presence of titanium (Ti) atoms in the second coordination shell of the $\mathrm{UO}_{2}{ }^{2+}$. Specific adsorption is usually irreversible. ${ }^{28}$ However, in the literature, specific adsorption is rarely differentiated from structural incorporation or surface precipitation. Specific adsorption may involve mononuclear complexes or polymeric species. Specific adsorption may occur with metals and their associated ligands (such as a U(VI)-carbonate ion) and specific adsorption is influenced by other solution- and surface-related variables. ${ }^{29}$

Surface Precipitation occurs by nucleation of new solid phase on a host surface (Figure 2.2D). For example, when the concentration of a dissolved metal such as $\mathrm{UO}_{2}{ }^{2+}$ is high enough to result in the super-saturation of one or more $\mathrm{UO}_{2}{ }^{2+}$-containing phases [such as $\left.\mathrm{U}(\mathrm{VI}) \mathrm{O}_{3} \cdot 2 \mathrm{H}_{2} \mathrm{O}_{(\mathrm{s})}\right]$ in the presence of another solid (such as MST), the other solid facilitates the nucleation of the new solid $\mathrm{UO}_{2}{ }^{2+}$-rich phase. Surface precipitation of U(VI) would result in the existence of several second shell $U$ atoms around each $U$. The sorption of colloidal $U$ species on surfaces would resemble the same local environment as observed for surface precipitation.

\subsection{Use of XAFS Techniques to Characterize Metal Uptake by Surfaces}

The local environment of metals associated with surfaces can be investigated with analytical techniques such as XAFS spectroscopy. The XAFS spectroscopic techniques are among the best techniques known for providing detailed chemical speciation information in environmental samples - particularly when information from multiple characterization techniques is available and when the phase of interest is amorphous, microcrystalline or nanocrystalline. The term XAFS is applicable to both X-ray absorption near-edge structure (XANES) and extended X-ray absorption fine-structure (EXAFS) spectroscopic techniques. The XAFS spectra give robust local structural information on coordination number $(\mathrm{CN})$, bonding symmetry, neighbor and near-neighbor atomic distances and bond disorder (as the root mean square deviations of distances about the average values). Additionally, the

\footnotetext{
${ }^{a}$ Axe, L. personal communication, National Synchrotron Light Source Annual User's Meeting, Brookhaven National Laboratory, Upton, NY, May, 2002.
}

Page 14 of 65 
information gained is atom specific - making it a versatile technique for structural determinations of atom clusters. ${ }^{30,31}$

The XANES techniques involve multiple scatterings of an ejected photoelectron with moderate kinetic energy with neighboring atoms. Unlike EXAFS, for XANES the ejected photoelectron does not enter the continuum. ${ }^{30}$ The XANES spectroscopic techniques can provide information on the local coordination environment and oxidation state of the metal of interest. $^{30}$ EXAFS spectroscopy in particular has been successfully applied to the structural elucidation of metal clusters and sorbed metals on surfaces because the technique does not require long range order (i.e., periodicity) or crystalline samples. XAFS techniques are often complemented by the results of X-ray diffraction (XRD) studies, which provide information on the bulk crystalline phases. Information on the structure of crystalline phases aids in the modeling of metal sorption using the XAFS data.

Prior XAFS studies have been conducted with sorbed radionuclides $\mathrm{Sr}^{2+}$ on hydrous $\mathrm{Mn}$ oxides, sorbed $\mathrm{Pu}$ on rancieite (a birnessite-type Mn oxide), as well as cesium and cobalt on layered birnessite-type Mn oxides. ${ }^{6,8,32,33}$ These X-ray absorption fine-structure spectroscopic studies provided fundamental structural information about the Mn oxides and their associated metals. However, these studies occurred at low ionic-strength, using neutral to basic solutions (i.e., solutions that do not possess the typical properties of SRS HLW tank fluids).

\subsection{Experimental Objectives}

The primary objective of this research involved obtaining information on the solids that form and the speciation of actinides associated with the solids after reaction of permanganate and reductant in highly alkaline solutions. Before this preliminary study, little information existed on the speciation of sorbed actinides of known oxidation states within these materials. We used XAFS techniques in this study to obtain information on the average local structural speciation of the sorbed actinides such as $\mathrm{CN}$, geometry, near and next nearest neighbor environment of the target metal.

We studied the local structural environment of actinides initially added to salt simulant solutions in the following forms: $\mathrm{Pu}(\mathrm{IV})$ and $\mathrm{Np}(\mathrm{V})$. To determine the nature of metal uptake using XAFS, our studies included Mn oxide solids with a range of actinide loadings. We also characterized actinide-free Mn oxide solids isolated from eight additional tests with XAFS and XRD techniques. These non-radioactive tests initially contained $0.01 \mathrm{M}$ permanganate and $0.045 \mathrm{M}$ reductant (either formate or $\mathrm{H}_{2} \mathrm{O}_{2}$ ) in the presence or absence of $0.01 \mathrm{M}$ seed $\mathrm{Sr}\left(\mathrm{NO}_{3}\right)_{2}$.

To test whether our results appear atomically realistic, we used molecular models to simulate the findings from our EXAFS studies. We complemented the findings from our XAFS analyses by the results obtained from our XRD studies, which provided information on the crystalline solid phases within our samples.

Page 15 of 65 
WSRC-TR-2002-00366, REVISION 0

\subsection{MATERIALS AND EXPERIMENTAL METHODS}

We prepared solid phase samples from permanganate treatment for XAFS and XRD analyses. The details of the sample preparation, XAFS data collection, XRD data collection and data analyses follow.

\subsection{Sample Prep aration}

\subsubsection{Actinide-con taining Mn Samples}

We prepared a series of actinide-loaded Mn oxide solid phases for XAFS analyses. Testing also required the preparation of HLW simulant salt solution with the composition given in Table 3-1 from reagent grade chemicals. Technicians spiked known volumes of the salt solutions individually with known levels of $\mathrm{Pu}(\mathrm{IV}), \mathrm{Np}(\mathrm{V})$ and $\mathrm{U}(\mathrm{VI})$. Researchers obtained nitric acid stock solutions of $\mathrm{Pu}(\mathrm{IV})$ and $\mathrm{Np}(\mathrm{V})$ from the Actinide Technology Section (SRTC). Uranium(VI) stock solutions used uranyl nitrate hexahydrate. The methods of solution preparation in our study resemble those used in previous MST adsorption and permanganate treatment studies ${ }^{34,35,36}$ except that for the higher radionuclide concentrations within our salt solutions. To obtain such high levels of dissolved $\mathrm{Pu}$ and $\mathrm{Np}$ (as noted in Table 3-2), we spiked the salt solutions with concentrations of $\mathrm{Pu}$ and $\mathrm{Np}$ that exceeded the typical solubility limits of these species. Technicians filtered the solutions after a 24-hour equilibration and submitted samples of the salt solutions for inductively-coupled plasma mass spectroscopy (ICP-MS) analyses to determine the levels of actinides in the salt solutions prior to use. Table 3-2 presents details of the sample preparation for the actinide-containing $\mathrm{Mn}$ oxide samples. A more detailed description of the sample preparation is given in Duff et al. (2002). ${ }^{1}$

Table 3-1 Salt solution composition used in permanganate testing with the actinides.

\begin{tabular}{|c|c|}
\hline Component & Concentration (M) \\
\hline $\mathrm{NaNO}_{3}$ & 2.60 \\
\hline $\mathrm{NaOH}$ & 1.33 \\
\hline $\mathrm{Na}_{2} \mathrm{SO}_{4}$ & 0.521 \\
\hline $\mathrm{NaAl}(\mathrm{OH})_{4}$ & 0.429 \\
\hline $\mathrm{NaNO}_{2}$ & 0.134 \\
\hline $\mathrm{Na}_{2} \mathrm{CO}_{3}$ & 0.026 \\
\hline Total Na $^{+}$ & 5.6 \\
\hline
\end{tabular}

To prepare the solids, known amounts of permanganate and $0.045 \mathrm{M} \mathrm{H}_{2} \mathrm{O}_{2}$ were added to known volumes of actinide solutions and sampled in batch as described in Table 3-2.

Sampling times (i.e., salt solution filtration) are approximate-within 20 minutes. $\mathrm{H}_{2} \mathrm{O}_{2}$ (at $0.45 \mathrm{M}$ ) was the reductant initially used in all of these tests. However, no color conversion occurred upon first addition. Although the $\mathrm{H}_{2} \mathrm{O}_{2}$ was recently opened, it was unreactive due Page 16 of 65 
to improper storage conditions. Sodium formate, which is a slow reductant relative to $\mathrm{H}_{2} \mathrm{O}_{2}$ (at equimolar concentrations) was added at a concentration of $0.045 \mathrm{M}$. However, a properly stored, unopened supply of $\mathrm{H}_{2} \mathrm{O}_{2}$ was located after the formate was added so $0.045 \mathrm{M} \mathrm{H}_{2} \mathrm{O}_{2}$ was then added (about 10 minutes after the formate was added). Upon addition of the $\mathrm{H}_{2} \mathrm{O}_{2}$, the conversion of the purple permanganate solutions to a characteristic black color (indicative of the formation of solids) was noticeably rapid. Because the formate-permanganate reaction is much slower than that of the $\mathrm{H}_{2} \mathrm{O}_{2}$-permanganate reaction, ${ }^{1,}{ }^{37}$ we deem $\mathrm{H}_{2} \mathrm{O}_{2}$ to be the most active reductant in these tests. This assumption is supported by Krot et al. (1998), who report that the reaction using $\mathrm{H}_{2} \mathrm{O}_{2}$ as the reductant is complete by the time the reactants are mixed. ${ }^{19}$

The solutions were equilibrated for up to 4 hours with intermittent swirling at room temperature. During sampling, the actinide-loaded Mn oxide suspensions were filtered with a $0.45-\mu \mathrm{m}$ nylon filter and the filtered solids were dried in air at ambient temperature. After filtration, samples of the salt solutions submitted for ICP-MS to determine the levels of actinides that were lost from solution. The amount of actinide lost from solution was used to calculate an expected actinide loading based solely on the formation of $\mathrm{MnO}_{2(\mathrm{~s})}$ (as shown in Table 3-2).

The calculated actinide loadings (assuming the formation of only $\mathrm{MnO}_{2}$ ) were not comparable to the actinide loadings we anticipated. Hence, XAFS data collection was only possible with one of the Pu samples (Test 12) and one of the Np samples (Test 17). Actual radionuclide loadings on $\mathrm{Mn}$ oxide samples were not determined.

The solids were not rinsed prior to analysis because rinsing could potentially alter the speciation of the actinides. The actinide-containing Mn solids were prepared for Pu- and NpXAFS analyses as described in Section 3.1.3. These solids were not analyzed using XRD techniques.

\subsubsection{Actinide-fre e Mn Oxides}

A series of actinide-free Mn oxide samples were prepared for XAFS and XRD analyses as described in Table 3-3. The same salt solution composition as described in Table 3-1 was used in these studies after the equilibrations. These solids were dried in air and submitted for XRD analyses and prepared for Mn- and Sr-XAFS studies as described in Section 3.1.3.

\subsubsection{XANES and EXAFS Data Collection}

\subsubsection{Studies Con ducted at the National Synchrotron Light Source}

The XAFS data were collected on beamline X23a2 (Figure 3.1) at the National Synchrotron Light Source [NSLS, Brookhaven National Laboratory (BNL), NY] Plutonium- 
XAFS data were collected at the $\mathrm{Pu} \mathrm{L}_{3}$-edge $(18,054 \mathrm{eV})$ on one of the air-dried filtered $\mathrm{Mn}$ solids (Test 12) listed in Table 3-2. Neptunium-XAFS data were collected at the $\mathrm{Np}_{3}$-edge $(17,610 \mathrm{eV})$ on one of the air-dried filtered Mn solids (Test 17) listed in Table 3-2.

Manganese-XAFS data were collected at the Mn K-edge $(6,539 \mathrm{eV})$ on all of the nonradioactive air-dried filtered Mn solids listed in Table 3-3. ${ }^{38}$ Strontium-XAFS data were collected at the $\mathrm{Sr} \mathrm{K}$-edge $(16,105 \mathrm{eV})$ on the four non-radioactive samples that received 0.01 $\mathrm{M}$ seed $\mathrm{Sr}$ as listed in Table 3-3. The XAFS data were collected in fluorescence mode using an unfocussed X-ray beam and a fixed-exit $\mathrm{Si}(311)$ monochromator. Ion chambers were used to collect incident (Io), transmission (It) and reference (Ir) signals (Figure 3.1). Simultaneous data collection of a reference (Ir) signal was performed by measuring a zirconium (Zr) metal foil (for $\mathrm{Np}$ and $\mathrm{Pu}$ ). The $\mathrm{Mn}$ - and $\mathrm{Sr}$-XAFS data were acquired in fluorescence and transmission. The Mn XAFS spectra were collected at the "magic angle" to preclude any effects of sample orientation on the spectra. ${ }^{33}$ Gas ratios for the data collection in Io were $100 \%$ argon for $\mathrm{Sr}, \mathrm{Np}$ and $\mathrm{Pu}$ analyses. For Mn, incident (Io) X-ray energy was monitored by an ionization chamber containing $100 \%$ free-flowing $\mathrm{N}$ gas whereas the transmission energy was monitored by an ionization chamber containing $100 \%$ free-flowing argon gas. These studies were conducted at room temperature (RT). 
Table 3-2 Sample preparation and chemical data for the U-, Np-, and Pu-loaded Mn oxide samples that were prepared for XAFS analyses.

\begin{tabular}{|c|c|c|c|c|c|c|c|c|}
\hline Test & $\begin{array}{c}\text { Solution } \\
\text { Volume } \\
\text { (mL) }\end{array}$ & $\begin{array}{c}\text { Sampling } \\
\text { Time } \\
\text { (Hours) }^{\mathrm{a}}\end{array}$ & $\begin{array}{c}\text { Initial } \\
\mathrm{MnO}_{4}^{-} \\
\text {Conc. } \\
\text { (M) }\end{array}$ & $\begin{array}{l}\text { Actinide } \\
\text { Species } \\
\text { Added }\end{array}$ & $\begin{array}{c}\text { Initial } \\
\text { Actinide } \\
\text { Solution } \\
\text { Conc. } \\
\left(\mu \mathrm{g} \mathrm{L}^{-1}\right)\end{array}$ & $\begin{array}{c}\text { Final } \\
\text { Actinide } \\
\text { Solution } \\
\text { Conc. } \\
\left(\mu \mathrm{g} \mathrm{L}^{-1}\right)\end{array}$ & \begin{tabular}{|c|} 
Calculated \\
Amount of \\
Dry Solids \\
Produced (as \\
g of $\mathrm{MnO}_{2}$ ) \\
\end{tabular} & $\begin{array}{l}\text { Calculated } \\
\text { Actinide } \\
\text { Loading (mg } \\
\text { Actinide } \mathbf{~ k g}^{-1} \\
\left.\text { of } \mathrm{MnO}_{2}\right)\end{array}$ \\
\hline 1 & 220 & 1 & 0.010 & $\mathrm{U}(\mathrm{VI})$ & 15350 & 11670 & 0.189 & 4280 \\
\hline 2 & 350 & 1 & 0.005 & $\mathrm{U}(\mathrm{VI})$ & 15350 & 13240 & 0.151 & 4910 \\
\hline 3 & 220 & 1 & 0.0025 & $\mathrm{U}(\mathrm{VI})$ & 15350 & 12530 & 0.047 & 13130 \\
\hline 4 & 220 & 2 & 0.010 & U(VI) & 15350 & 10580 & 0.189 & 5540 \\
\hline 5 & 220 & 2 & 0.005 & $\mathrm{U}(\mathrm{VI})$ & 15350 & 11440 & 0.095 & 9100 \\
\hline 6 & 350 & 2 & 0.0025 & U(VI) & 15350 & 11800 & 0.075 & 16480 \\
\hline 7 & 220 & 4 & 0.010 & $\mathrm{U}(\mathrm{VI})$ & 15350 & 10750 & 0.189 & 5350 \\
\hline 8 & 220 & 4 & 0.005 & $\mathrm{U}(\mathrm{VI})$ & 15350 & 11300 & 0.095 & 9420 \\
\hline 9 & 220 & 1 & 0.005 & $\mathrm{Pu}(\mathrm{IV})$ & 640 & 39 & 0.095 & 1400 \\
\hline 10 & 450 & 1 & 0.0025 & $\mathrm{Pu}(\mathrm{IV})$ & 640 & 92 & 0.097 & 2550 \\
\hline 11 & 220 & 2 & 0.005 & $\mathrm{Pu}(\mathrm{IV})$ & 640 & 22 & 0.095 & 1440 \\
\hline 12 & 450 & 2 & 0.0025 & $\mathrm{Pu}(\mathrm{IV})$ & 640 & 143 & 0.097 & 2310 \\
\hline 13 & 220 & 4 & 0.005 & $\mathrm{Pu}(\mathrm{IV})$ & 640 & 37 & 0.095 & 1400 \\
\hline 14 & 450 & 4 & 0.0025 & $\mathrm{Pu}(\mathrm{IV})$ & 640 & 12 & 0.097 & 2920 \\
\hline 15 & 220 & 1 & 0.005 & $\mathrm{~Np}(\mathrm{~V})$ & 1380 & 900 & 0.095 & 1120 \\
\hline 16 & 450 & 1 & 0.0025 & $\mathrm{~Np}(\mathrm{~V})$ & 1380 & 1150 & 0.097 & 1060 \\
\hline 17 & 220 & 2 & 0.005 & $\mathrm{~Np}(\mathrm{~V})$ & 1380 & 710 & 0.095 & 1550 \\
\hline 18 & 450 & 2 & 0.0025 & $\mathrm{~Np}(\mathrm{~V})$ & 1380 & 1090 & 0.097 & 1370 \\
\hline 19 & 220 & 4 & 0.005 & $\mathrm{~Np}(\mathrm{~V})$ & 1380 & 840 & 0.095 & 1260 \\
\hline 20 & 450 & 4 & 0.0025 & $\mathrm{~Np}(\mathrm{~V})$ & 1380 & 1190 & 0.097 & 890 \\
\hline
\end{tabular}


Table 3-3 Description of the preparation of actinide-free Mn oxide samples that were analyzed using Sr- and Mn-XAFS spectroscopic and XRD techniques.

\begin{tabular}{|c|c|c|c|c|}
\hline Sample & $\begin{array}{c}\text { Sampling } \\
\text { Time } \\
\text { (Hours) }^{\mathbf{a}}\end{array}$ & $\begin{array}{c}\text { Initial } \mathrm{MnO}_{4}^{-} \\
\text {Conc. }(\mathbf{M})\end{array}$ & $\begin{array}{c}\text { Reductant } \\
\text { Tested } \\
(\mathbf{a t ~ 0 . 0 4 5} \mathbf{M})\end{array}$ & $\begin{array}{c}\text { Initial Added Sr } \\
\text { Concentration (M) }\end{array}$ \\
\hline 0 & 4 & 0.01 & $\mathrm{H}_{2} \mathrm{O}_{2}$ & - \\
\hline 1 & 4 & 0.01 & $\mathrm{H}_{2} \mathrm{O}_{2}$ & 0.01 \\
\hline 2 & 4 & 0.01 & Sodium Formate & 0.01 \\
\hline 3 & 4 & 0.01 & Sodium Formate & - \\
\hline 4 & 168 & 0.01 & Sodium Formate & - \\
\hline 5 & 168 & 0.01 & $\mathrm{H}_{2} \mathrm{O}_{2}$ & 0.01 \\
\hline 6 & 168 & 0.01 & $\mathrm{H}_{2} \mathrm{O}_{2}$ & - \\
\hline 7 & 168 & 0.01 & Sodium Formate & 0.01 \\
\hline
\end{tabular}

A Lytle detector was used to collect fluorescence X-rays (If) (Figure 3.1), using an aluminum (Al) metal foil to reduce the background fluorescence counts. The monochromator energy was maximized using a piezo stack feedback energy stabilization system, with a settling time of 0.3 seconds per change in monochromatic energy. An X-ray beam size of 2 by $28 \mathrm{~mm}^{2}$ was used. Beamline energy calibration was done using foils of platinum ( $\mathrm{L}_{1}$-edge of 13,880 eV), $\mathrm{Zr}$ (K-edge, 17,998 eV), and molybdenum (K-edge, 20,000 eV).

For the XAFS spectral fits, reference standards consisted of library data for $\mathrm{Mn}^{39}$ and Sr solid phase standards. ${ }^{40,41}$ Simulations of EXAFS data were based on crystallographic data for known $\mathrm{Mn}, \mathrm{Sr}$ and actinide solid phases.

\subsubsection{Studies Conducted at the Advanced Photon Source}

XANES data for oxidation state calibration of Pu were collected at the Advanced Photon Source (APS), at Argonne National Laboratory (ANL, Argonne, IL) in 2000 using Pu standards that were provided by Don T. Reed of ANL. For these studies, the synchrotron hard X-ray fluorescence microprobe on the undulator (Station ID-C) at Sector 13 of the APS was used with a channel-cut Si(220) monochromator. ${ }^{42}$ Micro-focusing optics were used to produce the X-ray beam. ${ }^{43}$ A double elliptical Pt-coated Kirkpatrick-Baez mirror system angled at $2 \mathrm{mrad}$ was used to focus a monochromatic undulator X-ray beam at the $\mathrm{Pu}_{3}$ absorption edge $(18,054 \mathrm{eV})$ to a $4 \mu \mathrm{m}$ vertical by $7 \mu \mathrm{m}$ horizontal beam. ${ }^{44}$ Fluorescent $\mathrm{X}$ rays were detected with a $\mathrm{Si}(\mathrm{Li})$ energy dispersive detector $\left(30 \mathrm{~mm}^{2}\right.$ area, Canberra) mounted Page 20 of 65 
at $90^{\circ}$ to the incident beam and $2 \mathrm{~cm}$ from the standard mounts. Microprobe EXAFS spectra were collected on the L $\alpha$ emission line from $50 \mathrm{eV}$ below the Pu absorption edge to $600 \mathrm{eV}$ above the $\mathrm{Pu}$ edge in varying step increments from 0.4 to $2.5 \mathrm{eV}$. The monochromator position and the undulator gap were scanned simultaneously and the microprobe table was moved to track the position of the X-ray beam during each scan. Energy calibration was made with well-characterized $\mathrm{Pu}$ solid standards: $\mathrm{Pu}(\mathrm{IV}) \mathrm{O}_{2(\mathrm{~s})}, \mathrm{KPu}(\mathrm{V}) \mathrm{O}_{2} \mathrm{CO}_{3}$, and $\mathrm{Ba}_{3} \mathrm{Pu}(\mathrm{VI}) \mathrm{O}_{6}$ measured simultaneously with a $\mathrm{Zr}$ foil (K-edge, 17,998 eV). These studies were conducted at RT.

\subsubsection{XANES and EXAFS Data Analyses}

The background contribution to the EXAFS spectra was removed using an algorithm (AUTOBK) developed by Newville et al. (1993), which minimizes R-space values in low $k$ space. Each chi data set was read into the WINXAS analysis package. ${ }^{45,46}$ Replicate scans were co-added to improve $\mathrm{S} / \mathrm{N}$. After background subtraction and normalization, the $\mathrm{Np}$ XANES spectra were compared with that in the literature and the Pu XANES spectra were compared with our Pu XANES spectra from previous studies conducted at the APS. For the actinide-containing $\mathrm{Mn}$ solids, the $\mathrm{Np}$ - and $\mathrm{Pu}$-XAFS spectra were analyzed from 2 to about $11 \AA^{-1}$. For the actinide-free Mn solids, the Mn- and Sr-XAFS spectra were analyzed from 2 to $14 \AA^{-1}$. The chi data were $k^{3}$-weighted (or $k^{2}$-weighted) and Fourier-transformed (FT) to yield R-space or Radial Distribution Function (RDF) plots. ${ }^{47}$ Simulated EXAFS spectra were also generated based on the documented crystallographic properties for the $\mathrm{Sr}, \mathrm{Mn}, \mathrm{Pu}$ and $\mathrm{Np}$ solids using ab initio based theory, which involved FEFF 7.2 a program created by

researchers at the University of Washington. ${ }^{48,49,50,51,52,53}$

\subsubsection{XRD Data Collection}

The non-radioactive-containing samples were characterized by XRD using a Siemens D500 diffractometer with $\mathrm{CuK} \alpha$ radiation. The diffractometer is equipped with a $1^{\circ}$ degree divergence slit and divergence anti-scatter slit in addition to a $1^{\circ}$ degree divergence beam antiscatter slit and $2^{\circ}$ degree diffracted-beam Soller slit. The diffractometer uses a curved pyrolytic graphite monochromator with a $0.015^{\circ}$ receiving slit and a sodium iodide scintillation detector. The samples were mounted on a glass slide using collidon. The data were collected from 5 to $70^{\circ} 2$-theta, and a one-second dwell time for every $0.02^{\circ}$. For these analyses, the most intense reflection from some compounds can be detected at $0.5 \mathrm{wt} \%$. But for most compounds, a determination limit for a positive identification is $5 \mathrm{wt} \%$ or greater. Quantitative results can be obtained on some types of samples at \pm 15 percent of the amount present.

Page 21 of 65 


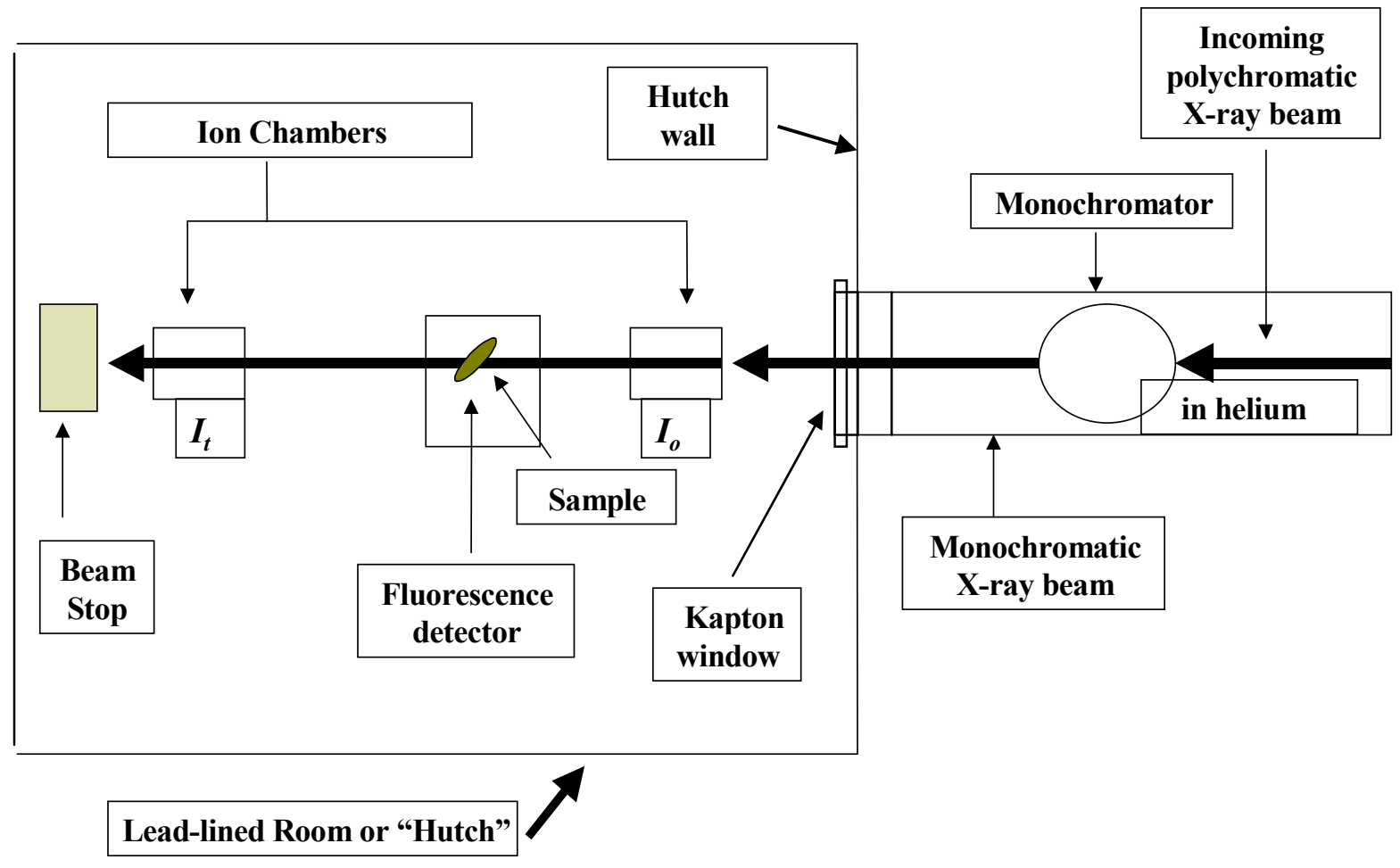

Figure 3.1 Diagram of the downstream portion of the hutch table at NIST beamline X23a2 (not drawn to scale). 
WSRC-TR-2002-00366, REVISION 0

\subsection{RESULTS}

\subsection{Background}

\subsubsection{Characteriza tion of Pu on Surfaces with XAFS}

Few XANES and EXAFS studies have characterized the local structural speciation of sorbed $\mathrm{Pu}$ on natural and synthetic mineral solids. ${ }^{8,54}$ These prior studies used natural geologic samples that contained a variety of minerals (such as zeolites, and trace levels of iron and $\mathrm{Mn}$ oxides and aluminosilicates) with $\mathrm{pH} \mathrm{9,} \mathrm{carbonate-dominated} \mathrm{groundwater} \mathrm{simulant}$ solutions. The testing added $\mathrm{Pu}(\mathrm{V})$ and the minerals found to sorb the $\mathrm{Pu}$ were mineral assemblages of Mn oxides and the alumino-silicate mineral, smectite. The Pu-XANES studies showed that the $\mathrm{Pu}(\mathrm{V})$ oxidized to $\mathrm{Pu}(\mathrm{VI})$ upon sorption to $\mathrm{Mn}$ oxide-smectite (aluminosilicate) bodies whereas the sorbed $\mathrm{Pu}$ on other $\mathrm{Mn}$ oxide-smectite bodies $\mathrm{Pu}$ did not undergo a change in average oxidation state. EXAFS studies conducted at the Pu-rich Mn oxide-smectite mineral assemblages indicate that the first shell $\mathrm{Pu}-\mathrm{O}$ bonding environments of the sorbed $\mathrm{Pu}$ on several mineral bodies varied greatly in $\mathrm{CN}$. Additionally, although the $\mathrm{Pu}$ XANES spectra indicated the average oxidation states of the Pu was $+\mathrm{V}$ and $+\mathrm{VI}$ (the results were spatially variable), there was no axial $\mathrm{O}$ bonding in the EXAFS. ${ }^{55}$ After 2 years of aging in air, XANES and EXAFS studies show the sorbed $\mathrm{Pu}$ on the Mn oxide-smectite mineral bodies had reduced to $\mathrm{Pu}(\mathrm{IV}){ }_{54}$-suggesting that this may be the most stable oxidation state of sorbed $\mathrm{Pu}$ over the long term. ${ }^{54}$ The change in speciation over the long term may be due to the electrochemical disproportionation of $\mathrm{Pu}$. More research would be required to suitably investigate the speciation transformations of sorbed $\mathrm{Pu}$ on solids.

\subsubsection{Characteriza tion of Np on Surfaces with XAFS}

Several Np-XAFS studies have characterized dissolved and solid forms of $\mathrm{Np}{ }^{56,57,58,59,60,61}$ Some of these studies present data on the characterization of a particular solid or dissolved species. Other studies provide simultaneously acquired electrochemical and spectroscopic data on the solutions of $\mathrm{Np}$ (III, IV, V, and VI) and mixtures thereof. ${ }^{57,58}$ These spectroelectrochemical studies observed that solutions of $\mathrm{Np}(\mathrm{IV})$ exhibit a more positive XANES edge energy than that of $\mathrm{Np}(\mathrm{V})$ - based on the inflection point of the first derivative. This finding is somewhat surprising because dissolved and solid phase forms of actinides ( $\mathrm{U}$ and $\mathrm{Pu}$ ) typically have reported XANES edge energies that increase with an increase in the average oxidation state of the material. ${ }^{8,62,63}$

The molecular orbital interactions which influence the XANES behavior of $f$-elements are complex and small differences in coordination environment in combination with the different ionic radii of each Np valence may influence the XANES spectra. This non-linear shift in the Np-XANES edges energies of some actinides does not conform to that typically observed for the other actinides. This behavior has not been observed with Np solids because few if any studies exist on the XANES of valence-state characterized Np(III, IV, V, and VI) solids. These spectroelectrochemical studies also demonstrated that dissolved $\mathrm{Np}(\mathrm{V})$ and

Page 23 of 65 
$\mathrm{Np}(\mathrm{VI})$ species exhibit a shoulder feature on the high energy side of the main absorption

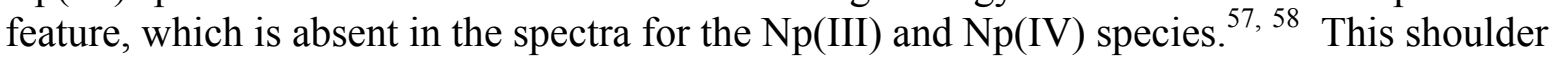
feature is attributed to the presence of axial $\mathrm{O}$ bonding.

A few XAFS studies examined sorbed Np on solids. One study performed with $\mathrm{Np}(\mathrm{V}) \mathrm{O}_{2}{ }^{+}$on the iron $(\mathrm{Fe})$ oxide goethite $(\mathrm{FeOOH})$ characterized the first shell environment of the sorbed $\mathrm{Np}^{64}$ The authors determined that the first shell contained two subshells, with 2 $\mathrm{O}$ atoms at $1.85 \AA$ and $5.5 \mathrm{O}$ atoms at $2.51 \AA$. This environment is fairly consistent with that of a $\mathrm{Np}(\mathrm{V})$ species. No data were reported for the second coordination shell environment so the nature of the sorption could either not be determined from the XAFS (these early 1992 studies were some of the first published for $\mathrm{Np}$ in solution and on surfaces) or the results indicate that the association of the $\mathrm{Np}$ is an outer sphere/electrostatic mechanism.

A second more recent study that investigated the local environment of $\mathrm{Np}$ in the presence of hydrothermally altered cements determined that the first shell environment of the $\mathrm{Np}$ [added as $\mathrm{Np}(\mathrm{V})$ ] involved a combination of $\mathrm{Np}(\mathrm{IV})$ and $\mathrm{Np}(\mathrm{V})$ species. ${ }^{65}$ These researchers used XANES absorption edge determinations and the degree of "axial" $\mathrm{O}$ bonding from the EXAFS to estimate the amount of $\mathrm{Np}(\mathrm{V})$. They reported that most of the $\mathrm{Np}(\mathrm{V})$ reduced over time in the solution or concrete slurries that had $\mathrm{pH}$ values of 9.3 through 12.3.

An XAFS study by Moyes et al. (2002) with Np(V) sorption to the ferrous sulfide mineral called mackinawite determined that the added $\mathrm{Np}(\mathrm{V})$ reduced to $\mathrm{Np}(\mathrm{IV})$ upon sorption to the Fe(II)- and sulfide-rich surface in aqueous solutions ( $\mathrm{pH} 7$ to 8). ${ }^{61}$ They observed the reduction of $\mathrm{Np}(\mathrm{V})$ by the ferrous sulfide mineral from their data, which indicated a loss of axial $\mathrm{O}$ bonding and the emergence of longer $(2.25 \AA)$ near neighbor $\mathrm{O}$ bonding and some near neighbor sulfur $(\mathrm{S})$ bonding. The sorption process converts the Np to a less mobile and less soluble species. However, the affinity of $\mathrm{Np}(\mathrm{V})$ for the mackinawite was very low as evidenced by the large proportion of $\mathrm{Np}$ that remained in the contact solutions after the equilibration.

\subsection{XANES Studies}

For most metals, the position of the absorption edge in the XANES spectra depends on the oxidation state. ${ }^{66}$ The higher energy for the absorption edge, the higher the oxidation state is for the atom of interest. XANES spectra are typically used to provide information on the average oxidation state of the element of interest. Small shifts (a few eV) in XANES absorption edge energies can occur when a metal undergoes a change in average oxidation state. Qualitative features in the XANES can also provide information on the bonding environment of the element of interest. Bonding environment information can be oxidationstate specific.

\subsubsection{Manganese XANES Studies with the Non-radioactive Mn Solids}

The Mn XANES spectra for the solids isolated from Sample 0 (listed in Table 3-3) and several Mn oxide references are shown in Figure 4.1. Spectra for the remaining Page 24 of 65 
permanganate-treated Samples 1 through 7 resembled that of Sample 0 (data not shown). The Mn XANES spectra for the eight Mn solids appear similar - regardless of whether the test used formate or $\mathrm{H}_{2} \mathrm{O}_{2}$ as the reductant or whether the test added seed Sr. The Mn XANES spectra for the Sample 0 do not resemble that of $\mathrm{Mn}$ (II) solids (biogenic $\mathrm{MnCO}_{3(\mathrm{~s})}$, also known as rhodochrosite) as shown in Figure 4.1. Similarities exist between the pre-edge spectra for the Sample 0 and that for other predominantly $\mathrm{Mn}(\mathrm{IV})$ oxides such as pyrolusite $\left[\mathrm{MnO}_{2(\mathrm{~s})}\right]$, cryptomelane $\left[\mathrm{K}_{\mathrm{x}}[\mathrm{Mn}(\mathrm{III}, \mathrm{IV})]_{9} \mathrm{O}_{16(\mathrm{~s})}\right]$, birnessite $\left[\mathrm{Na}_{4} \mathrm{Mn}_{14} \mathrm{O}_{27} \cdot 9 \mathrm{H}_{2} \mathrm{O}_{(\mathrm{s})}\right]$ and todorokite $\left.[\mathrm{Ca}, \mathrm{Na}, \mathrm{K})_{\mathrm{x}}[\mathrm{Mn}(\mathrm{III}, \mathrm{IV})]_{6} \mathrm{O}_{12} \cdot 3.5 \mathrm{H}_{2} \mathrm{O}_{(\mathrm{s})}\right]$. These similarities are most evident in the shape of the absorption edges, the energy values at the maxima of the main absorption features (i.e., the white lines) and the energy at which a pre-edge feature occurs for these predominantly Mn(IV)-containing solids (Figure 4.1). The Mn XANES spectra for bixbyite [a Mn(III) solid] show some similarities to these Mn(IV)-containing minerals but the slope of the absorption edge in the XANES for this solid is fairly different in addition to the maxima of the white line for this species. The difference in slope is indicative of a Mn oxide solid with a large amount of $\mathrm{Mn}(\mathrm{III}){ }^{67}$

\subsubsection{Actinide XA NES Studies with the Actinide-loaded Mn Solids}

For $\mathrm{Np}$ and $\mathrm{Pu}$, changes in oxidation state in our samples were anticipated during permanganate treatment, due to the likelihood that a reaction with permanganate (a strong oxidant) or with peroxide (also a strong oxidant) could promote redox reactions with these actinides. Additionally, it is possible that more than one oxidation state of these actinides could be soluble and stable in the HLW salt simulants. ${ }^{68,69}$ It is thought that $\mathrm{Pu}(\mathrm{IV})$ is the most probable oxidation state of $\mathrm{Pu}$ in HLW solutions and that $\mathrm{Np}(\mathrm{V})$ is the most stable oxidation state of $\mathrm{Np}$ in alkaline solutions (based on the work of I.G. Tananaev). ${ }^{70}$ However, these determinations of oxidation state speciation were done using solvent extraction techniques which may induce changes in actinide oxidation state speciation during extraction. $^{71}$ Some assessments of actinide oxidation state have been based on predictive thermodynamic calculations. ${ }^{71}$ Therefore, we conducted $\mathrm{Np}$ - and Pu-XANES analyses to obtain information on the oxidation states and structural environments of the actinides in our samples.

The results of the ICP-MS data for the samples from the actinide-containing test (listed in Table 3-2) indicated that in general, the two-hour equilibrations were the best suite of samples to select for XAFS analyses. Data collection with the remaining samples (from the 2-hour equilibrations) was attempted but the actinide loadings were far below the calculated levels listed in Table 3-2. This finding suggests that a significant amount of salts other than the $\mathrm{MnO}_{2(\mathrm{~s})}$ precipitated during our tests, a process that could effectively lower the average actinide level in the solid phases to levels that are difficult to detect using X-ray absorption techniques.

Page 25 of 65 


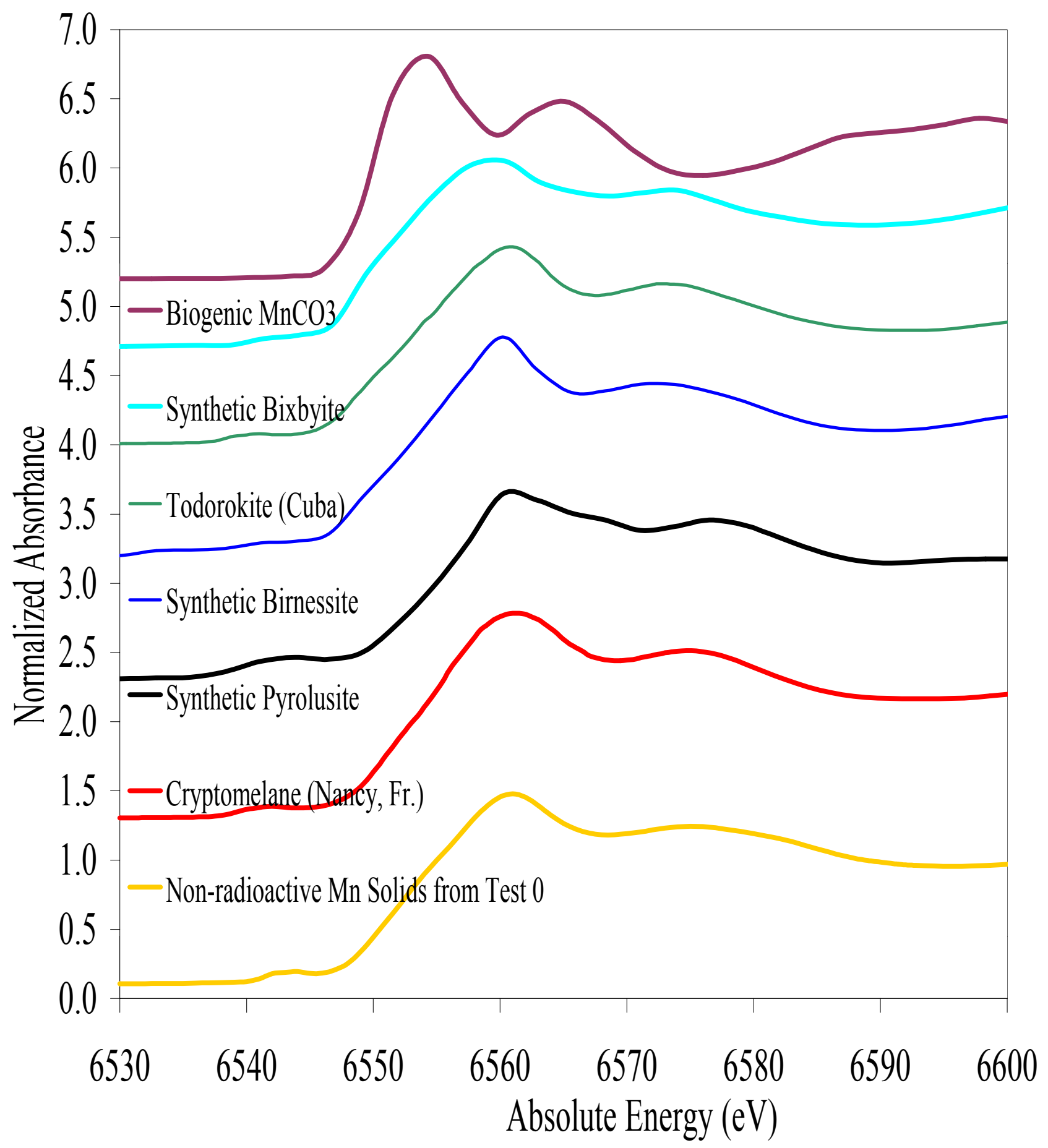

Figure 4.1 Normalized Mn XANES spectra for the non-radioactive permanganate sample 0 and several $\mathrm{Mn}$ oxide reference materials. Spectra for $\mathrm{MnCO}_{3}$, bixbyite, birnessite and pyrolusite from Fredrickson et al. (2002) and spectra for cryptomelane and todorokite from Duff et al. (2002). ${ }^{39,41}$ 


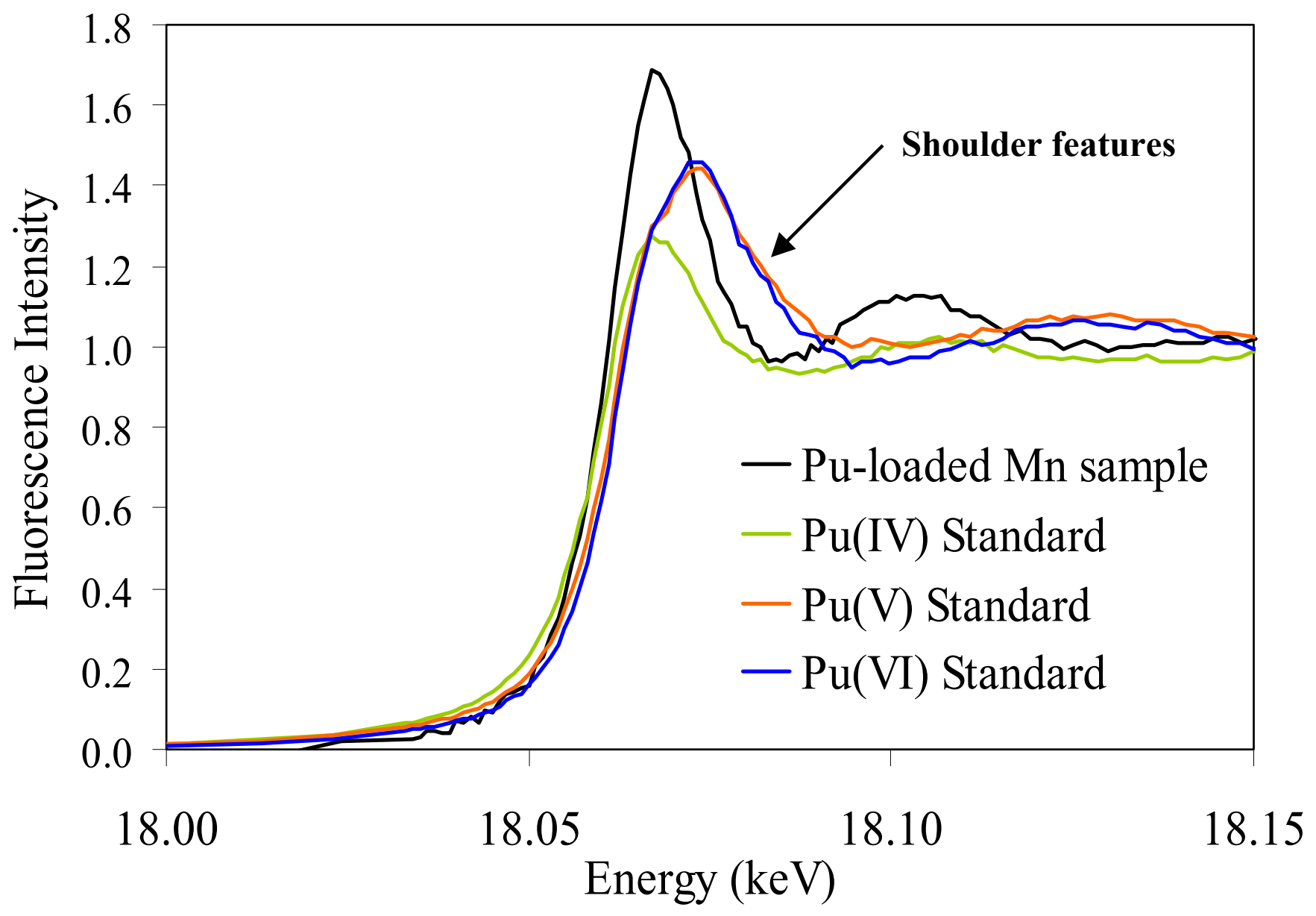

Figure 4.2 Plot of the plutonium-XANES spectra for the Pu-loaded $\mathrm{Mn}$ sample and the $\mathrm{Pu}$ standards: $\mathrm{Pu}(\mathrm{IV}) \mathrm{O}_{2}, \mathrm{KPu}(\mathrm{V}) \mathrm{O}_{2} \mathrm{CO}_{3}$ and $\mathrm{Ba}_{3} \mathrm{Pu}(\mathrm{VI}) \mathrm{O}_{6}$. The Pu-loaded Mn oxide solid had a calculated loading of $2310 \mathrm{mg} \mathrm{Pu} \mathrm{kg}^{-1}$ of $\mathrm{MnO}_{2}$ [added as $\mathrm{Pu}(\mathrm{IV})$ ] . 


\subsubsection{Plutonium XANES Studies}

The Pu-XANES spectra for the Pu-loaded Mn sample and the Pu standards are shown in Figure 4.2. The Pu-loaded Mn sample (Test 12) had a XANES edge energy consistent with that of $\mathrm{Pu}(\mathrm{IV})$. Because of the possibility of multiple oxidation states (up to four) for $\mathrm{Pu}$ species in solution and possibly on surfaces, the interpretation of the XANES must consider the likelihood of multiple oxidation states. Because the average $\mathrm{Pu}$ oxidation state in these samples is $+\mathrm{IV}$, there is some possibility of multiple oxidation states. The spectra for the $\mathrm{Pu}$ in the Test $12 \mathrm{Mn}$ oxide sample does not have the shoulder feature indicative of a $+\mathrm{V}$ or $+\mathrm{VI}$ $\mathrm{Pu}$ species. The absence of this feature generally indicates the spectra contain more $\mathrm{Pu}(\mathrm{IV})$ and $\mathrm{Pu}(\mathrm{III})$ than $\mathrm{Pu}(\mathrm{V})$ and $\mathrm{Pu}(\mathrm{VI})$ species. ${ }^{72}$

The results from the Pu EXAFS analyses for this sample will provide additional but indirect information on the oxidation state behavior of the actinides. This is because most metals such as the actinides have oxidation-state specific structures. By inference, we can determine the oxidation state of the actinide of interest from the EXAFS results and better support these conclusions from the XANES analyses.

\subsubsection{Neptunium XANES Studies}

The Np-XANES ( $\mathrm{L}_{3}$-edge) spectra for the Np-loaded Mn oxide sample are shown in Figure 4.3. The sample XANES spectra have an edge energy that is consistent with that of published values for $\mathrm{Np}(\mathrm{IV})$ or $\mathrm{Np}(\mathrm{V})$. There is very limited information on the XANES spectra of Np solutions of known oxidation states but the case is more extreme for XANES studies with $\mathrm{Np}$ solids of known oxidation states. However, published $\mathrm{Np} \mathrm{L}_{3}$-edge XANES spectra for extremely well characterized acidic Np solutions indicate that the XANES spectra for $\mathrm{Np}(\mathrm{IV})$ and $\mathrm{Np}(\mathrm{V})$ species have similar edge energies. ${ }^{57,58}$ Mathematical methods that have been used to determine the XANES edge energies typically produce slightly different results. ${ }^{73}$ However, the visual similarities in these $\mathrm{Np}(\mathrm{IV})$ and $\mathrm{Np}(\mathrm{V})$ XANES spectra indicate that the dissolved $\mathrm{Np}(\mathrm{IV})$ and $\mathrm{Np}(\mathrm{V})$ species tend to have nearly over-lapping XANES spectra. In addition to the Np edge energy which suggests $\mathrm{Np}$ is present as $\mathrm{Np}(\mathrm{IV})$ or $(\mathrm{V})$, the distinct feature in the XANES spectra for our sample indicates that the Np is more likely to be present as $\mathrm{Np}(\mathrm{V})$. A strong shoulder feature on the high energy side of the main absorption feature is present. This feature is thought to be a multiple scattering resonance (MSR) associated with the two axial $\mathrm{O}$ atoms associated with most pentavalent and hexavalent forms of the actinides (specifically, for $\mathrm{Pu}, \mathrm{Np}$, and $\mathrm{U}$ ) — as discussed in Duff et al. (1999). ${ }^{8,55}$

Page 28 of 65 


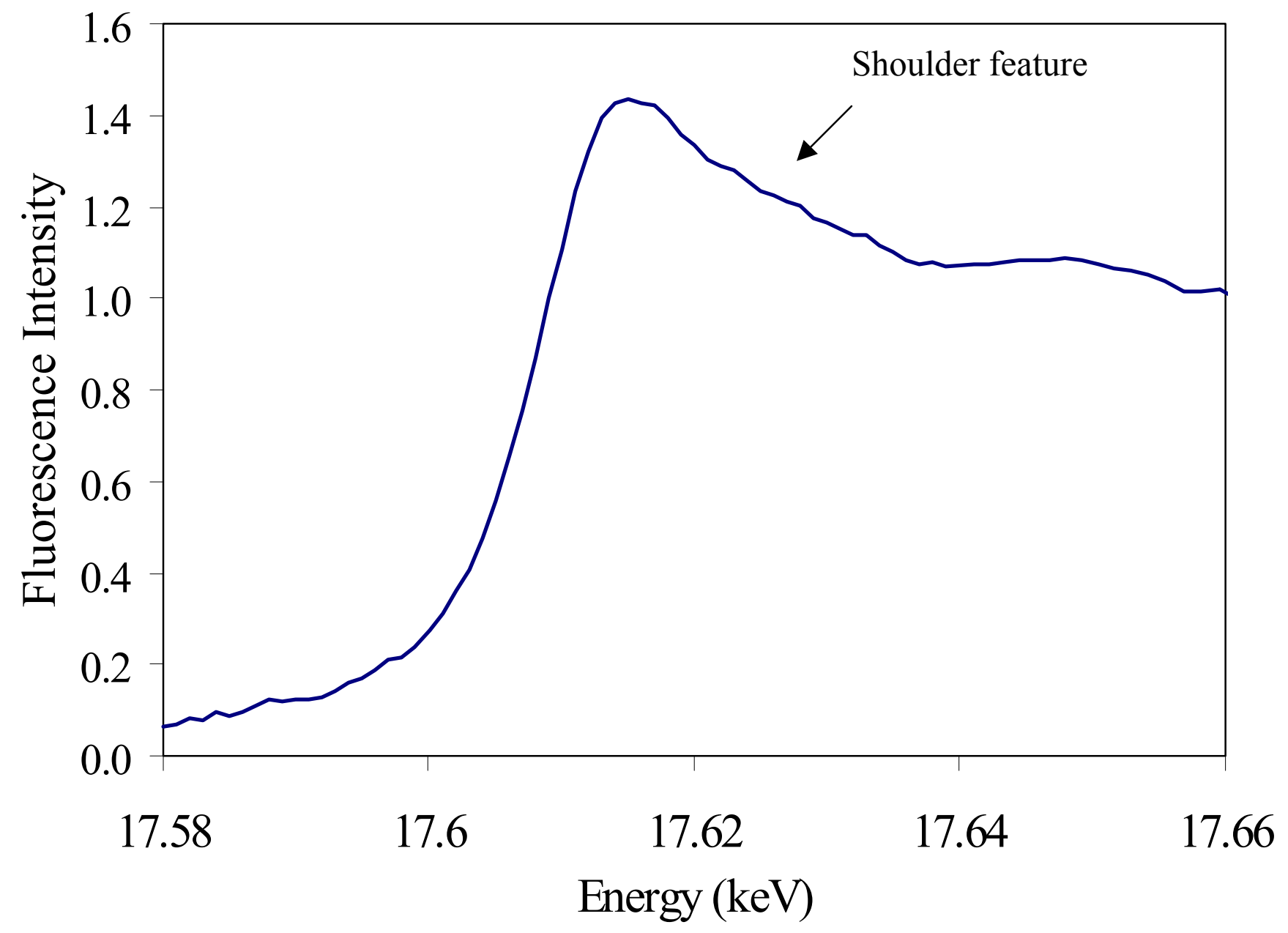

Figure 4.3 Plot of the neptunium-XANES spectra for the Np-loaded Mn sample. Energy calibration performed with a $\mathrm{Zr}$ metal foil at the $\mathrm{Zr}$ K-edge. The Np loading for the $\mathrm{Mn}$ sample was $1550 \mathrm{mg} \mathrm{Np} \mathrm{kg}^{-1}$ of $\mathrm{MnO}_{2}$. 


\subsection{EXAFS Analyses}

In simple terms, chi data (the plot of the wavevector in reciprocal space) show the oscillation patterns (both constructive and destructive interference patterns) of the atoms in the neighbor environment of the element of interest. The chi data represent part of the photoelectron wave that can be defined by the EXAFS equation. ${ }^{30,31,74}$ The EXAFS equation is shown in a highly simplified form below (see list of definitions for explanation of equation terms).

$$
\operatorname{Chi}(\mathrm{k})=\frac{\mathrm{F}(\mathrm{k}) * \mathrm{~N} * \mathrm{~S}}{\mathrm{k}^{*} \mathrm{R}^{2}} \mathrm{So}^{2} e^{\left(-2 * \mathrm{k}^{3} \sigma^{2}\right)} \sin [2 * \mathrm{k} * \mathrm{R}+\delta(\mathrm{K})]
$$

\subsubsection{Manganese Chi Data for the Actinide-free Manganese Oxide Samples}

The $k^{2}$-weighted chi spectra for the $\mathrm{Mn}$ in the eight permanganate treatment samples are shown in Figure 4.4. In general, the spectra are very similar and of high quality. ${ }^{75} \mathrm{~A}$ model simulation of the $\mathrm{Mn}\left(\mathrm{IV}\right.$,III) oxide mineral called birnessite $\left[\mathrm{Na}_{4} \mathrm{Mn}_{14} \mathrm{O}_{27} \bullet 9 \mathrm{H}_{2} \mathrm{O}\right.$ ] is also shown in Figure 4.4. These Mn-EXAFS spectra were qualitatively compared with library spectra and spectral FEFF simulations for a variety of other Mn phases such as Ca-rich birnessites, $\mathrm{MnO}_{2}$ (pyrolusite), $\mathrm{Mn}_{2} \mathrm{O}_{3}$ (bixbyite), $\mathrm{K}_{\mathrm{x}}[\mathrm{Mn}(\mathrm{III}, \mathrm{IV})]_{9} \mathrm{O}_{16}$ (cryptomelane), (Ca,Mn)O $4 \mathrm{MnO}_{2} \cdot 3 \mathrm{H}_{2} \mathrm{O}$ (rancieite), $\mathrm{Mn}_{3} \mathrm{O}_{4}$ (hausmanite), $\mathrm{LiAl}_{2}\left[\mathrm{Mn}_{2}(\mathrm{IV}), \mathrm{Mn}(\mathrm{III})\right] \mathrm{O}_{6}(\mathrm{OH})_{6}$ (lithiophorite), $\mathrm{MnCO}_{3}$ (rhodochrosite) and (Ca,Na, $\left.\mathrm{K}\right)_{\mathrm{x}}[\mathrm{Mn}(\mathrm{III}, \mathrm{IV})]_{6} \mathrm{O}_{12} \cdot 3.5 \mathrm{H}_{2} \mathrm{O}$ (todorokite) (data not shown). Birnessite, in the sodium form $\left[\mathrm{Na}_{4} \mathrm{Mn}_{14} \mathrm{O}_{27} \cdot 9 \mathrm{H}_{2} \mathrm{O}_{(\mathrm{s})}\right]$ was the closest match for these spectra. The FEFF simulation for this material overlapped well with the sample spectra in amplitude and phase. These similarities suggest the particles are crystalline. Unlike cryptomelane, todorokite and pyrolusite, which have corner-linked octahedra, the sodium-rich birnessites tend to have a two-dimensional structure because nearly all of the Mn octahedra are edge-linked. This type of bonding is reflected more so in the Mn EXAFS than in the Mn XANES because Mn EXAFS spectra provide the more robust structural information.

\subsubsection{Strontium Chi Data for the Actinide-free Mn Oxide Samples}

The $k^{2}$-weighted chi spectra for the $\mathrm{Sr}$ in the four permanganate treatment samples that contained added seed $\mathrm{Sr}$ are shown in Figure 4.5. As with the Mn EXAFS spectra for these samples, the Sr EXAFS spectra are very similar and of high quality. A model simulation of the crystalline $\mathrm{SrCO}_{3(\mathrm{~s})}$ mineral called strontianite, which has an orthorhombic space group and nine first shell Sr-O distances is also shown in Figure 4.5. According to our database for the EXAFS data for Sr solid phase structures (data not shown), strontianite was the best match for these spectra. Although the FEFF simulation of the chi data for strontianite does not compare well with our sample data, the literature data for strontianite do compare quite well. ${ }^{76}$ 


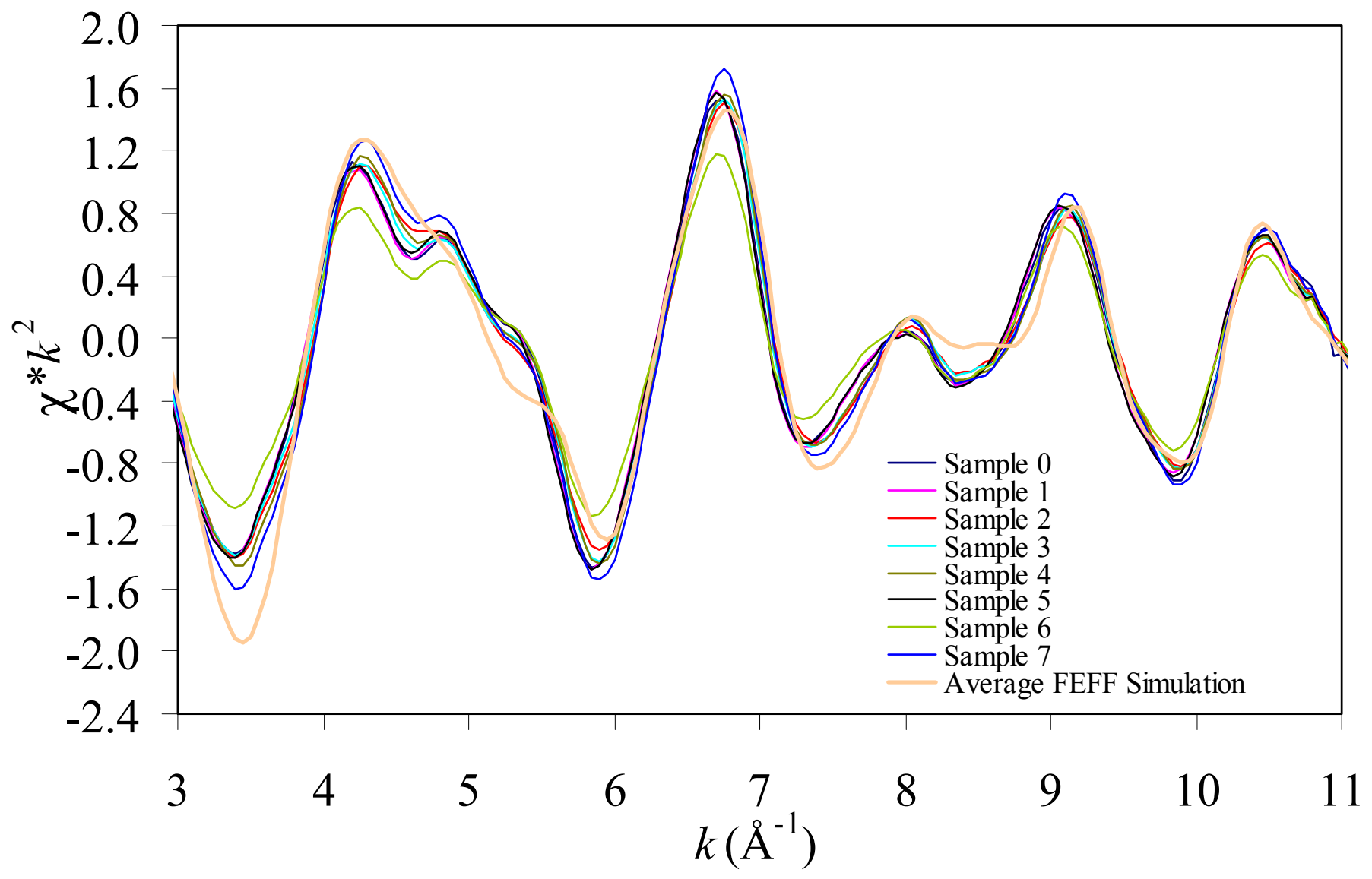

Figure 4.4 The $k^{2}$-weighted chi data for $\mathrm{Mn}$ in the solids formed in the actinide-free permanganate tests (listed in Table 3-2) and a FEFF simulation of the Mn oxide called birnessite. Samples $0,1,5$ and 6 had $0.045 \mathrm{M} \mathrm{H}_{2} \mathrm{O}_{2}$ as the reductant. Samples 2, 3, 4 and 7 had $0.045 \mathrm{M}$ sodium formate added as the reductant. 


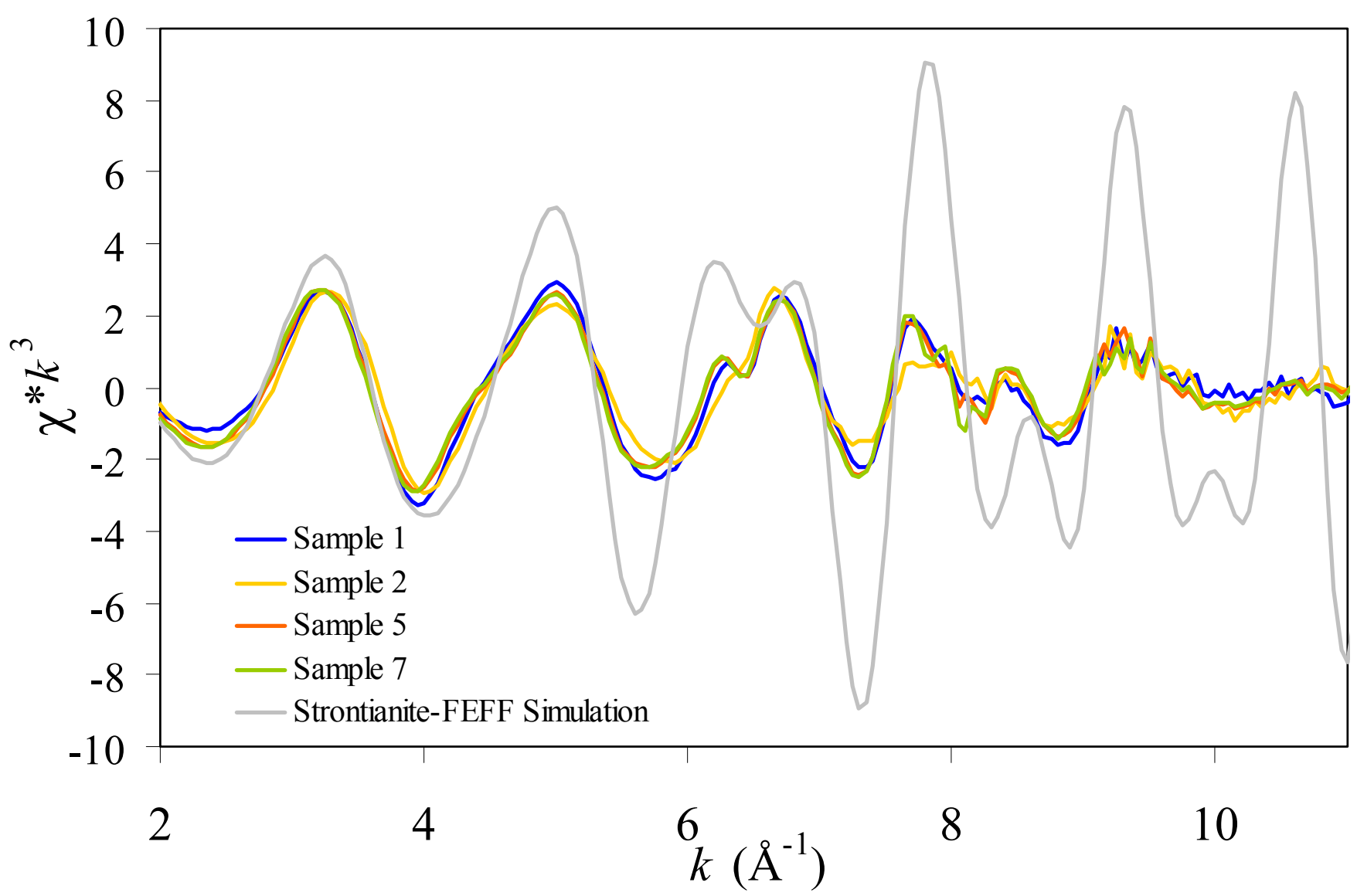

Figure 4.5 The $k^{3}$-weighted chi data (the plot of the wavevector in reciprocal space) for $\mathrm{Sr}$ in the four Sr-treated Mn samples and a FEFF simulation of the chi data for the mineral strontianite $\left[\mathrm{SrCO}_{3(\mathrm{~s})}\right]$. Samples 1 and 5 had $0.045 \mathrm{M} \mathrm{H}_{2} \mathrm{O}_{2}$ added as the reductant. Samples 2 and 7 had formate added as the reductant. 
The differences between the amplitude of the simulation and of the spectra may be due to a highly amorphous (i.e., poorly ordered) structure. Although less likely, it may also be due to the presence of extremely small (nanocrystalline) $\mathrm{SrCO}_{3(\mathrm{~s})}$ particle sizes. If the structure of the $\mathrm{SrCO}_{3(\mathrm{~s})}$ were highly amorphous (i.e., the structure does not possess atoms at highly consistent positions), there would be numerous environments of the atoms in the outer $\mathrm{Sr}$ coordination shells. This type of behavior would result in a dampening of the EXAFS signal at high $k$-space where the heavy atom back-scattering contribution to the chi data is most readily seen (Figure 4.5). A dampening of the chi data is also apparent at a lesser degree at low $\mathrm{k}$-space. It is likely that these $\mathrm{Sr}$ particles are amorphous and not nanoparticles because large, white solids were visually observed in the treatments that had received seed Sr, suggesting the particles are fairly large. This observation would need additional confirmation using an appropriate particle size determination or microscopic imaging technique. ${ }^{77}$

\subsubsection{Plutonium C hi Data for the Mn Sample}

The $\mathrm{Pu}$-containing $\mathrm{Mn}$ oxide sample from the $0.0025 \mathrm{M}$ permanganate treatment (Test 12) had a calculated $\mathrm{Pu}$ loading of $2,310 \mathrm{mg} \mathrm{Pu} \mathrm{kg}$-1 of $\mathrm{MnO}_{2(\mathrm{~s})}$. Data quality, which was in part related to $\mathrm{Pu}$ concentration in the sample, was marginal. EXAFS analyses of first and second coordination shell atoms were performed with care to not over-interpret the data. Another problem we had that was not associated with the samples was the beamline. The recent replacement of the monochromator screw with a newly machined one resulted in a background of oscillations. These oscillations were most apparent when the level of the $\mathrm{Pu}$ was very low. The artifact, which was not visible during data collection and our preliminary data analyses during data collection is shown in Figure 4.6 after $7 \AA^{-1}$ (shown with brackets). Hence, the $k$-weighting of the chi data was set to 1 (instead of the typical value of 2 or 3 ) to avoid amplification of this artifact signal at high $k$-space. The portion of the chi data selected for analyses (i.e., the spectral range in which the signal from the sample Pu exceeded that of the background oscillation due to the malfunctioning screw) is shown in Figure 4.7. These data were corrected to remove the contribution of the background oscillation of the malfunctioning screw.

The remaining Pu-loaded Mn oxide samples from the 2-hour equilibration had lower levels of $\mathrm{Pu}$ that that of the sample in Test 12. No XAFS data were acquired for those treatments. Despite the high level of noise in the data, it is evident that the amplitude of the chi data at low $k$-space is indicative of a light atom interaction with $\mathrm{Pu}$. This is evident because the amplitude of the oscillations dampens after $7 \AA^{-1}$, which is typical for O.

\subsubsection{Neptunium Chi Data for the Mn Sample}

The $k^{2}$-weighted chi spectra for the $\mathrm{Np}$ in one of the Np-loaded Mn oxide samples is shown in Figure 4.8. The remaining samples from the 2-hour equilibration had very low levels of $\mathrm{Np}$. Hence, no $\mathrm{Np}$ XAFS data were acquired for those treatments. The contribution of the monochromator screw (as discussed in Section 4.3.3) did not effect the data quality because of the high level of $\mathrm{Np}$ signal in the samples. The $\mathrm{Np}$ chi data that were collected out to about $10 \AA^{-1}$ were used in the model fit analyses.

Page 33 of 65 
WSRC-TR-2002-00366, REVISION 0

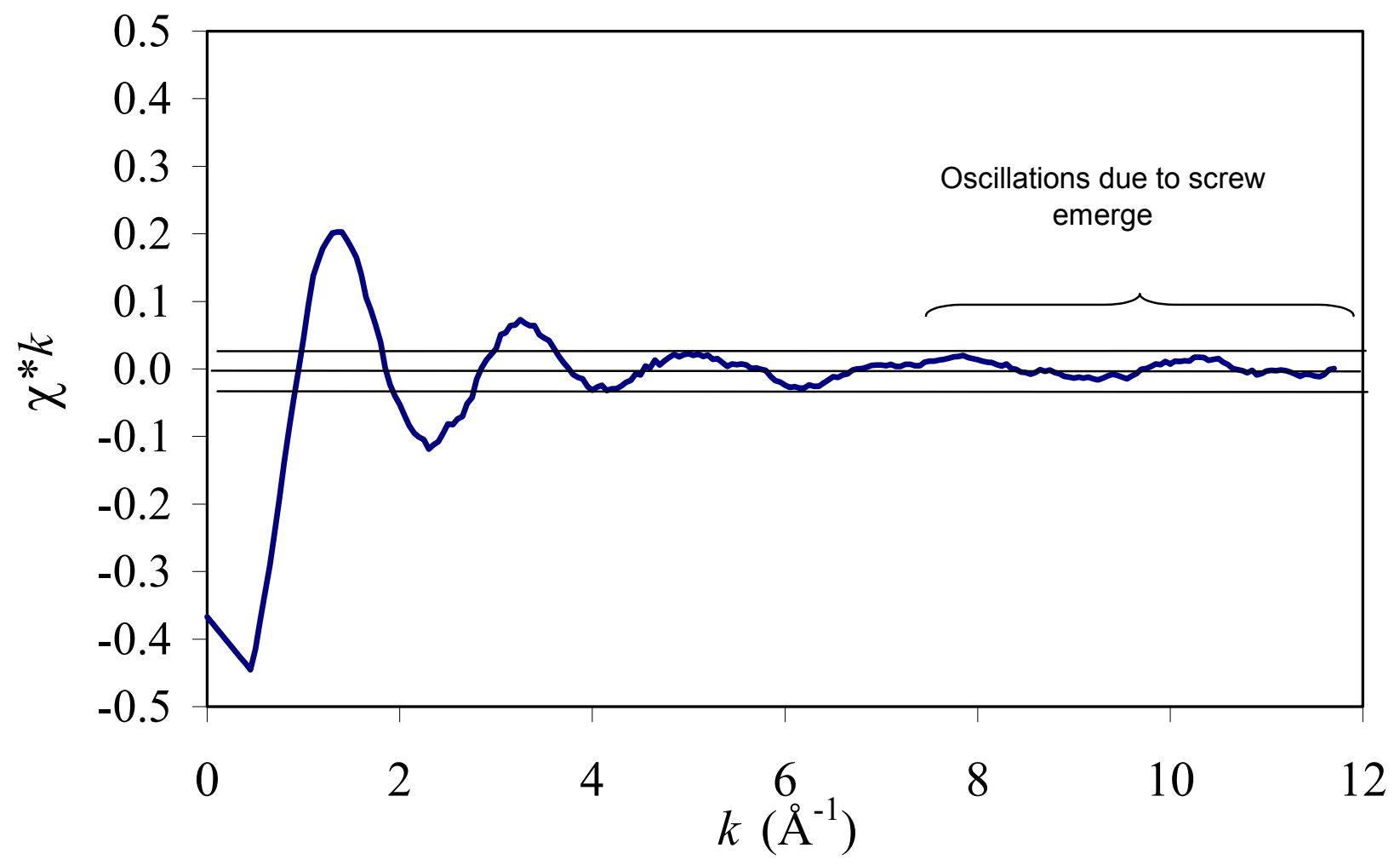

Figure 4.6 The $k^{1}$-weighted chi data (the plot of the wavevector in reciprocal space) for $\mathrm{Pu}$ in the Pu-loaded Mn oxide sample. 
WSRC-TR-2002-00366, REVISION 0

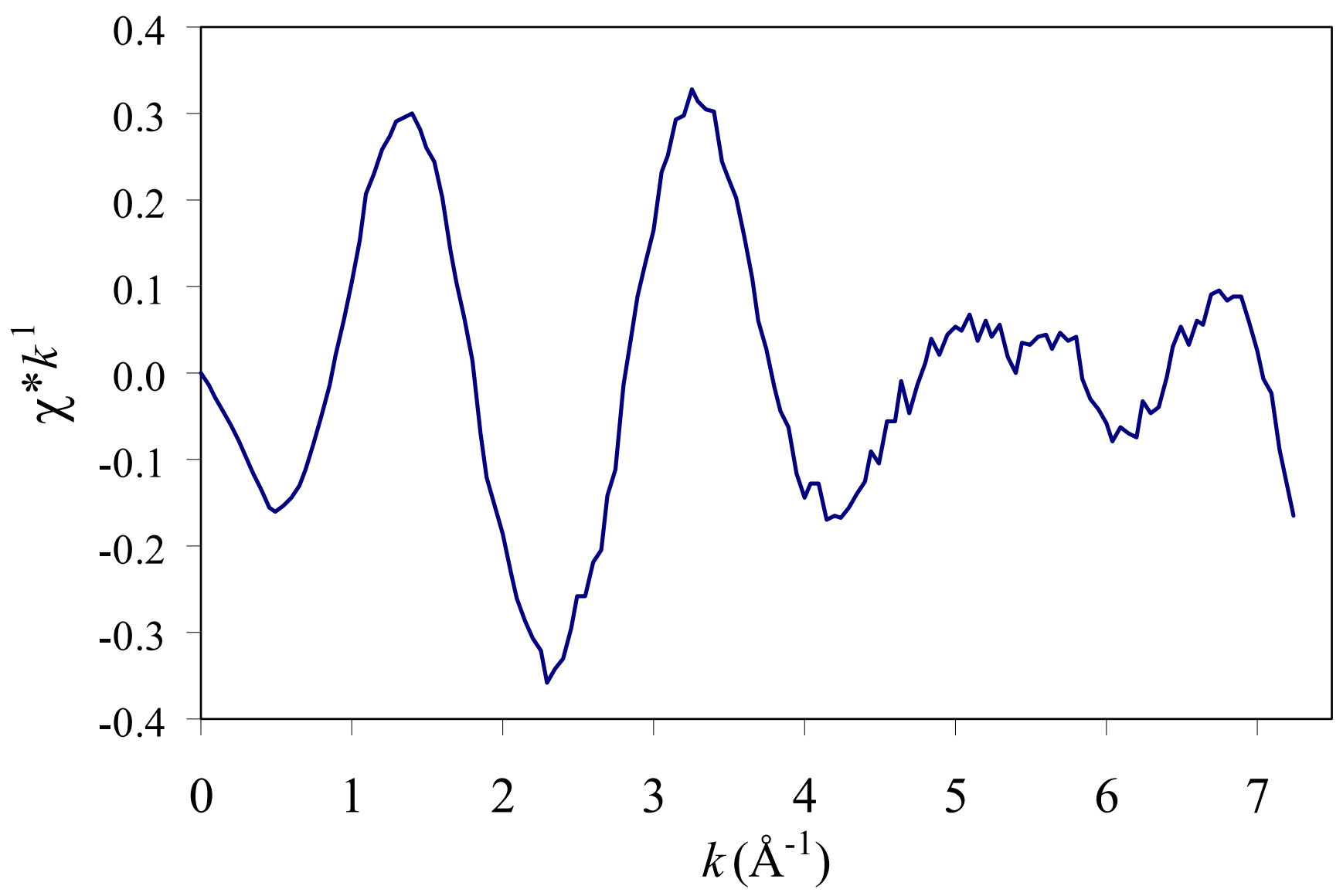

Figure 4.7 The portion of $k^{1}$-weighted chi data (the plot of the wavevector in reciprocal space) for Pu in the Pu-loaded Mn oxide sample that was selected for model fits. 
WSRC-TR-2002-00366, REVISION 0

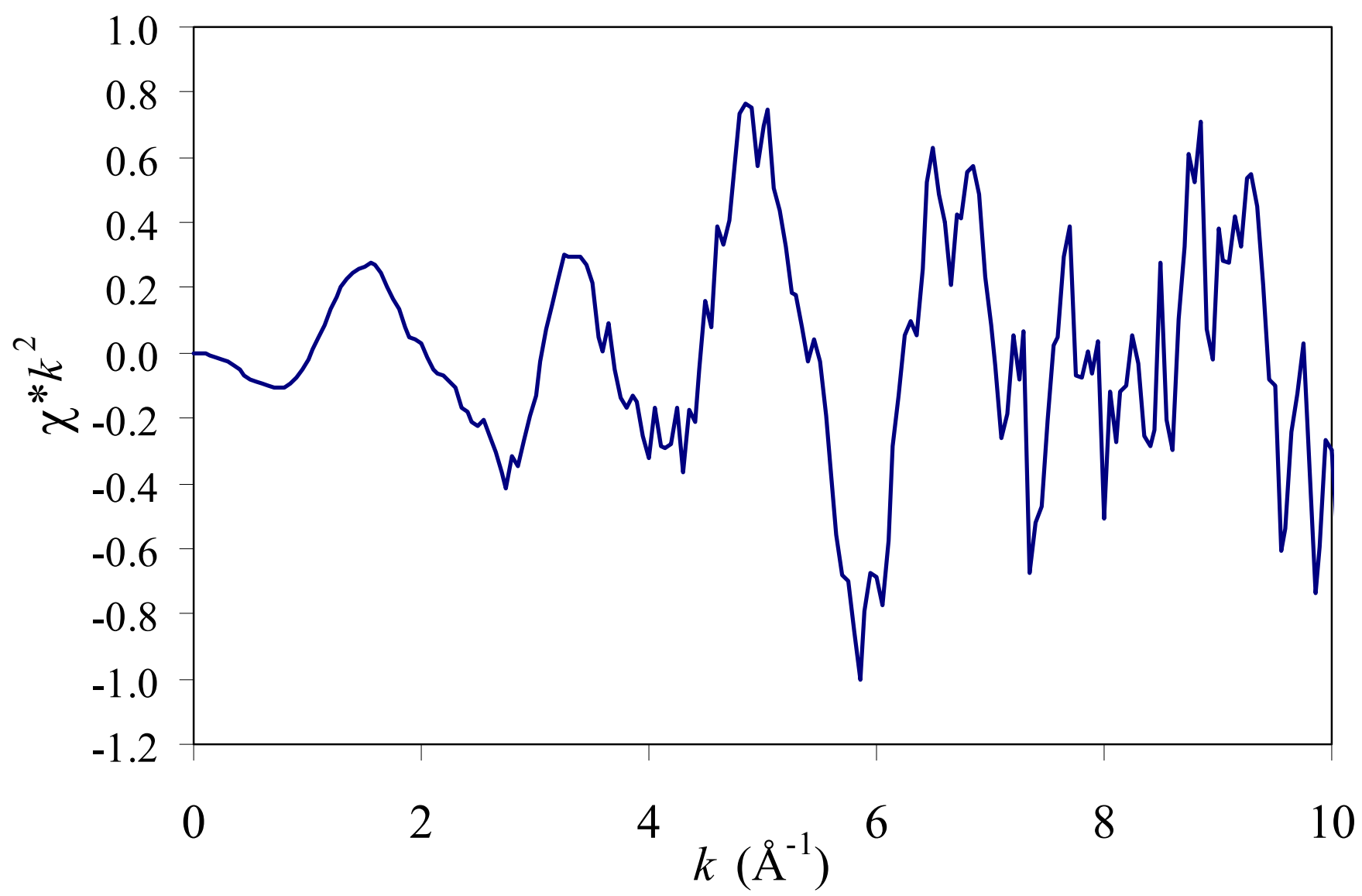

Figure 4.8 The $k^{2}$-weighted chi data (the plot of the wavevector in reciprocal space) for $\mathrm{Np}$ in the Np-loaded sample. 
WSRC-TR-2002-00366, REVISION 0

\subsubsection{Manganese F ourier Transform Data for the Actinide-free Mn Samples}

The Fourier Transformed (FT) chi data for Mn in Samples 0 through 7 are shown in Figures 4.9 through 4.16. The data typically show that the Mn first shell environment $\mathrm{O}$ atoms at $1.9 \AA$ (the number of first shell $\mathrm{O}$ atoms was fixed to 6) and in the $\mathrm{Mn}$ second coordination shell contains 3 to $5 \mathrm{Mn}$ atoms at $2.88 \AA$. The $\mathrm{H}_{2} \mathrm{O}_{2}$ treatments had slightly larger second coordination shell $\mathrm{Mn}-\mathrm{Mn} \mathrm{CN}$ values than those treatments that had formate added as the reductant. This implies that the Mn oxides produced from the reduction of permanganate by peroxide ion may be more ordered than those produced by the reduction via formate ion. Collectively, the Mn EXAFS data for all of these samples were similar. The data indicate that $\mathrm{Mn}$ octahedra in the Mn solids contain edge-sharing behavior, as evidenced by the short $2.88 \AA$ distance between the first and second coordination shell $\mathrm{Mn}$ atoms, which approximates that illustrated for the Mn-Mn radial distance shown in Figure 2-1C. If facesharing Mn octahedra were present in the sample, a peak near $2.5 \AA$ (Figure 2-1B) in the FT data for Mn would be present. If corner-sharing Mn octahedra existed in the sample there would be a peak near $3.8 \AA$ (Figure 2-1D) in the Mn FT data. The XAFS data show little effect of equilibration time on permanganate treatment, (samples were pulled from the 4- and 168-hour time periods) suggesting that the solids form within a 4-hour period and are structurally stable for several days in the salt solutions.

These data are consistent with that of a hexagonal sodium birnessite-type solid, which has only edge-sharing behavior. However, the number of $\mathrm{Mn}$ atoms in the second coordination shell are less than 6, suggesting that there are a high number of Mn octahedral groups on the outside of the particles. This is illustrated in Figure 4.17, which shows a simulation of atoms ( $\mathrm{MnO}_{6}$ groups) that have an average $\mathrm{Mn}-\mathrm{Mn} \mathrm{CN}$ of 3.43. Results from TEM studies (conducted at ANL) with the Mn-rich particles in solids isolated from the permanganate treatment process indicate that there are two types of Mn oxide particle morphologies. ${ }^{18}$ These morphologies consist of hexagonal platelets and fibrous material. The TEM studies provide spatially-resolved imaging on a near atomic scale. Our Mn EXAFS studies, which provide average structural information on an atomic scale, cannot discern between two or more morphological populations. Collectively, these TEM and EXAFS studies indicate the illustration in Figure 4.17 is not completely representative of all of the Mn oxide particles in our samples because the particles have different morphologies. The small $\mathrm{CN}$ values in the data may also indicate that the particles are amorphous. The TEM studies indicate that there was some difficulty in obtaining a lattice fringe pattern from the spectra. It is possible that some of the particles are amorphous and some are crystalline.

Page 37 of 65 
WSRC-TR-2002-00366, REVISION 0

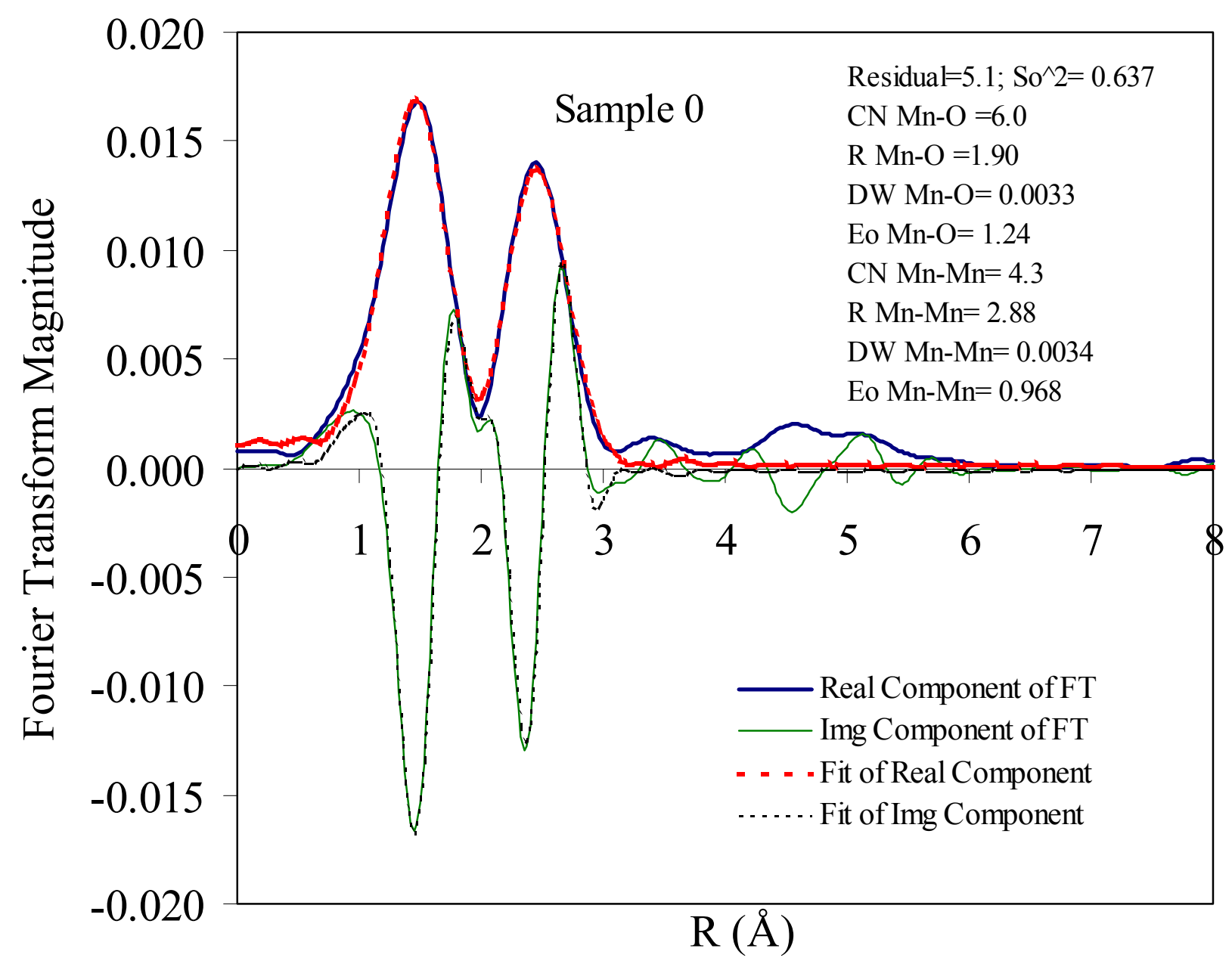

Figure 4.9 FT and model fit data for Mn in Sample 0 (4-hour equilibration without seed $\mathrm{Sr}$ ) uncorrected for phase shift. 


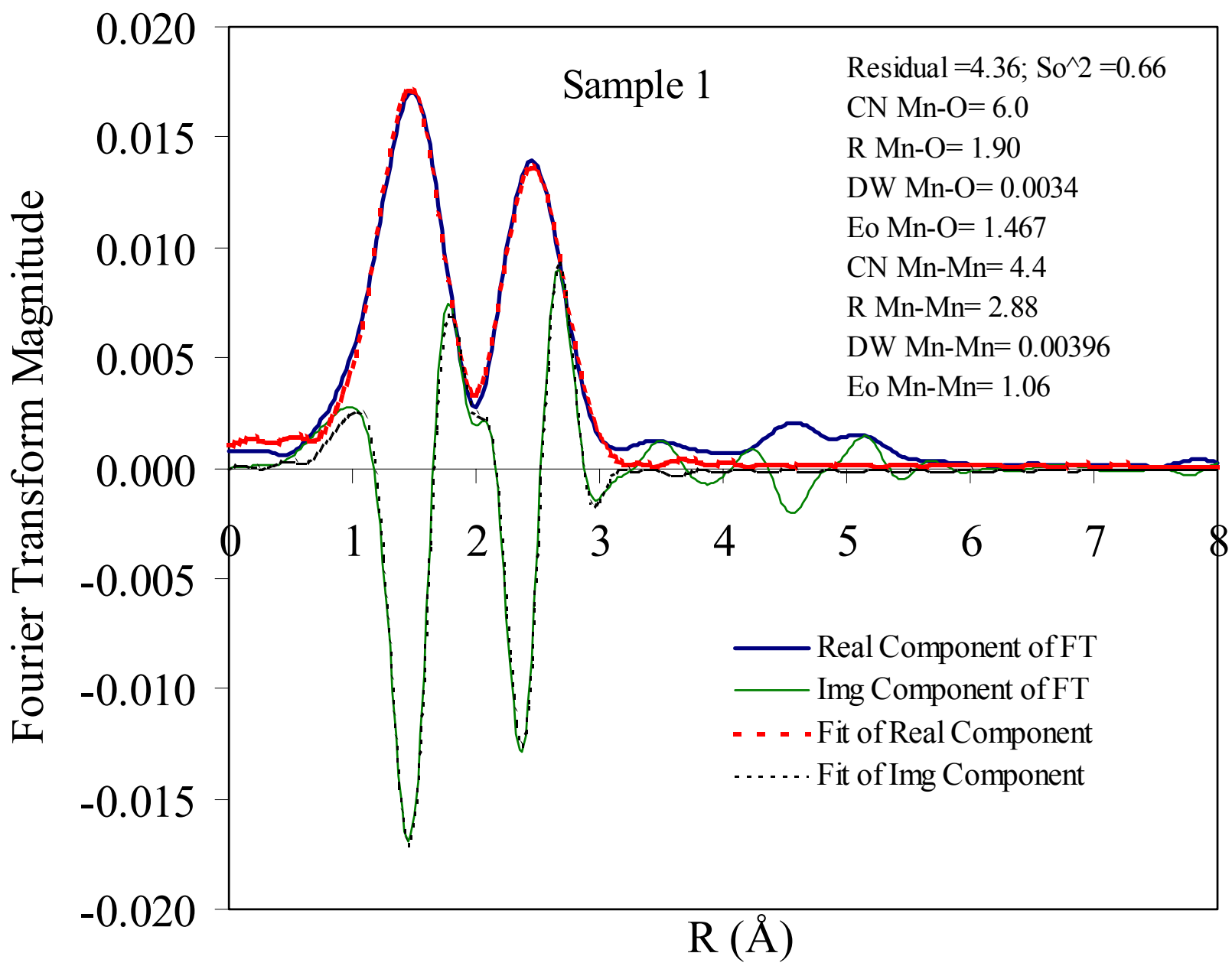

Figure 4.10 FT and model fit data for $\mathrm{Mn}$ in Sample 1 (4-hour equilibration using $\mathrm{H}_{2} \mathrm{O}_{2}$ with seed $\mathrm{Sr}$ ) - uncorrected for phase shift. 
WSRC-TR-2002-00366, REVISION 0

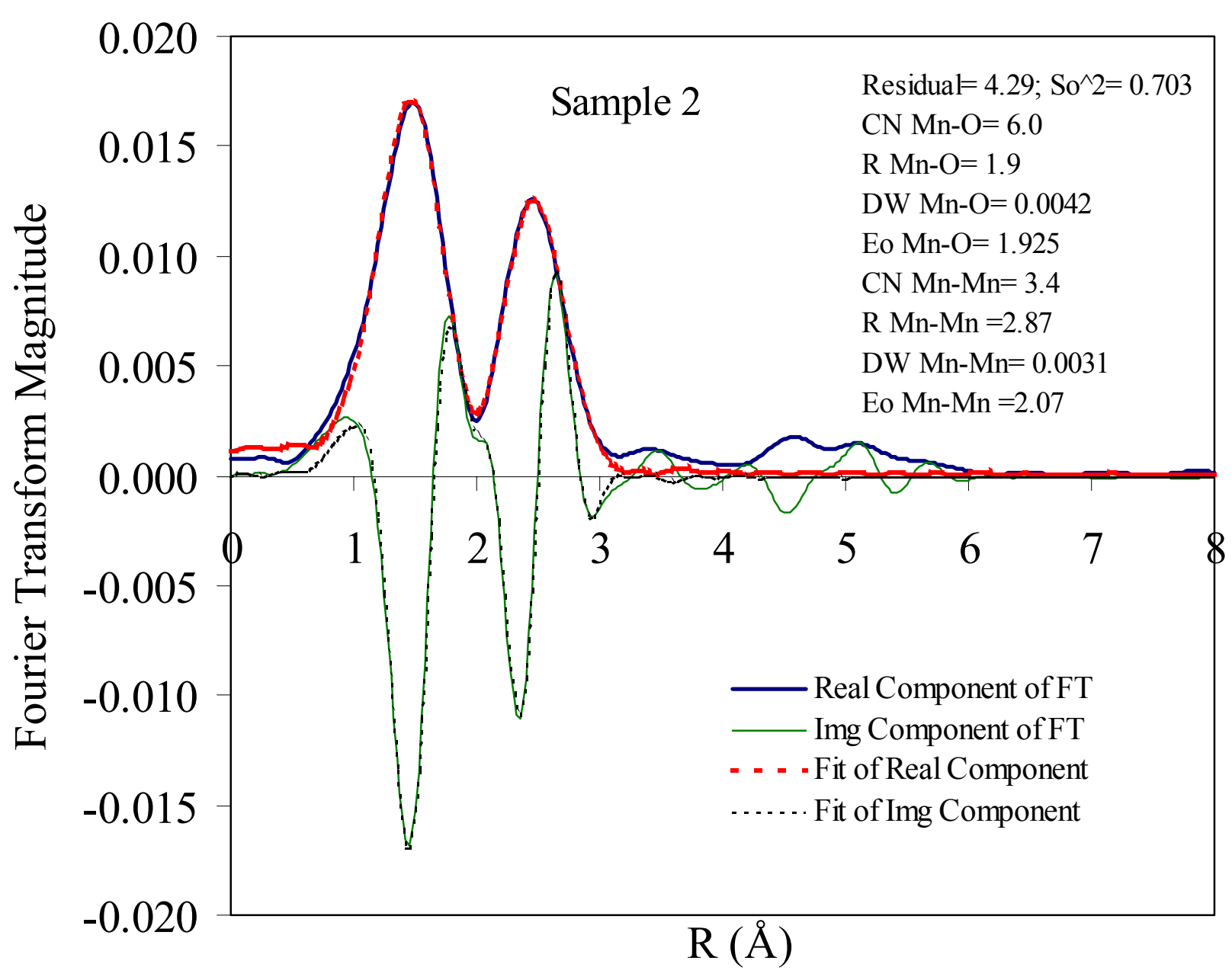

Figure 4.11 FT and model fit data for Mn in Sample 2 (4-hour equilibration using formate with seed $\mathrm{Sr}$ ) - uncorrected for phase shift. 
WSRC-TR-2002-00366, REVISION 0

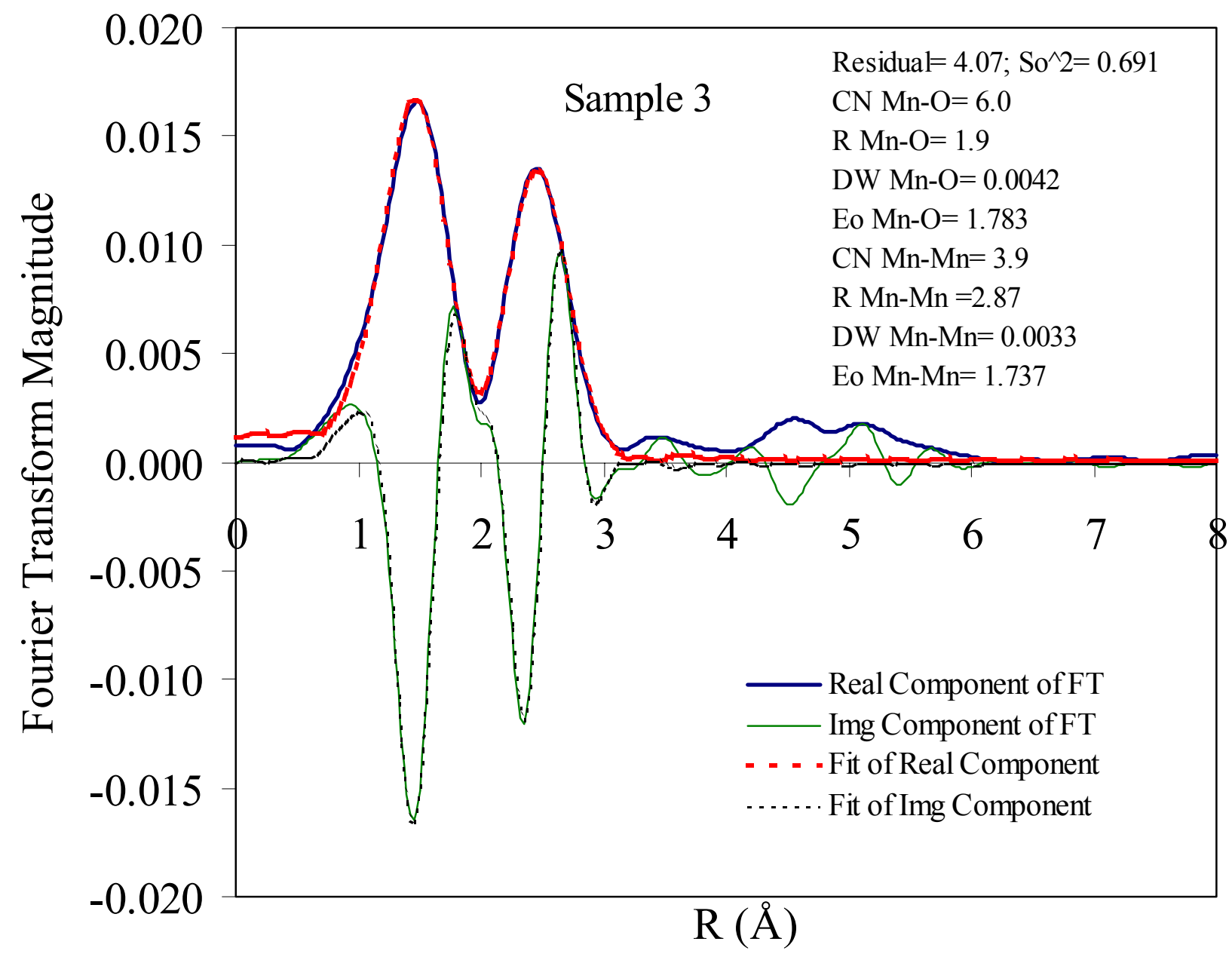

Figure 4.12 FT and model fit data for Mn in Sample 3 (4-hour equilibration using formate without seed $\mathrm{Sr}$ ) - uncorrected for phase shift. 


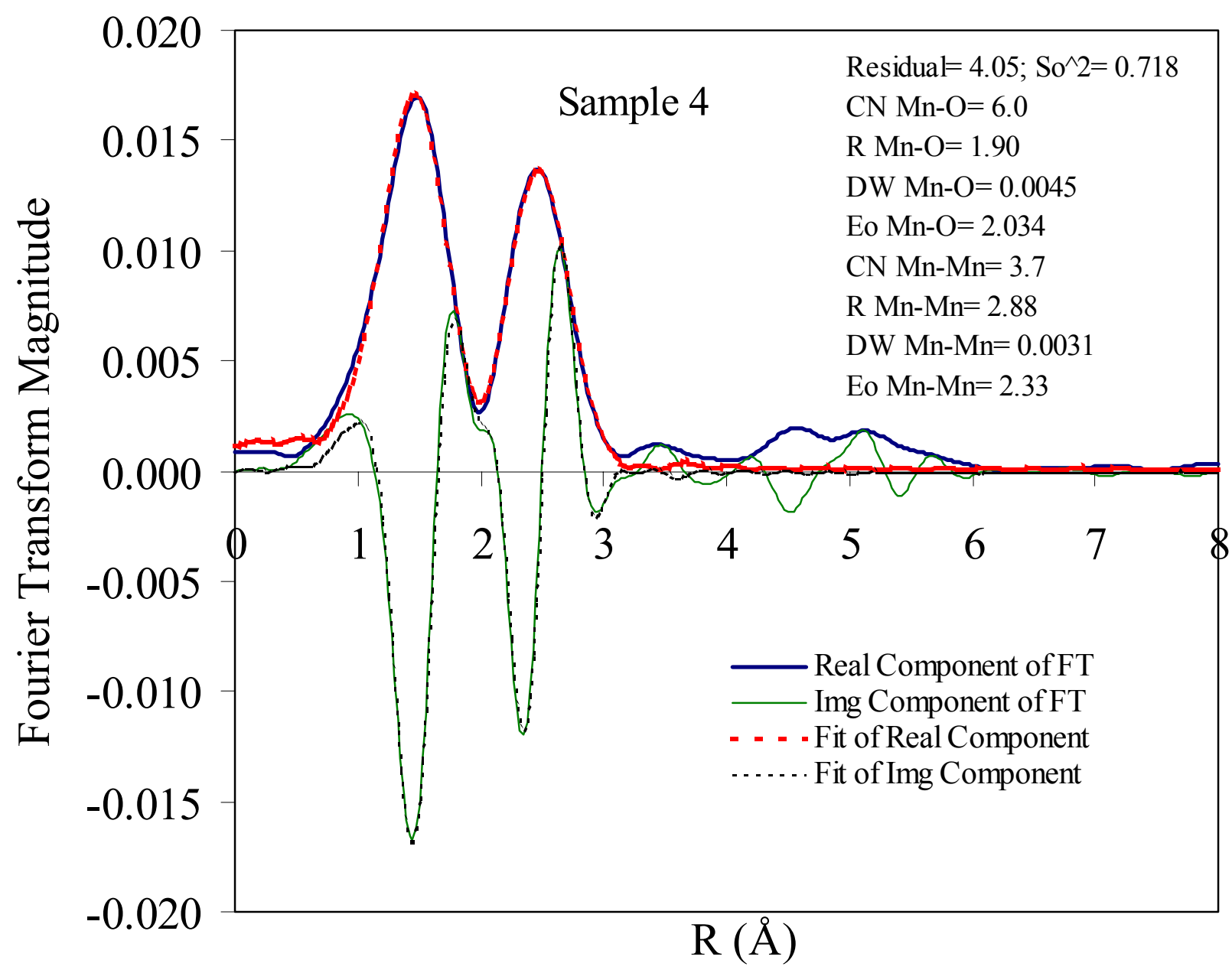

Figure 4.13 FT and model fit data for Mn in Sample 4 (168-hour equilibration using formate without seed $\mathrm{Sr}$ ) - uncorrected for phase shift. 


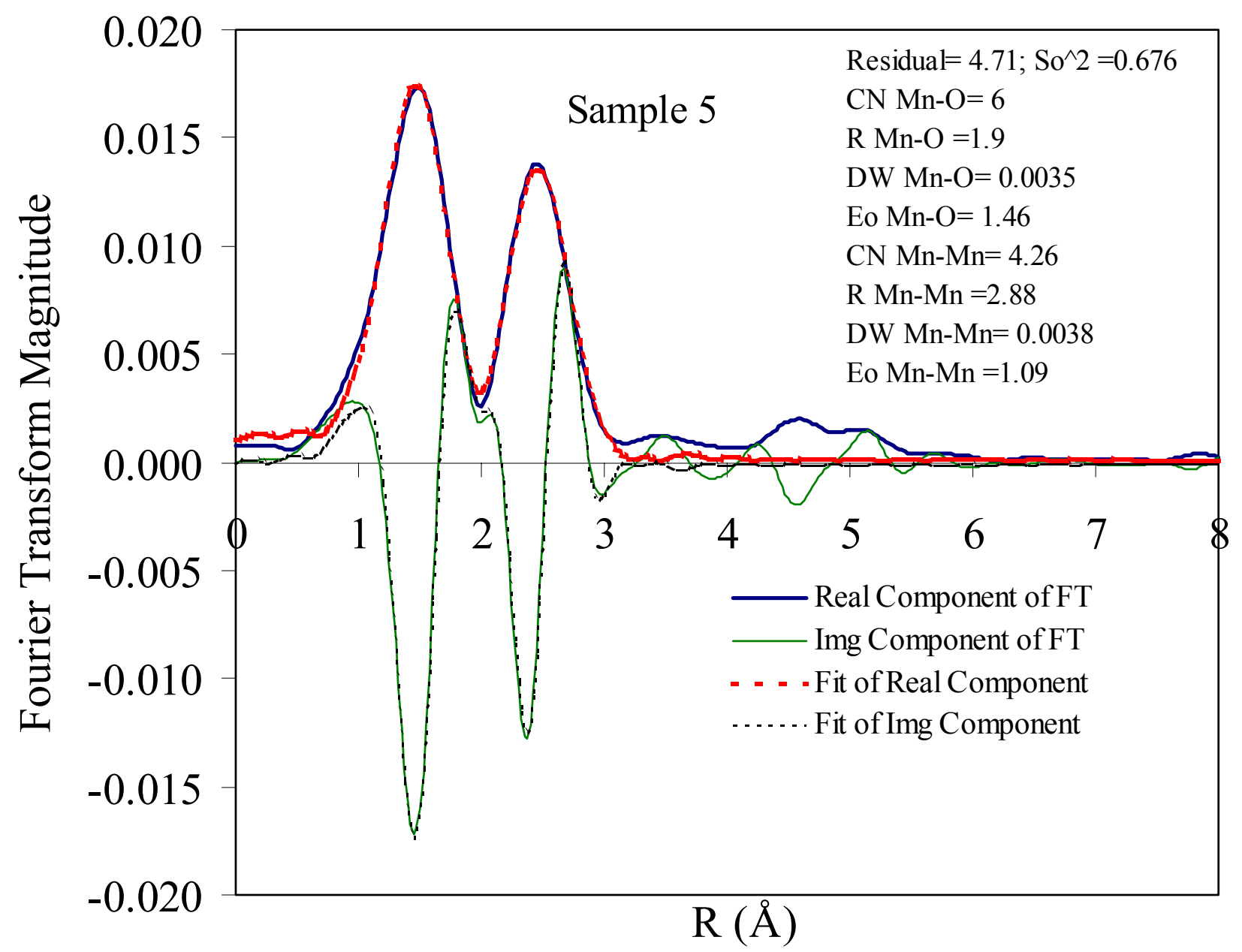

Figure 4.14 FT and model fit data for Mn in Sample 5 (168-hour equilibration using $\mathrm{H}_{2} \mathrm{O}_{2}$ with seed $\mathrm{Sr}$ ) - uncorrected for phase shift. 


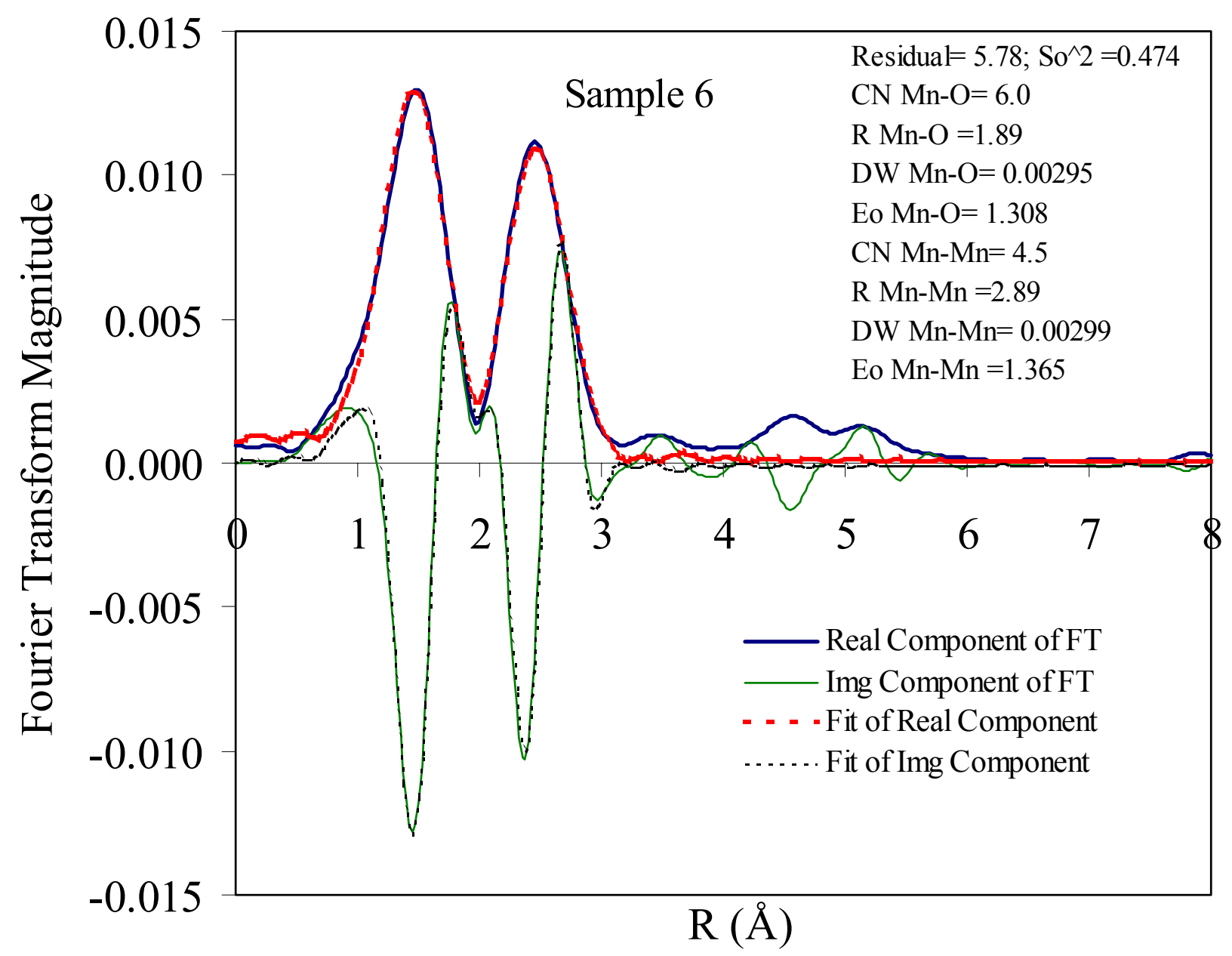

Figure 4.15 FT and model fit data for Mn in Sample 6 (168-hour equilibration using $\mathrm{H}_{2} \mathrm{O}_{2}$ without seed $\mathrm{Sr}$ ) — uncorrected for phase shift. 


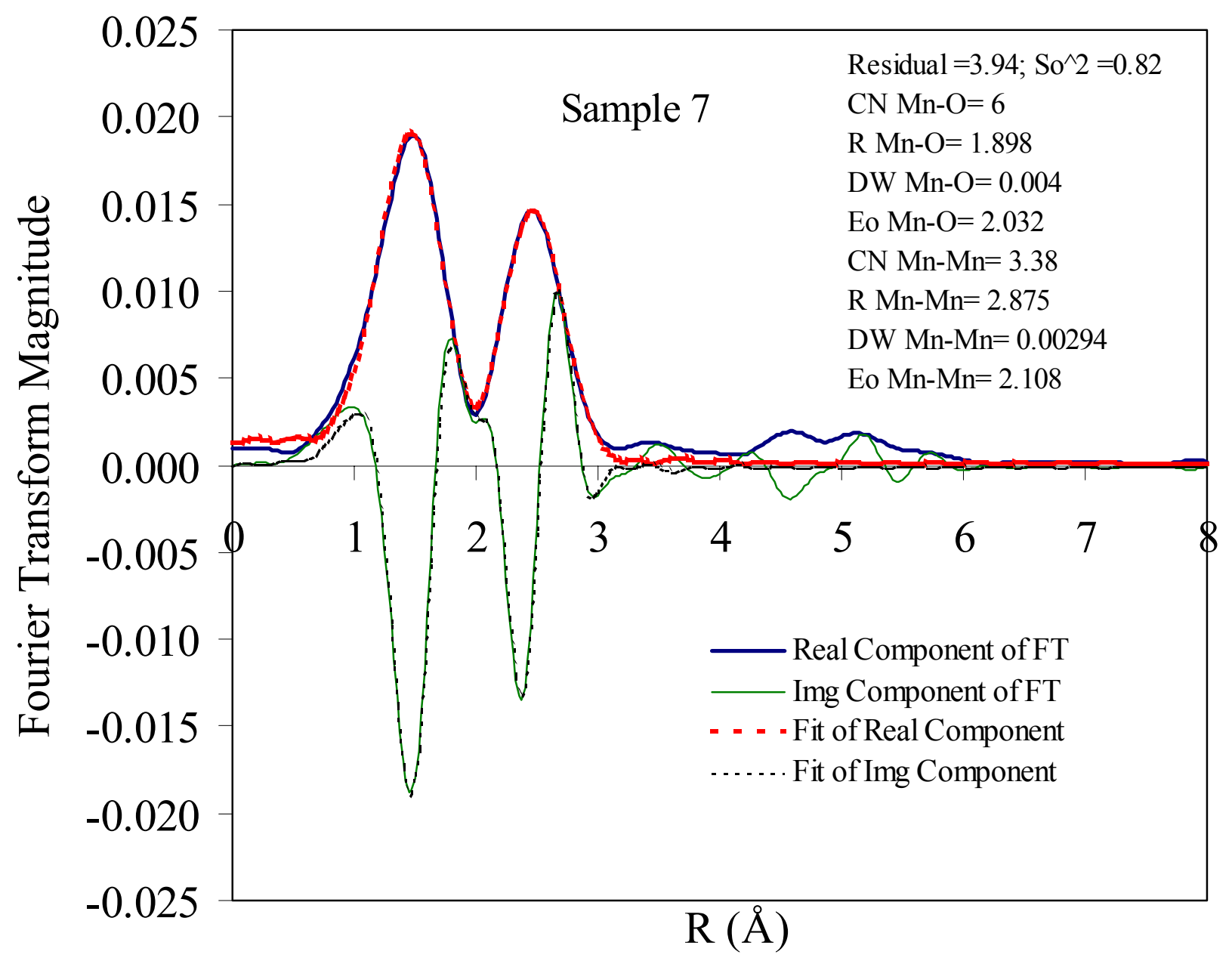

Figure 4.16 FT and model fit data for Mn in Sample 7 (168-hour equilibration using formate with seed $\mathrm{Sr}$ ) - uncorrected for phase shift. 


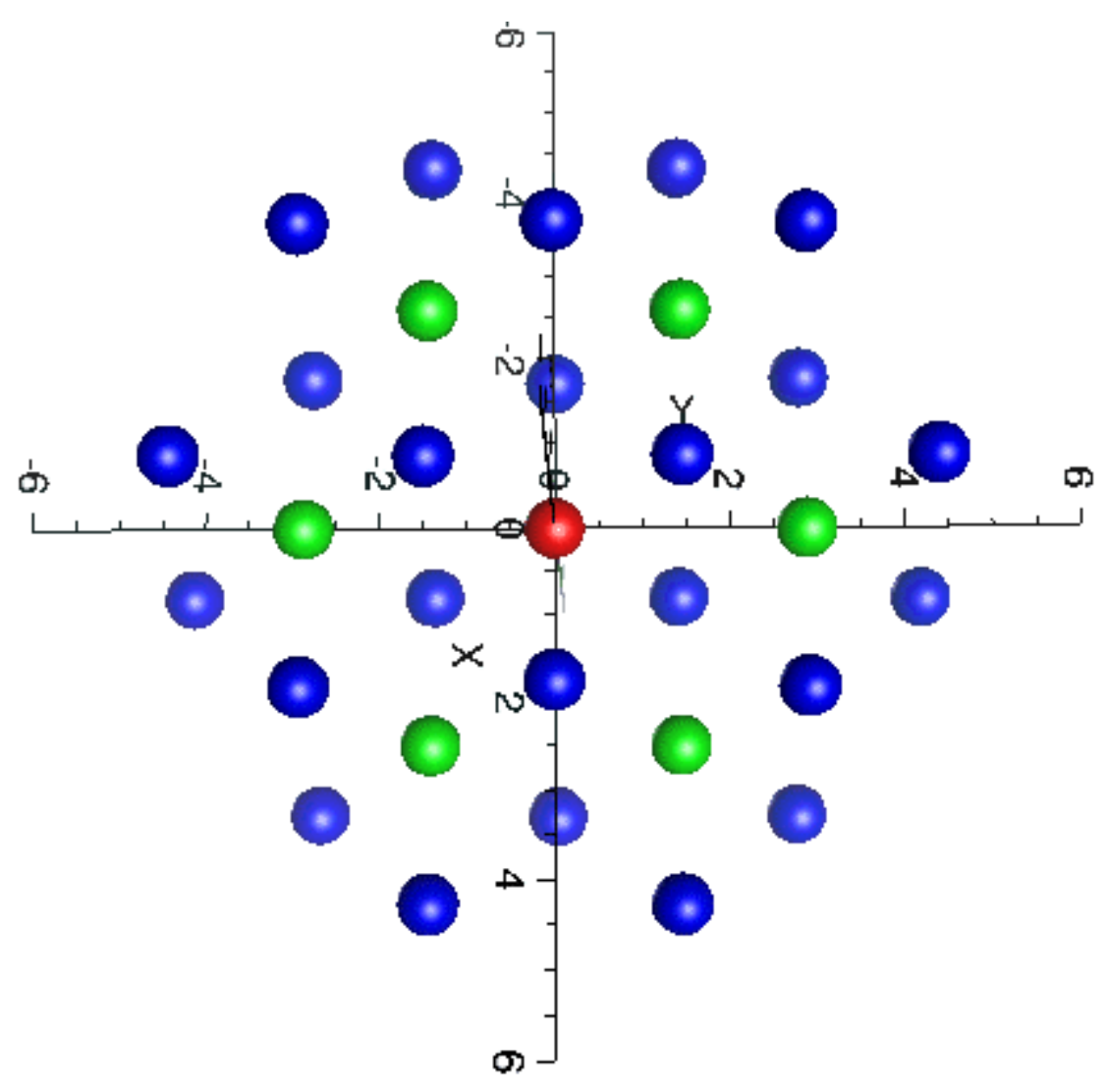

Figure 4.17 Large sheets of edge-sharing Mn octahedra (i.e., those solids that can be identified by XRD because they have sufficient long range crystalline order) would have a $\mathrm{Mn}-\mathrm{Mn} \mathrm{CN}$ of 6 . The reduced $\mathrm{CN}$ of 4 that the sheets are limited in size. For example, the assembly of atoms above consists of $6 \mathrm{Mn}$ (green) around a central Mn (red). The average Mn-Mn CN would be 3.43. 
WSRC-TR-2002-00366, REVISION 0

\subsubsection{Plutonium F ourier Transform and Model Fit Data}

The FT and model simulation data for $\mathrm{Pu}$ in the Mn oxide sample are shown in Figure 4.18 and Figure 4.19. An average radial distance of $2.34 \AA$ for eight $\mathrm{Pu}-\mathrm{O}$ interactions is nearly consistent with that of $\mathrm{Pu}-\mathrm{O}$ first shell distance at $2.38 \AA$ for a $\mathrm{Pu}(\mathrm{IV}) \mathrm{O}_{2}$ solid, which indirectly supports that the $\mathrm{Pu}$ in the sample is probably tetravalent (Figure 4.18). These findings are consistent with the results of the Pu XANES studies with these materials as discussed in Section 4.2.2.1, which supports an assignment of +4 to the $\mathrm{Pu}$ valence.

Our fits of the Pu XAFS data indicate there are several second coordination shell Mn atoms $(2.9 \pm 1.5)$ at $3.4 \AA$ (Figure 4.19). The Pu-Mn interaction indicates that Pu may be associated with the Mn oxide (a birnessite-type phase) via sorption in the interlayer region (where hydrated $\mathrm{Na}^{+}$is typically present) and possibly substitution for $\mathrm{Mn}$ in structural vacancies within the birnessite.

Fits for additional higher shell elements show that the $\mathrm{Pu}$ (on average) is present in a polymeric form but if we assume this is the only form of $\mathrm{Pu}$, it appears to be too small to be truly colloidal. It is possible that there are several populations of Pu species, such as monomers and polymers of $\mathrm{Pu}(\mathrm{IV})$ species. The presence of higher shell $\mathrm{O}$ interactions in addition to the Pu also supports the existence of a polymeric Pu oxide species. Due to their large size, polymeric species are not likely to fit within structural vacancies in birnessite. Fairly flat colloidal particles of Pu could be present in the interlayer region of the birnessite, although the fit would be somewhat restrictive. If some of the Mn oxide particles were amorphous, this behavior would permit more flexibility with regard to Pu uptake on an atomic scale. A pictorial representation of the Pu XAFS data is shown in Figure 4.20. Colloidal Pu material has not been observed in studies with real tank wastes from the SRS. ${ }^{78}$ It is possible that the $\mathrm{Pu}$ is present as two or more populations of species such as monomeric and larger polymeric species. XAFS data provide average $\mathrm{CN}$ and radial distance values and not information on the distribution of species populations in our samples. 


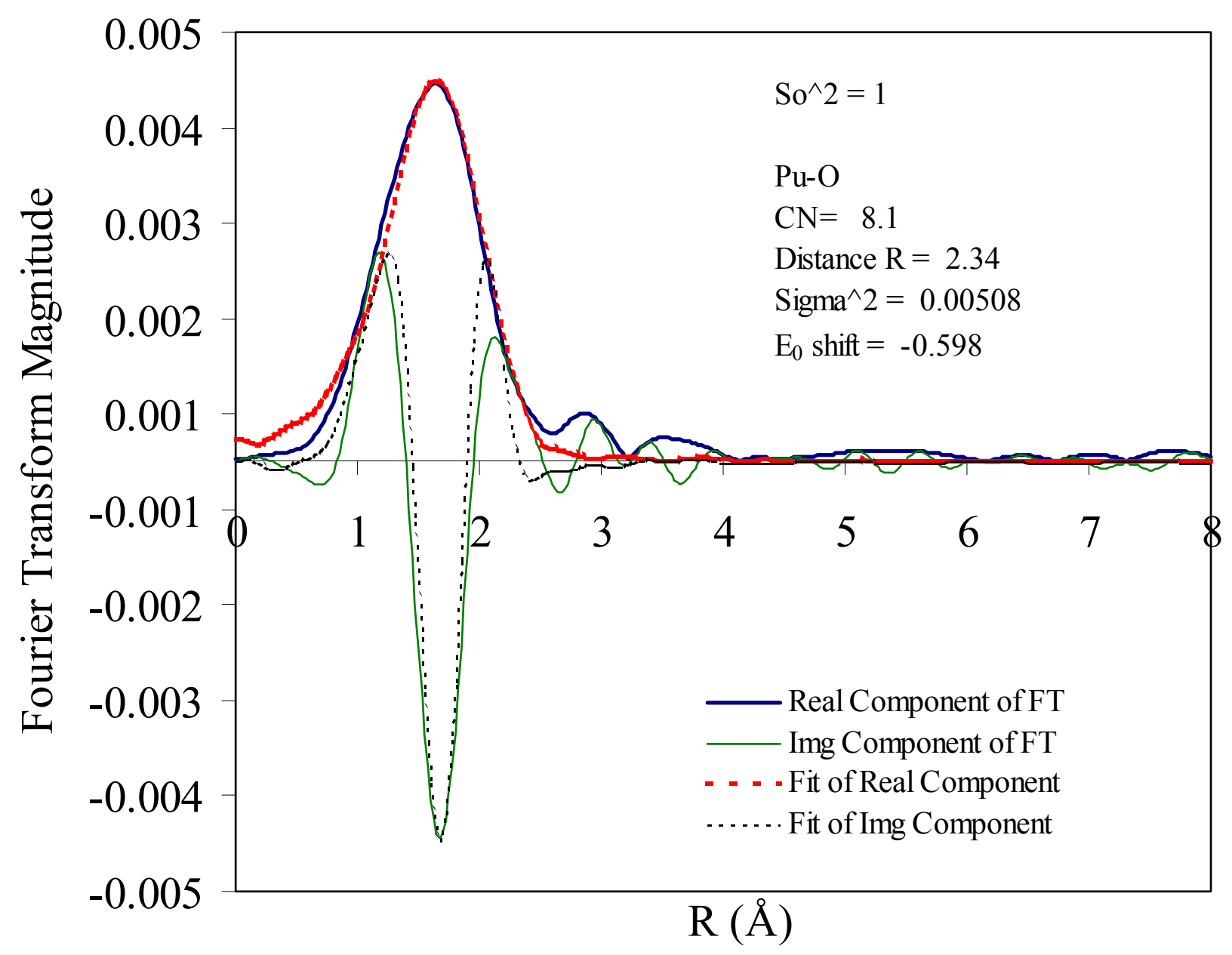

Figure 4.18 FT and first shell model fit data for the Pu-loaded Mn oxide sampleuncorrected for phase shift. 
WSRC-TR-2002-00366, REVISION 0

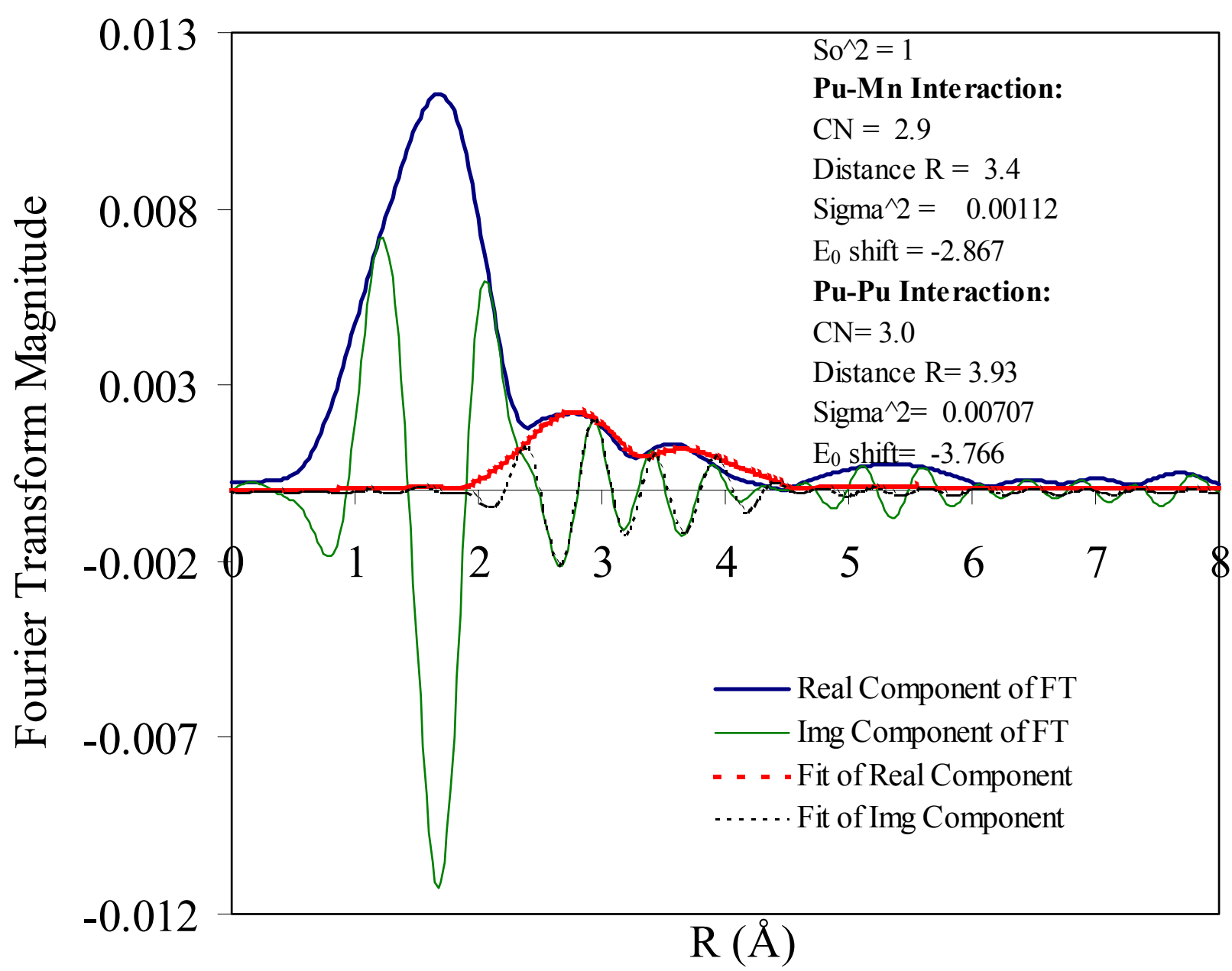

Figure 4.19 FT and second coordination shell model fit data for the Pu-loaded Mn oxide sample-uncorrected for phase shift. 


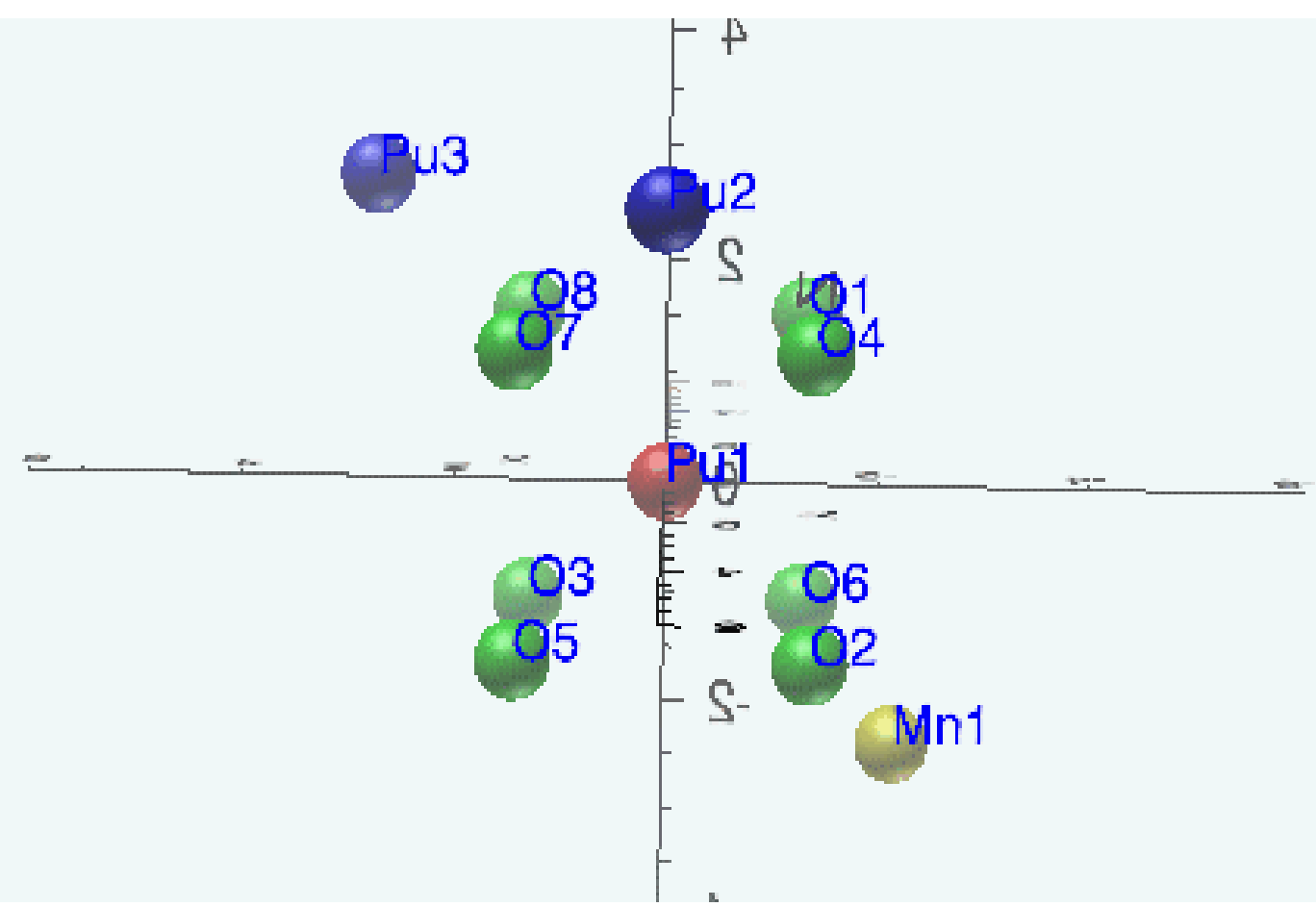

Figure 4.20 Model of the fits from EXAFS data analyses showing the association of more than one $\mathrm{Pu}$ atom (blue spheres) and a Mn atom (gold spheres) in the outer shell of the $\mathrm{Pu}(\mathrm{IV})$ (red spheres), that has eight first-shell $\mathrm{O}$ atoms (green spheres). 


\subsubsection{Neptunium Fourier Transform and Model Fit Data}

The Np FT data and model simulation results for the Np-loaded Mn sample, which

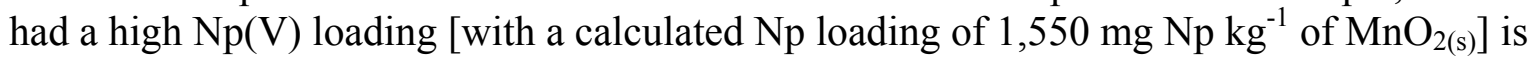
shown in Figure 4.21. We detected a split first $\mathrm{Np}$ coordination shell. The first shell fits indicate that there are two Np-O interactions at radial distances of $1.98 \AA$ and $2.60 \AA$ as shown in Figure 4.21. Most axial Np-O (Oax) radial distances are typically a few one hundreds of an angstrom less than $1.95 \AA$. Therefore, our short Np-O distance of $1.98 \AA$ is somewhat unexpected. ${ }^{57}$ Most equatorial (Oeq) $\mathrm{Np}-\mathrm{O}$ distances for dissolved $\mathrm{Np}(\mathrm{V})$ range from 2.49 to $2.61 \AA$. If we consider our longer $\mathrm{Np}-\mathrm{O}$ distance to be representative of Oeq bonds, the distance lies within the range typically observed for dissolved $\mathrm{Np}(\mathrm{V}) \mathrm{O}_{2}{ }^{+}$species.

We could not obtain a suitable fit for $\mathrm{Np}-\mathrm{Mn}$ or $\mathrm{Np}-\mathrm{Np}$ interactions in the outer $\mathrm{Np}$ shell region of the Np EXAFS data. This suggests that there may be outer sphere adsorption of $\mathrm{Np}$ species on the Mn oxide. If we had detected $\mathrm{Np}-\mathrm{Np}$ interactions in the second coordination shell, we would have concluded that polymeric $\mathrm{Np}$ species are present. Because actinide local structure is often related to oxidation state, our results indicate the $\mathrm{Np}$ is probably present as an oxidized form [as $\mathrm{Np}(\mathrm{V}) \mathrm{O}_{2}{ }^{+}$or $\left.\mathrm{Np}(\mathrm{VI}) \mathrm{O}_{2}{ }^{2+}\right]$ rather than a reduced form [as $\mathrm{Np}$ (III) or $\mathrm{Np}(\mathrm{IV})]$. This is because the first shell of the $\mathrm{Np}$ in our sample contains $\mathrm{O}$ atoms at two different and well-separated distances. The first shell $\mathrm{O}$ distances that we observe for the $\mathrm{Np}$ in our sample are atypical of $\mathrm{Np}$ (III) and $\mathrm{Np}$ (IV) species because these more reduced species usually have much longer $\mathrm{Np}-\mathrm{O}$ bonds (from 2.39 to $2.52 \AA$ ) than that of the shortest $\mathrm{Np}-\mathrm{O}$ bonds observed for the $\mathrm{Np}(\mathrm{V})$ and $\mathrm{Np}(\mathrm{VI})$ species. Additionally, there is typically no splitting of the first coordination shell for $\mathrm{Np}$ (III) and $\mathrm{Np}$ (IV) species and the $\mathrm{Np}$ XANES data indicate the $\mathrm{Np}$ is probably present as $\mathrm{Np}(\mathrm{V})$ more so than $\mathrm{Np}(\mathrm{VI})$ or $\mathrm{Np}(\mathrm{IV})$.

Another possible explanation of the $\mathrm{Np}$ behavior is that the $\mathrm{Np}(\mathrm{V})$ converted to a less soluble form upon reaction with the peroxide and this conversion resembled "uptake" from solution. This type of conversion could also be reversible and result in the release of Np into solution post Mn precipitation as has been observed in previous studies. ${ }^{1}$ The conversion of $\mathrm{Np}(\mathrm{V})$ to more reduced (i.e., less soluble and more sorptive) species such as $\mathrm{Np}(\mathrm{IV})$ after reaction with permanganate and the subsequent oxidation of the $N p(I V)$ to $N p(V)$ by the birnessite-type $\mathrm{Mn}$ oxide (Mn oxides are also considered to be oxidizing agents) ${ }^{10}$ followed by the release of soluble $\mathrm{Np}(\mathrm{V})$ is also possible. In this case, the $\mathrm{Np}(\mathrm{V})$ is likely to resemble a monomeric species, much like that in our EXAFS studies. Additionally, the coprecipitation of $\mathrm{Np}(\mathrm{V})$ with the Mn oxides that form may not be favored due to the large size of the $\mathrm{NpO}_{2}{ }^{+}$ ion $(\sim 1.85 \AA)$ relative to the $\mathrm{Pu}^{4+}$ ion $(0.86$ to $0.96 \AA)$. The large $\mathrm{Np}$ ion is not likely to substitute for the small $\mathrm{Mn}^{4+}$ ion $(0.54 \AA)$ in the Mn oxide structure.

In summary, our results agree with most of the previous Np EXAFS studies, which detected only outer sphere sorption of $\mathrm{Np}$ species on the Mn solid that we examined. ${ }^{64}$ Few if any characterization studies have been conducted with $\mathrm{Np}$ that is associated with Mn oxides. We observe outer sphere sorption of $\mathrm{Np}\left(\mathrm{V} \mathrm{O}_{2}{ }^{+}\right.$species on the Mn oxides in simulated HLW salt solutions although our other studies with $\mathrm{Np}(\mathrm{V})$ added to MST indicate that the nature of Np sorption is inner sphere. ${ }^{35}$

Page 51 of 65 


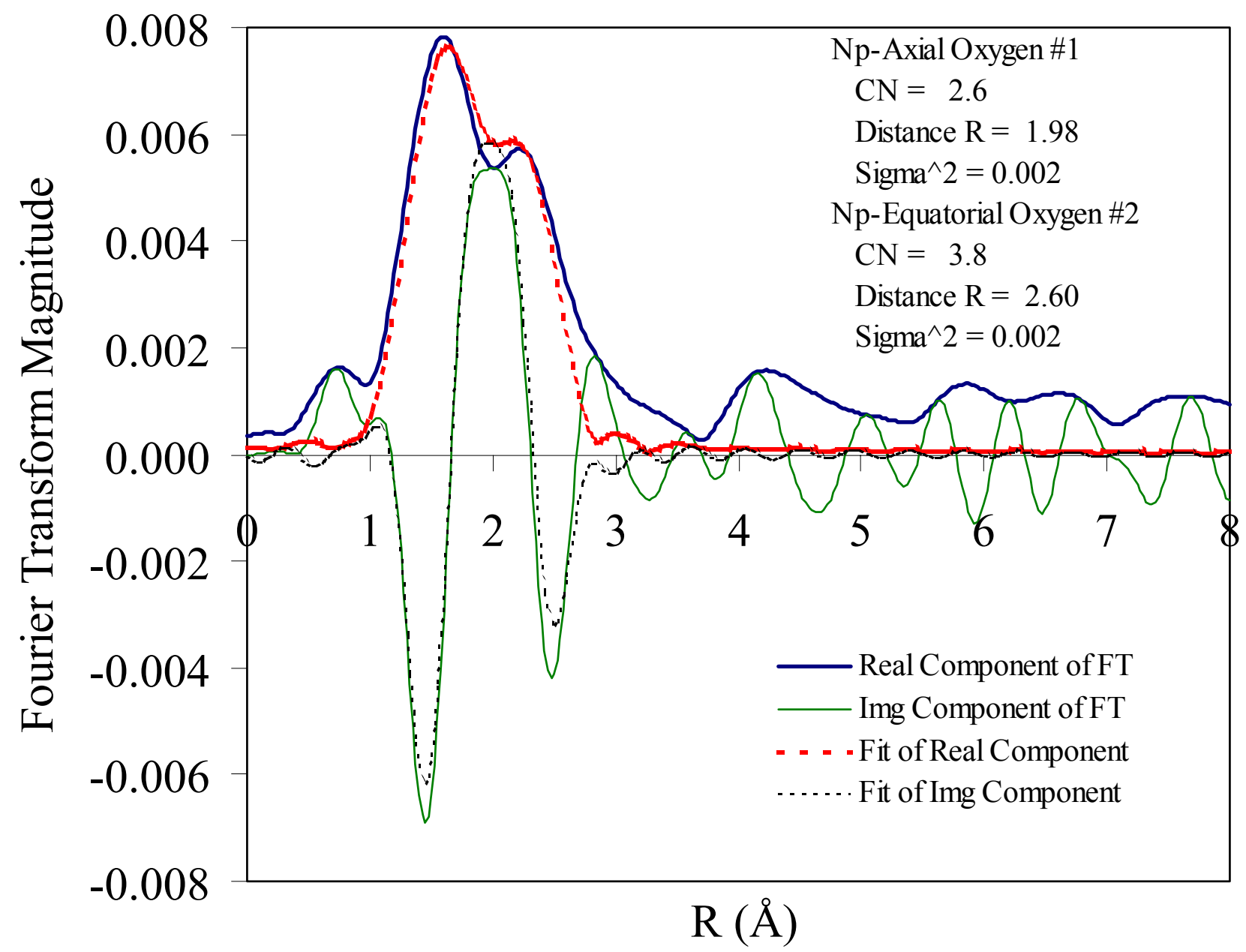

Figure 4.21 FT XAFS data and first shell model fits for the Np-loaded Mn oxide sampleuncorrected for phase shift. 


\subsection{X-ray Diffraction Analyses of Mn Samples}

The four air-dried Mn samples from the 4-hour samplings (as described in Table 3-2) were analyzed by X-ray powder diffraction techniques at SRTC for their crystalline phases. Comparisons with a database of the diffraction patterns for potential crystalline solids were made. All treatments had patterns, which matched with that of $\mathrm{NaNO}_{3}, \mathrm{SrCO}_{3}$, sodium aluminum oxide, hydrated $\mathrm{Na}_{2} \mathrm{CO}_{3}$, and a hydrated sodium nitrate-sulfate salt. Many of the phases identified did not have large pronounced diffraction peaks - indicating the possible presence of amorphous forms of these salts. A calcium aluminum oxide was identified in one of the samples, but due to the low level of calcium in our salt solutions, this solid was not an expected phase. A crystalline sodium birnessite phase, which has some overlapping peaks with the calcium aluminum oxide, could be present instead of the $\mathrm{Ca}$ aluminum oxide phase. However, no crystalline Mn oxide phases could be identified in the spectra. As evidenced by the intensity of the diffraction peaks, strontianite was found to be a dominant crystalline phase in the treatments that had added seed $\mathrm{Sr}$ whereas the treatments that did not contain added seed $\mathrm{Sr}$ also contained strontianite but in trace amounts (compare Figures $\mathbf{4 . 2 2}$ and $\mathbf{4 . 2 4}$ with Figures 4.23 and 4.25). The trace level of $\mathrm{Sr}$ in the treatments that did not contain added seed $\mathrm{Sr}$ is from the low level of "tramp" $\mathrm{Sr}$ in the reagent grade chemicals (specifically, the sodium carbonate) used to prepare the salt solutions. The exclamation marks in the key for these figures (Figures 4.22 through 4.25) represent the symbols that precede the waters of hydration in the structural formula for the crystalline species identified.

TEM analyses (by ANL) of the Pu-loaded Mn oxide material show that large crystallites of $\mathrm{Al}$ oxide were common to this sample. ${ }^{18}$ Additionally, the Mn oxide particles had trace levels of nitrogen $(\mathrm{N}), \mathrm{S}$ and $\mathrm{Al}$, which support the possible existence of salts in poorly diffracting (amorphous) forms. The SEM analyses of the Mn oxide material used in the ANL feasibility study show large fibrous particles, which were rich in $\mathrm{Na}, \mathrm{O}$ and $\mathrm{Al}$, which supports an assignment of a sodium alumina phase. The SEM and TEM analyses are not completely comparable with our XRD analyses because the EM techniques are spatially resolved and the XRD analyses apply to the bulk phase material. 
WSRC-TR-2002-00366, REVISION 0

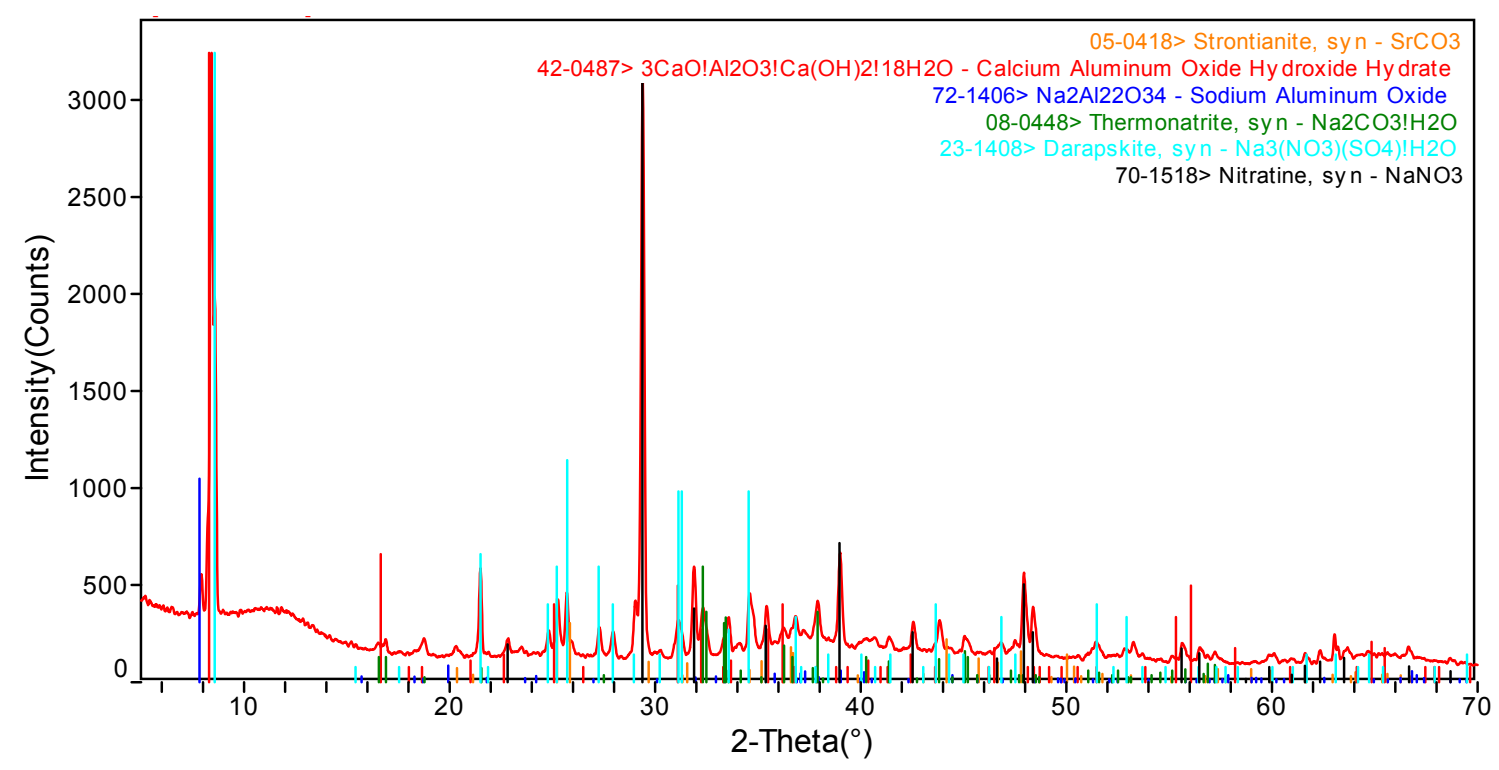

Figure 4.22 X-ray powder diffractogram for Sample 0 (containing $\mathrm{H}_{2} \mathrm{O}_{2}$ and no seed $\mathrm{Sr}$ ).

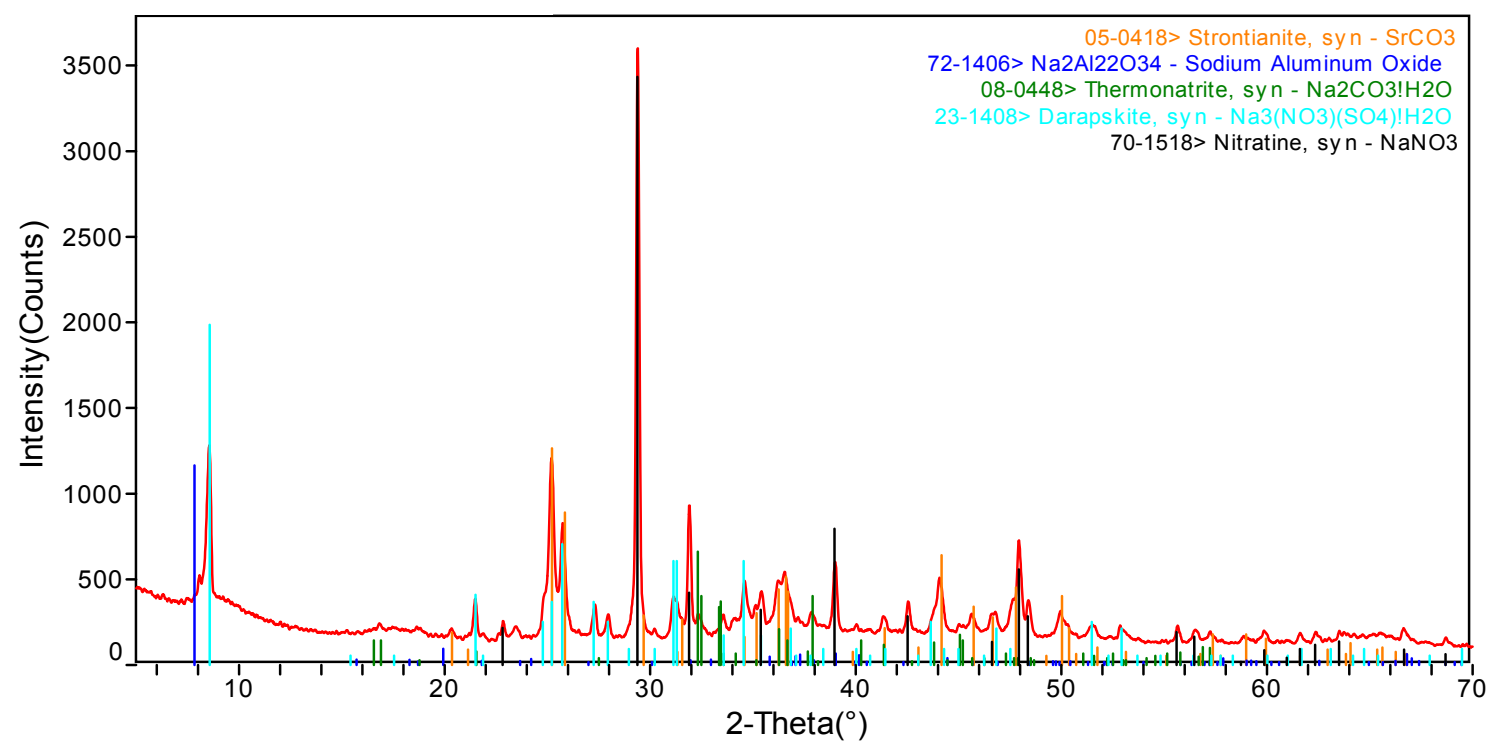

Figure 4.23 X-ray powder diffractogram for Sample 1 (containing $\mathrm{H}_{2} \mathrm{O}_{2}$ and seed $\mathrm{Sr}$ ). 


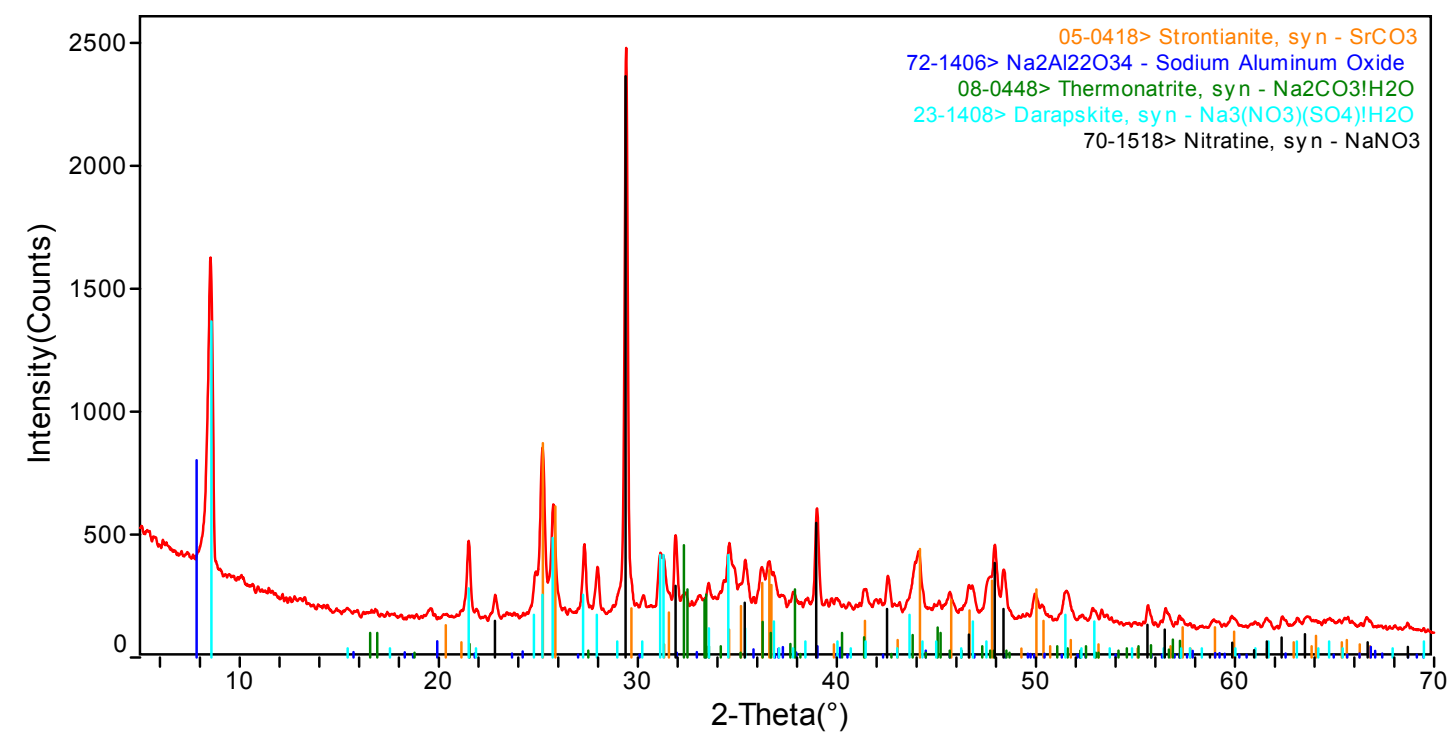

Figure 4.24 X-ray powder diffractogram for Sample 2 (containing formate and no seed $\mathrm{Sr}$ ).

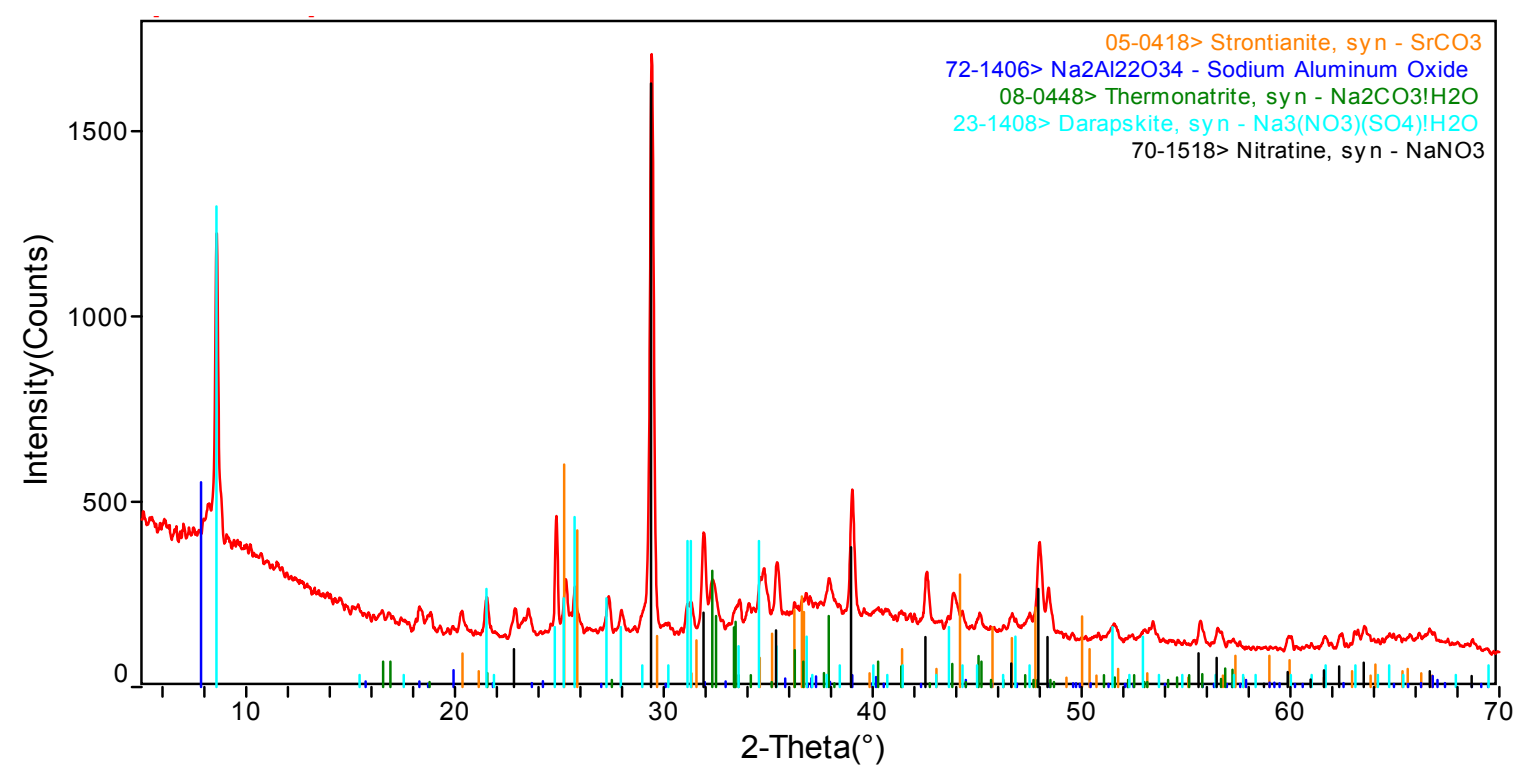

Figure 4.25 X-ray powder diffractogram for Sample 3 (containing formate and seed $\mathrm{Sr}$ ). 
WSRC-TR-2002-00366, REVISION 0

\subsubsection{Mn Oxide Formation in Highly Basic Solutions}

Manganese-oxide particles possess high negative surface charges - even in low $\mathrm{pH}$ (e.g., $\mathrm{pH}$ 2) solutions, where the protonation of most metal oxide surfaces is favored. ${ }^{79}$ This type of behavior is very unusual because the metal oxides of aluminum, titanium and iron typically possess a net positive surface charges in solutions with $\mathrm{pH}$ values below 5 . Hence, in the geologic environment, the negative charge on Mn oxide solids makes them very competitive for cationic species (such as $\mathrm{UO}_{2}{ }^{2+}, \mathrm{Sr}^{2+}$ etc...). At high $\mathrm{pH}$, the oxide solids like birnessite are likely to have much higher (negative) surface charges (due to the deprotonation of hydroxyl groups present at broken edges sites, at kinks or other surface defects) indicating that they should have a high sorptive affinity for cationic species such as $\mathrm{Pu}^{4+}, \mathrm{Co}^{2+}$ and $\mathrm{Sr}^{2+}$. Additionally, sorbed redox-active species on birnessite-type minerals may undergo oxidation by $\mathrm{Mn}(\mathrm{IV})$ as observed with rancieite. ${ }^{8}$

High levels of dissolved $\mathrm{Na}^{+}$promote the formation of a poorly crystalline $\mathrm{Na}$ birnessite phase — as evidenced by the absence of peaks in the XRD spectra. ${ }^{80}$ Our HLW simulant solutions contain several salts, which are at near supersaturated levels. The process of making the simulant solutions initially under acidic conditions followed by the slow addition of $\mathrm{NaOH}$ to create alkaline conditions (as described in the methods section of this report) favors the development of supersaturated conditions. In the absence of a rapidly precipitating phase (in our case, a Mn oxide), these salts are likely to remain at supersaturation. This process is referred to as homogeneous nucleation. ${ }^{25}$ The rapid precipitation of birnessite (and strontianite) could induce the precipitation of other salts that are below supersaturation if the birnessite surfaces lower of the activation energy for the secondary precipitation reaction.

The high degree of supersaturation that occurs during permanganate reduction in our tests is likely to yield high nucleation rates and small crystallites. Crystal growth or "ripening" of the nano-crystalline birnessite may be deterred by the presence of numerous salts that adhere to the freshly precipitated Mn oxide surfaces, which are highly charged and can thus attract precipitating phases. Additionally, these salts may preclude the sorption of radionuclides post (Mn oxide) precipitation by forming a passive coating and occluding surface sorption sites. ${ }^{81}$ The analytical results from electron microscopy studies with the Mn oxides produced by the permanganate reduction process (by ANL) demonstrated the presence of $\mathrm{Na}, \mathrm{Al}, \mathrm{N}, \mathrm{O}$ and $\mathrm{S}$ (i.e., salts) that were in very close proximity to the Mn oxide particles - as evidenced by the energy dispersive spectrometry results. ${ }^{18}$ Our Mn oxide samples were not rinsed prior to analyses and some salts may have also formed while the samples were air dried.

Studies show that the induction period of birnessite formation in solutions ranging from 0.17 to $3.6 \mathrm{M} \mathrm{OH}^{-}$is highest at high hydroxide levels. ${ }^{82,83}$ Additionally, crystallization rates are also greatest when the $\mathrm{OH}^{-}$levels are high. These findings indicate that actinide removal rates should be greater at high $\mathrm{OH}^{-}$concentrations. Some of these previously mentioned studies vary from ours in that some researchers begin their Mn oxide syntheses using $\mathrm{Mn}(\mathrm{II})$ and permanganate ion and the sodium birnessite was transformed from a 
precursor feitknechtite $(\beta-\mathrm{MnOOH})$ phase. $^{82}$

\subsection{Influence of Strontianite on Sr and Actinide Removal}

The precipitation of $\mathrm{SrCO}_{3(\mathrm{~s})}$ is likely to also remove radiostrontium from solution. However, other radionuclides, such as $\mathrm{Pu}$ may also be removed by this precipitating phase. Other carbonate solids, such as the calcium carbonates (specifically, the $\mathrm{CaCO}_{3(\mathrm{~s})}$ polymorphs called calcite and aragonite) show a noted affinity for the structural uptake and sorption of $\mathrm{Pu}$, Am and $U^{84}$ This behavior has been observed in oceanic coral depositional records. For these reasons, we suspect that strontianite may have a synergistic role in actinide removal.

\subsection{CONCLUSIONS}

The Mn precipitate that forms upon reduction of permanganate in alkaline salt solutions is a layered Mn oxide with a structure like that of hexagonal birnessite. This Mn phase is in the nanoparticle range and it does not possess long range crystalline order (i.e., it is amorphous to X-ray diffraction). This highly reactive phase can offer both interlayer and vacancy sites for radionuclide sorption. This phase was stable over 168 hours and the reductant choice had little effect on the Mn oxide structure formed.

The actinides $(\mathrm{Np}$ and $\mathrm{Pu})$ in this study were removed by different mechanisms as listed below.

- $\mathrm{Pu}$ sorbed via an inner sphere mechanism as most likely monomeric and polymeric species on the Mn octahedra of a birnessite-type phase. This type of sorption is not highly reversible and has been observed for sorbed $\mathrm{Pu}$ on $\mathrm{Mn}$ oxides in the literature.

- $\mathrm{Np}$ is associated with the solids in the sample via outer sphere sorption of monomeric species. This type of $\mathrm{Np}$ removal is more subject to reversibility than inner sphere sorption. The $\mathrm{Np}$ in our sample could also be the result of redox reaction with peroxide, permanganate and ultimately, the precipitating Mn oxide phase which results in an initial uptake of $\mathrm{Np}$ from solution followed by the release of $\mathrm{Np}$ into solution as observed in previous studies. Regardless of the mechanism of retention in comparison to $\mathrm{Pu}$, published research ${ }^{17}$ indicates that $\mathrm{Mn}$ oxides have a low affinity for $\mathrm{Np}$ so a weak association of $\mathrm{Np}$ with the solids in our system agrees with previous but limited work.

The form of $\mathrm{Sr}$ that precipitates upon the addition of $0.01 \mathrm{M} \mathrm{Sr}\left(\mathrm{NO}_{3}\right)_{2}$ to our systems is a mixture of amorphous and crystalline $\mathrm{SrCO}_{3}$ or strontianite. This phase may have an affinity for actinides such as $\mathrm{Pu}$.

The formation of salts (either amorphous or crystalline) other than $\mathrm{SrCO}_{3}$ and $\mathrm{Mn}$ oxides and the enrichment of $\mathrm{Al}^{18}$ in our samples effectively decreased the actinide loadings that were anticipated. This occurrence complicated our ability to detect the actinides with

Page 57 of 65 
XAFS techniques. The Mn oxides are highly charged and reactive solids, which can attract dissolved solutes. The salts that precipitate in the sample may occlude surface sites on the Mn oxides $^{81}$ and further limit their ability to remove radionuclides post precipitation as previously observed in RPP studies. ${ }^{85}$

\subsection{ACKNOW LEDGEMENTS}

The authors thank H. Harmon (PNNL) and P. Suggs (DOE), J. Woicik (NIST), A. Ackerman (BNL), M. McAvoy (BNL), R. Zantopp (BNL), N. Gmur (BNL), T. Heuer (BNL), G. Shepherd (BNL), S. Musolino (BNL), R. Casey (BNL), J. Carter, (WSRC), and L. Papouchado (SRTC) for their assistance, support and ideas associated with this study. Betty Croy and K. Prettel (both of SRTC) are acknowledged for their assistance in the preparation of the permanganate samples. Mira Malek, P. Woller, and R. Boyce (all of SRTC) performed the ICP-MS analyses. David Missimer (SRTC) helped with the XRD analyses. Patrick Jackson (DOE) helped put a subcontract in place with NIST.

Mr. T. McCoy and his co-workers (at SRTC) kindly prepared the aluminum metal and plastic sample holders according to our specifications. Rene Johnson and J. Russell (both of WSRC) are acknowledged for their help with shipping these samples. Connie Pierce (WSRC) provided excellent health physics support in the laboratory.

\subsection{REFEREN CES}

\footnotetext{
${ }^{1}$ Duff, M. C., Hobbs, D. T. and Fink, S. D. (2002). Permanganate Treatment Optimization Studies for Strontium and Actinide Removal from High Level Waste Simulants, WSRC-TR-2002-0027, January 14, 2002.

${ }^{2}$ Barnes, M. J., Hobbs, D. T., Duff, M. C. and Fink, S. D. (2002). Permanganate Reduction of Savannah River Site Actual Waste Samples for Strontium and Actinide Removal. WSRC-TR-200200048, Rev. 1, May 2, 2002.

${ }^{3}$ Nash, C., Rosencrance, S. W., Wilmarth, W. R. and Walker, B. (2000). Investigation of Varied Strontium-transuranic Precipitation Chemistries for Crossflow Filtration, BNF-003-98-0171, April 18, 2000 .

${ }^{4}$ Hallen, R. T., Bryan, R. T. and Hoopes, F. V. (2000). Development of an Alternative Treatment Scheme for Sr/TRU Removal: Permanganate Treatment of AN-107 Waste. Report PNWD-3047, BNFL-RPT-025 Rev. 0, Pacific Northwest National Laboratory, July 2000.

${ }^{5}$ Peretrukin, V. F., Silin, V. I., Kareta, A. V., Gelis, A., V., Shilov, V. P., German, K. E., Firsova, E. V., Maslennikov, A. G. and Trushina, V. E. (1998). Purification of Alkaline Solutions and Wastes from Actinides and Technetium by Co-precipitation with Some Carriers using the Method of Appearing Reagents: Final report, Report PNNL-11988, UC-2030, Pacific Northwest National Laboratory, Sept. 1998.
}

Page 58 of 65 
${ }^{5}$ Means, J. L., Crerar, D. A., Borcsik, M. P. and Duguid, J. O. (1978). Adsorption of Co and selected actinides by $\mathrm{Mn}$ and Fe oxides in soils and sediments. Geochim. Cosmochim. Acta 42, 1763-1773.

${ }^{6}$ Dyer, A., Pillinger, M., Harjula, R. and Amin, S. (2000). Sorption characteristics of radionuclides on synthetic birnessite-type layered manganese oxides. J. Mat. Chem. 10, 1867-1874.

${ }^{7}$ Axe, L., Tyson, T. A., Trivedi, P. and Morrison, T. (2000). Local structure analyses of strontium sorption to hydrous manganese oxide. J. Coll. Interf. Sci. 224, 408-416.

${ }^{8}$ Duff, M. C., Hunter, D. B., Triay, I. R., Bertsch, P. M., Reed, D. T., Sutton, S. R., Shea-McCarthy, G., Kitten, J., Eng, R., Chipera, S. J. and Vaniman, D. T. (1999). Mineral associations and average oxidation states of sorbed Pu on tuff. Environ. Sci. Technol. 33, 2163-2169.

${ }^{9}$ Dyer, A., Pillinger, M., Newton, J., Harjula, R., Moller, T. and Amin, S. (2000). Sorption behavior of radionuclides on crystalline synthetic tunnel manganese oxides. Chem. Mater. 12, 3798-3804.

${ }^{10}$ Zachara, J. M., Gassman, P. L., Smith, S. C. and Taylor, D. (1995). Oxidation and adsorption of Co(II)EDTA ${ }^{2-}$ complexes in subsurface materials with iron and manganese oxide grain coatings. Geochim. Cosmochim. Acta 59, 4449-4463.

${ }^{11}$ Morgenstern, A. and Choppin, G. R. (2002). Kinetics of the oxidation of Pu(IV) by manganese dioxide. Radiochim. Acta 90, 69-74.

${ }^{12}$ Crespo, M. T., Gascon, J. L. and Acena, M. L. (1993). Techniques and analytical methods in the determination of uranium, thorium, plutonium, americium and radium by adsorption on manganese dioxide. Sci. Tot. Environ. 130, 383-391.

${ }^{13}$ Sidhu, R. S. and Hoff, P. (1999). Rapid determination of environmental plutonium in large water samples by means of manganese dioxide co-precipitation and extraction chromatographic separation. Radiochimica Acta 84, 89-93.

${ }^{14}$ Shen, Y. F., Zerger, R. P., DeGuzman, R., Suib, S. L., McCurdy, L., Potter, D. I. and O'Young, C.L. (1993). Octahedral molecular sieves: Synthesis, characterization and applications. Science 260, 511-515.

${ }^{15}$ Chukrov, F. V., Sakharov, B. A., Gorshkov, A. I., Drits, V. A. and Dikov, Yu. P. (1985). Crystal structure of birnessite from the Pacific Ocean. Inst. Geol. Rev. 27, 1082-1088.

${ }^{16}$ Al-Alttar, L. and Dyer, A. (2002). Sorption behavior of uranium on birnessite, a layered manganese oxide. J. Mater. Chem. 12, 1381-1386.

${ }^{17}$ Milyutin, V. V. and Tananaev, I. G. (1993). Sorption of Np(VI), Np(V) and Pu(VI) on inorganic sorbents from neutral and basic media. Translated from Radiokhimiya 35, 70-75.

${ }^{18}$ Dietz, N. L., Fortner, J. A., Dai, Z., Bradley, J. P., Duff, M. C., Hobbs, D. T. and Fink, S. D. (2002). Transmission Electron Microscopy Analyses of Strontium and Actinide-Bearing Monosodium Titanate and Permanganate Treatment Solids. WSRC-TR-2002-00363, September 12, 2002. 
${ }^{19}$ Krot, N. N., Bessonov, A. A., Gelis, A. V., Shilov, V. P., Perminov, V. P. and Astafurova, L. N. (1998). Coprecipitation of transuranium elements from alkaline solution by the method of appearing agents. I. Coprecipitation of $\mathrm{Pu}(\mathrm{VI}, \mathrm{V})$ with manganese dioxide. Radiochem. 40, 347-352.

${ }^{20}$ Lou, J., Huang, A., Park, H. S., Suib, S. L. and O’Young, C.-L. (1998). Crystallization of sodiumbirnessite and accompanied phase transformation. Chem. Mater. 10, 1561-1568.

${ }^{21}$ Kuz'minski, Ye V., Andriiko, A. A. and Nyrkova, L. I. (1994). Chemical and phase composition of manganese oxides obtained by Mn(II) oxidation in nitrate solutions. J. Power Sources 52, 49-53.

${ }^{22}$ Ching, S., Pertrovay, D. J., Jorgensen, M. L. and Suib, S. L. (1997). Sol-gel synthesis of layered birnessite-type manganese oxides. Inorg. Chem. 36, 883-890.

${ }^{23}$ Crespo, M. T., Gascon, J. L. and Acena, M. L. (1993). Techniques and analytical methods in the determination of uranium, thorium, plutonium, americium and radium by adsorption on manganese dioxide. Sci.Tot.Environ. 130, 383-391.

${ }^{24}$ El-Naggar, I. M., El-Asby, M. A., Abdel-Hamid, M. M. and Aly, H. F. (1993). Sorption behavior of uranium and thorium on cryptomelane-type hydrous manganese dioxide from aqueous solution. Solv. Extract. Ion Exchange 11, 521-540.

${ }^{25}$ Stumm, W. (1992). Chemistry of the Solid-Water Interface: Processes at the Mineral-Water and Particle-Water Interface in Natural Systems. Wiley-Interscience, NY.

${ }^{26}$ McBride, M. B. (1994). Environmental Chemistry of Soils. Oxford Press, NY.

${ }^{27}$ Due to the small nature of nanoparticles, they often have more atoms at the solid-water interface than inside the solid. The use of spectroscopic techniques to elucidate the exact location of sorbing metals in such solids may potentially result in an inability to determine whether the metal is in an interlayer or vacancy site.

${ }^{28}$ Sorption reversibility is tested by leaching the metal loaded solid with a target metal-free solution that has the same properties (i.e. ionic strength, background electrolytes, $\mathrm{pH}$ etc...) and measuring the leachate solution to determine whether any target metal is released. Specifically adsorbed species are typically not leached with lower ionic strength solutions and specific adsorption processes are not a function ionic strength (assuming the electrolytes do not interact with the sorbed species via complexation etc.). Outer-sphere species can be readily removed with solutions of low ionic strength or solutions that contain high concentrations of a cation that has a higher affinity for the surface than the outer-sphere species. Therefore, outer-sphere sorption is viewed as reversible and a function of ionic strength.

${ }^{29}$ Specific adsorption is typically a function of surface charge properties. When a participating surface has a charge that varies with solution $\mathrm{pH}$, specific adsorption exhibits $\mathrm{pH}$-dependent behavior. For example, a surface that is highly protonated (at low $\mathrm{pH}$ ) will have more affinity for negatively-charged species (such as than negatively-charged species). As the $\mathrm{pH}$ decreases, the surface charge of $\mathrm{pH}-$ dependent charged surfaces becomes more negative and the uptake of positively charged species is favored. Therefore, the surface of metal oxides for example specifically adsorbs more positively charged species as the solution $\mathrm{pH}$ increases. However, this behavior is generalized. As the solution $\mathrm{pH}$ increases sorbing species undergoes a change in speciation-such as hydrolysis. In this case, the

Page 60 of 65 
amount of specific adsorption becomes a function of solution speciation. Ion exchange resins that sorb free ions of actinides (e.g., the non-hydrolyzed $\mathrm{Pu}^{4+}$ species) at high $\mathrm{H}^{+}$concentrations (i.e., low $\mathrm{pH}$ ) will release sorbed $\mathrm{Pu}^{4+}$ species when the solution $\mathrm{pH}$ is raised-due to the hydrolysis of the sorbed $\mathrm{Pu}^{4+}$ (e.g., $\left.\mathrm{Pu}(\mathrm{OH})_{3}{ }^{+}, \mathrm{Pu}(\mathrm{OH})_{2}{ }^{2+}\right)$. The hydrolysis species have a lower overall charge and their size (as an ion group) is larger than the free ion-making them have a lower affinity for the surface. Other processes that can influence sorption are metal complexation with ligands (i.e., with carbonate ion) or in the case of anions, protonation (e.g., $\mathrm{PO}_{4}{ }^{3-}+\mathrm{H}^{+} \rightarrow \mathrm{HPO}_{4}{ }^{2-}$ ). Specific adsorption processes are a function of many variables.

${ }^{30}$ Koningsberger, D. C. and Prins, R. (1988). X-ray Absorption: Techniques of EXAFS, SEXAFS and $X A N E S$, Wiley, New York.

${ }^{31}$ Stern, E. A. (1974). Theory of extended X-ray absorption fine structure. Phys. Rev. B10, 3027-3037.

${ }^{32}$ Strobe, P., Durr, J., Tuilier, M.-H. and Charlenton, J.-C. (1993). Extended X-ray absorption fine structure study of potassium and caesium phyllomanganates. J. Mater. Chem. 3, 453-458.

${ }^{33}$ Manceau, A., Drits, V. A., Silvester, E., Bartoli, C. and Lanson, B. (1997). Structural mechanism of $\mathrm{Co}^{2+}$ oxidation by the phyllomanganate buserite. Amer. Min. 82, 1150-1175.

${ }^{34}$ Hobbs, D. T., Blume, M. S. and Thacker, H. L. (2000). Phase V simulant testing of monosodium titanate adsorption kinetics. WSRC-TR-2000-00142, May 24, 2000.

${ }^{35}$ Duff, M. C., Hunter, D. B., Hobbs, D. T., Barnes, M. J. and Fink, S. D. (2001). Characterization of Sorbed Uranium, Plutonium and Neptunium on Monosodium Titanate. WSRC-TR-2001-00356, Sept. 19, 2001.

${ }^{36}$ High actinide loadings were necessary for the detection of a suitable XAFS signal.

${ }^{37}$ The formate reaction is a step-wise conversion of $\mathrm{Mn}$ (VII) to Mn(III, IV) whereas the peroxide reaction is an instantaneous conversion of $\mathrm{Mn}(\mathrm{VI})$ to $\mathrm{Mn}(\mathrm{III}, \mathrm{IV})$ - according to Krot et al. (1998).

${ }^{38}$ Manganese XAFS data collection was not conducted on the actinide-loaded Mn solids because Mn XAFS data collection at the Mn K absorption edge requires low energy hard X-rays, which could potentially (but unlikely) produce some of heat load on the sample. In lieu of safety, the possibility of sample heating was avoided by not performing the Mn XAFS analyses on the actinide-loaded samples and by using surrogate cold samples instead.

${ }^{39}$ Duff, M. C., Hunter, D. B., Bish, D. L. and Bertsch, P. M. (2002). Spectroscopic examination of a cerium-rich manganese oxide: Rancieite. To be submitted to Geochim. Cosmochim. Acta.

${ }^{40}$ Duff, M. C., Hunter, D. B., Hobbs, D. T. and Fink, S. D. (2001). Characterization of sorbed strontium on monosodium titanate. WSRC-TR-2001-00245, Rev. 0.

${ }^{41}$ Fredrickson, J. K., Zachara, J. M., Kennedy, D. W., Liu, C., Duff, M. C., Hunter, D. B. and Dohnalkova, A. (2002). Influence of Mn oxides on the reduction of U(VI) by the metal-reducing bacterium Shewanella putrefaciens. Geochim. Cosmochim. Acta 66, 3247-3262. 
${ }^{42}$ Duff, M. C., Newville, M., Hunter, D. B., Sutton, S. R., Triay, I. R., Vaniman, D. T., Bertsch, P. M., Eng, P. and Rivers. M. L. Investigation of heterogeneous speciation of sorbed plutonium on tuff using microprobe-X-ray techniques (in preparation).

${ }^{43}$ Yang, B. X., Rivers, M. L., Schildkamp, W. and Eng, P. (1995). GEOCARS micro-focusing Kirkpatrick-Baez mirror bender development. Rev. Sci. Instrum. 66, 2278.

${ }^{44}$ Eng, P. J., Rivers, M. L., Yang, B. X. and Schildkamp, W. (1995). Microfocusing 4-keV to 65-keV X-rays with bent Kirkpatrick-Baez mirrors. Proc. SPIE 2516, 41-51.

${ }^{45}$ Ressler, T. (1999). WinXAS. A program for X-ray absorption spectroscopy data analysis under MS Windows. J. Synchr. Rad. 5, 118-122.

${ }^{46}$ Newville, M., Livins, P., Yacoby, Y., Rehr, J. J. and Stern, E. A. (1993). Near-edge X-rayabsorption fine-structure of $\mathrm{Pb}-\mathrm{A}$ comparison of theory and experiment. Phys. Rev. B-Cond. Matter 47, 14126-14131.

${ }^{47}$ Sayers, D. E. and Bunker, B. A. (1988). In X-ray Absorption: Techniques of EXAFS, SEXAFS and $X A N E S$. Koningsberger, D. C. and Prins, R. (eds). Wiley, New York, Chap. 6.

${ }^{48}$ FEFF is a software package that was generated by researchers at the Univ. of Washington with DOE funding support. Access and use of this software is free within the DOE complex.

${ }^{49}$ Mustre de Leon, J., Rehr, J. J., Zabinsky, S. I. and Albers, R. C. (1991). Ab initio curved-wave xray-absorption fine structure. Phys. Rev. B44, 4146.

${ }^{50}$ Rehr, J. J. and Albers, R. C. (1990). Scattering-matrix formulation of curved-wave multiplescattering theory: Application to x-ray-absorption fine structure. Phys. Rev. B41, 8139.

${ }^{51}$ Rehr, J. J., Mustre de Leon, J., Zabinsky, S. I. and Albers, R. C. (1991). Theoretical X-ray absorption fine structure standards. J. Am. Chem. Soc. 113, 5135.

${ }^{52}$ Rehr, J. J., Zabinsky, S. I. and Albers, R. C. (1992). High-order multiple scattering calculations of xray-absorption fine structure. Phys. Rev. Let. 69, 3397.

${ }^{53}$ Stern, E. A., Newville, M., Ravel, B., Yacoby, Y. and Haskel, D. (1995). The UWAFS analysis package - Philosophy and details. Physica B 208-209, 117-120.

${ }^{54}$ Duff, M. C., Newville, M., Hunter, D. B., Sutton, S. R., Triay, I. R., Vaniman, D. T., Bertsch. P. M., Eng, P. and Rivers,' M. L. Heterogeneous plutonium sorption on Yucca Mountain tuff. APS Forefront, Advanced Photon Source, Argonne National Lab. ANL/APS/TB-42, Oct. 1, 2001.

${ }^{55}$ The bonding environments of dissolved actinides such as $\mathrm{Pu}(\mathrm{V})$ and $\mathrm{Pu}(\mathrm{VI})$ typically contain two types of $\mathrm{O}$ bonds. The first type of bond consists of a short "dioxo" bond that ranges from 1.75 to 1.81 $\AA($ for $\mathrm{Pu}(\mathrm{V}))$, which is generally perpendicular to the equatorial oxygen atoms. The equatorial actinide-oxygen bonds have longer bond lengths of 2.3 to $2.55 \AA$ (for $\mathrm{Pu}$ ) and these are single actinide-O bonds. A two-dimensional example of a $\mathrm{Pu}$ species is shown below.

Page 62 of 65 


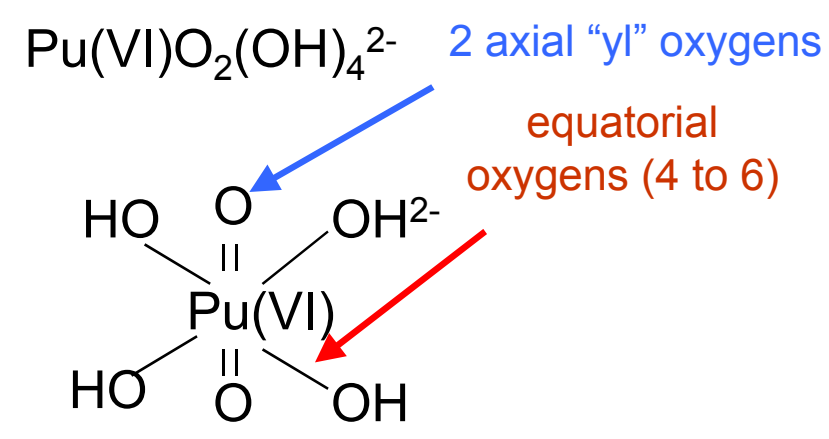

${ }^{56}$ Allen, P. G., Bucher, J. J., Shuh, D. K., Edelstein, N. M. and Reich, T. (1997). Investigation of aquo and chloro complexes of $\mathrm{UO}_{2}{ }^{2+}, \mathrm{NpO}_{2}{ }^{+}, \mathrm{Np}^{4+}$ and $\mathrm{Pu}^{3+}$ by X-ray absorption fine structure spectroscopy. Inorg. Chem. 36, 4676-4683.

${ }^{57}$ Antonio, M. R., Soderholm, L., Williams, C. W., Blaudeau, J-P. and Bursten, B. E. (2001). Neptunium redox speciation. Radiochim. Acta, 89, 17-25.

${ }^{58}$ Soderholm, L., Antonio, M. R., Williams, C. W. and Wasserman, S. R. (2001). XANES spectroelectrochemistry: A new method for determining formal potentials. Anal. Chem. 71, 4622-4628.

${ }^{59}$ Clark, D. L., Conradson, S. D., Ekberg, S. A., Hess, N. J., Neu, N. P., Palmer, P. D., Runde, W. and Tait, C. D. (1996). EXAFS studies of pentevalent neptunium carbonato complexes. Structural eluclidation of the principal constituents of neptunium in groundwater environments. J. Am. Chem. Soc. 118, 2089-2090.

${ }^{60}$ Clark, D. L., Conradson, S. D., Ekberg, S. A., Hess, N. J., Janecky, D. J., Neu, N. P., Palmer, P. D., Runde, W. and Tait, C. D. (1996). A multi-method approach to actinide speciation applied to pentavalent neptunium carbonate complexation. New J. Chem. 20, 211-220.

${ }^{61}$ Moyes, L. et al. (2002). An X-ray absorption spectroscopy study of neptunium(V) reactions with mackinawite (FeS). Env. Sci. Technol. 36, 179-183.

${ }^{62}$ Bertsch, P. M., Hunter, D. B., Sutton, S. R., Bajt, S. and Rivers, M. L. (1994). In situ chemical speciation of uranium in soils and sediment by micro X-ray absorption spectroscopy. Environ. Sci. Technol., 28, 80-984.

${ }^{63}$ Conradson, S. D., Al Mahamid, I., Clark, D. L, Hess, N. J., Hudson, E. A., Neu, M. P., Palmer, P. D., Runde, W. H. and Tait, C. D. (1998). X-ray absorption edges of plutonium in different oxidation states. Polyhedra 1998, 17, 599-602.

${ }^{64}$ Combes, J.-M, Chisholm-Brause, C. J., Brown, G. E., Jr., Parks, G. A., Conradson, S. D., Eller, P.G., Triay, I. R., Hobart, D. E. and Meijer, A. (1992). EXAFS spectroscopic study of neptunium(V) sorption at the $\propto-\mathrm{FeOOH} /$ water interface. Env. Sci. Technol. 26, 376-382.

${ }^{65}$ Zhao, P., Allen, P. G., Sylwester, E. R. and Viani, B. E. (2000). The partitioning of uranium and neptunium onto hydrothermally altered concrete. Radiochim. Acta. 88, 729-736.

Page 63 of 65 
WSRC-TR-2002-00366, REVISION 0

${ }^{66}$ It is also related to the ionization energy (the energy required to remove an electron from an isolated atom in its ground state) for the metal of interest in addition to other factors, which are beyond the scope of this report.

${ }^{67}$ Manceau, A., Schlegel, M., Musso, M., Sole, V. A., Gathier, C., Petit, P. and Trolard, F. (2000). Crystal chemistry of natural and synthetic goethite. Geochim. Cosmochim. Acta 64, 3643-3661.

${ }^{68}$ Hobbs, D. T. and Karraker, D. G. (1996). Recent results on the solubility of uranium and plutonium in Savannah River Site Waste Supernate. Nucl. Technol. 114, 318-324.

${ }^{69}$ Delegard, C. H. (1987). Solubility of $\mathrm{PuO}_{2} \cdot \mathrm{xH}_{2} \mathrm{O}$ in alkaline Hanford high-level waste solution. Radiochim. Acta 41, 11-21.

${ }^{70}$ Peretrukin, V. F., Shilov, V. P. and Pikaev, A. K. (1995). Alkaline chemistry of transuranium elements and technetium and the treatment of alkaline radioactive wastes. Westinghouse Hanford Company, WHC-EP-0817.

${ }^{71}$ Additionally, these methods may not be capable of separating oxidation states of actinides in their polymeric and colloidal forms. In comparison to monomeric forms of actinides, the polymeric forms are likely to have different extractabilities due to there size and charge attributes. They may not readily form monomeric forms under the conditions and timeframes of the extraction.

${ }^{72}$ Spectra for $\mathrm{Pu}(\mathrm{III})$ are not included but the features in these spectra closely resemble that of $\mathrm{Pu}(\mathrm{IV})$ in that they do not possess a shoulder feature like the $\mathrm{Pu}(\mathrm{V})$ and $\mathrm{Pu}(\mathrm{VI})$ species.

${ }^{73}$ There are numerous mathematical methods by which XANES spectra are interpreted. In theory the XANES edge energy is proportional to the average oxidation state of the species of interest but there is some possibility that coordination may affect the edge. One general and highly simplified interpretation of the XANES spectra is that it reflects the ionization potential of the core electron of interest, which in our case for the actinide $\mathrm{L}_{3}$ edge is the $2 \mathrm{p}_{3 / 2}$ orbital electron. However, theoretical and experimental measurements can differ.

Some of the mathematical methods used consist of mere differences in the energy at some set point within the normalized adsorption edge step. Other methods include the inflection point of the first derivative. Some methods utilize the second derivative, which we conclude to be more problematic than the first derivative method. Other methods utilize linear combinations of endmember spectra but such procedures require an apriori knowledge of the species involved. Other methods use mathematical functions (Lorentzian and Gaussian functions in combination with arctangent functions) to fit the spectra and generate a value for the inflection point of the XANES edge. The equations used to generate these functions require fitting nine or more empirical variables.

${ }^{74}$ Teo, B. K. (1986). EXAFS: Basic Principles and Data Analysis. Inorganic Chemistry Concepts, Vol. 9, Springer-Verlag. Berlin.

${ }^{75}$ Based on the limited amount of the sample absorbance of the X-ray beam, our experience with pure Mn oxide samples of similar thicknesses (i.e., path lengths) indicates that these permanganate-treated Mn oxide samples do not contain a large amount of $\mathrm{MnO}_{2}$ - as would be consistent with pure $\mathrm{Mn}$ oxides. Normally, we can perform transmission measurements, which are absorption-based measurements that require high levels of the element of interest, which in this case is Mn. However,

Page 64 of 65 
our fluorescence-based measurements provided better signal to noise and they were not subject to selfabsorption (a problem typically observed when fluorescence-based measurements are made on highly concentrated samples).

${ }^{76}$ Parkman, R. H., Charnock, J. M., Livens, F. R. and Vaughn, D. J. (1998). A study of the interaction of strontium ions in aqueous solution with the surfaces of calcite and kaolinite. Geochim. Cosmochim. Acta 62, 1481-1492.

${ }^{77}$ White solids were also visually observed in the treatments lacking seed $\mathrm{Sr}$, but the particle sizes appeared much smaller. These smaller size particles were most likely salts (such as $\mathrm{NaNO}_{3}$ ), that precipitated during the permanganate reaction as will be discussed.

${ }^{78}$ Hobbs, D. T., Peters, T. B. and Wheeler, D. J. (2001). Investigation of Savannah River Site high level waste solutions for evidence of colloidal plutonium. Westinghouse Savannah River Company, WSRC-TR-2001-00103.

${ }^{79}$ MacKenzie, R. M. (1989). In Minerals in Soil Environments. Soil Sci. Soc. America Book Series, 2nd Ed., Dixon, J. B. and S. B. Weed, Eds. Soil Sci. Soc. America, Madison, WI. pp. 439-465.

${ }^{80}$ Feng, Q., Sun, E., Yansagisa, K. and Yamaski, N. (1997). Synthesis of birnessite-type sodium manganese oxides by solution reaction and hydrothermal methods. J. Soc. Japan 105, 564-568.

${ }^{81}$ Jenne, E. A. (1977). Trace element sorption by sediments and soils-Sites and processes. Symposium on Molybdenum in the Environment, Vol. 2, Chapell, W. and Peterson, K. eds. M. Dekker, Inc. N. Y.

${ }^{82}$ Luo, J., Hunag, A., Park, S. H., Suib, S. L. and O’Young, C-L. (1998). Crystallization of sodiumbirnessite and accompanied phase transformation. Chem. Mater. 10, 1561-1568.

${ }^{83}$ Krot, N., Shilov, V., Bessonov, A., Budantseva, N., Charushnikova, I., Perminov, V. and Astafurova, L. Investigation on the Coprecipitation of Transuranium Elements from Alkaline Solutions by the Method of Appearing Reagents. Westinghouse Hanford Company, WHC-EP-0898, June, 1996.

${ }^{84}$ Meece, D. R. and Benninger, L. K. (1993). The precipitation of Pu and other radionuclides with $\mathrm{CaCO}_{3}$. Geochim. Cosmochim. Acta. 57, 1447-1458.

${ }^{85}$ Wilmarth, W. R. (1999). Strontium/TRU Scoping Tests. WSRC-NB-1999-00112, pp. 37-39 and 62. 